\title{
Wages, prices, and employment in a Keynesian long run
}

\author{
Stephen A. Marglin* \\ Harvard University, Cambridge, MA, USA
}

The central question this paper addresses is the same one I explored in my joint work with Amit Bhaduri 25 years ago: under what circumstances are high wages good for employment? I extend our 1990 argument in three directions. First, instead of mark-up pricing, I model labor and product markets separately. The labor supply to the capitalist sector of the economy is assumed à la Lewis to be unlimited. Consequently the wage cannot be determined endogenously but is fixed by an extended notion of subsistence based on Smith, Ricardo, and Marx. For tractability the product market is assumed to be perfectly competitive. The second innovation is to show how disequilibrium adjustment resolves the overdetermination inherent in the model. There are three equations - aggregate demand, goods supply, and labor supply - but two unknowns - the labor-capital ratio and the real price (the inverse of the real wage). Consequently equilibrium does not even exist until we define the adjustment process. The third innovation is to distinguish capital deepening from capital widening. This is important because, ceteris paribus, wage-led growth is more likely to stimulate the economy the greater the fraction of investment devoted to capital deepening. A final section of the paper shows that US data on employment and inflation since the 1950 s are consistent with the theory developed in this paper.

Keywords: flexprice adjustment, fixprice adjustment, conventional wage, unlimited supplies of labor, capital widening, capital deepening, Phillips curve

JEL codes: $B 22, B 41, E 12, N 12, O 41$

\section{INTRODUCTION}

Are high wages good for employment? Does higher employment lead to more inflation? When do higher prices mean stagflation? This essay lays out and tests a new framework for assessing the relationship between prices and wages on the one hand and output and employment on the other. I build on my work with Amit Bhaduri of a quarter of a century ago (Marglin and Bhaduri 1990; Bhaduri and Marglin 1990). The central innovation of this joint work was to question the conventional wisdom of left-leaning political economy that higher wages are always good for employment and output. Higher wages, Bhaduri and I argued, may decrease aggregate demand through a negative impact on investment demand. Here, I expand the argument by focusing on the differences in

* Thanks to Mark Setterfield and anonymous referees for constructive suggestions both substantive and editorial. I have not followed all their suggestions, but enough to make them unindicted co-conspirators. This essay is excerpted from my forthcoming book (working title: Raising Keynes: A General Theory for the 21st Century). 
the relationship between wages and employment under different adjustment regimes. The expanded model allows me to examine supply and demand shocks under different dynamic assumptions, and to test the Keynesian idea that aggregate demand matters against data on employment and inflation. I also offer an argument about how different types of investment respond to profitability and capacity utilization, an argument intended to clarify the impact of wages on aggregate demand via the investment channel.

From a mainstream point of view, the entire tradition in which Bhaduri and I situated our work - the tradition in which aggregate demand matters in the long run as well as in the short run - was conceived in error. The process of consolidating the Keynesian revolution made a role for aggregate demand contingent on one form or another of market imperfection or friction, and the resulting sand in the wheels was supposed to operate only in the short term. By the late 1960s, when the neoclassical counterrevolution had begun in earnest, the Keynesians had already abandoned the long run to the neoclassicals. Robert Solow's 1956 essay was widely understood to have demonstrated the irrelevance of aggregate demand, even though the 'demonstration,' as Solow himself recognized (ibid., p. 91), is simply an assumption.

The counter-revolution, led by Milton Friedman (1968) and Edmund Phelps (1968), delivered the knock-out punch - or so it was believed. A positive relationship between employment and inflation, enshrined in the Phillips curve (Phillips 1958), was understood by Keynesians to reflect the operation of aggregate demand. The counterrevolutionaries dismissed the Phillips curve as the result of misperceptions that would necessarily disappear as agents developed more sophistication about the economy. The implication was that demand cannot matter in the long run. Indeed, Friedman and Phelps predicted that periods of high inflation would not be accompanied by higher economic activity. In the long run there is no Phillips curve, no trade-off between economic activity and price stability. In this perspective raising money wages is necessarily an exercise in futility: higher wages can mean only higher inflation, with no impact on employment and output. The classical dichotomy with a vengeance!

Some years later, Robert Lucas (1981, p. 560) claimed that experience had borne out the Friedman-Phelps predictions:

The central forecast to which their [Friedman and Phelps's] reasoning led was a conditional one, to the effect that a high-inflation decade should not have less unemployment on average than a low-inflation decade. We got the high inflation decade, and with it as clear-cut an experimental discrimination as macroeconomics is ever likely to see, and Friedman and Phelps were right. It really is as simple as that.

We have a lot more data available today than Lucas had at his disposal in 1981. And the data do appear to bear out the prediction that there is no relationship between employment and inflation. Figure 1 plots the data over more than half a century. Analysing these data, economists have found, if anything, a negative relationship between real economic activity and inflation. Cross-sectional studies by Stanley Fischer (1993), Robert Barro (1996), and others have found a significant negative correlation between growth and inflation, but their results are dominated by high inflation rates, where negative supply-side effects plausibly dominate. More striking are the findings of Moshin Khan and Abdelhak Senhadji (2001), who separate poor and rich countries and find that for the rich countries the threshold above which inflation is associated with lower GDP growth is only 1-3 percent per year.

None of this should surprise us. Once it has been determined that demand does not matter in the long run, it makes sense to treat all observations symmetrically and look for supply-side effects. 


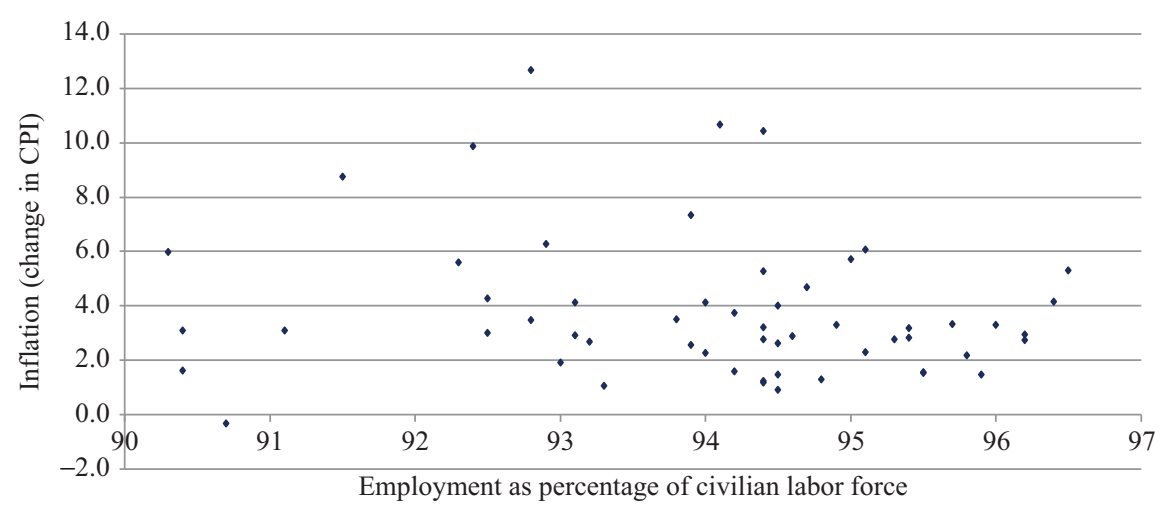

Figure 1 Employment vs inflation, 1956-2011

Appearances notwithstanding, we can make sense of the data in terms of a Phillips curve along which movements reflect demand shocks but which is itself moved by supply shocks, as Robert Gordon $(1984 ; 2013)$ and others have argued. Demand shocks result in the standard Phillips result, a positive relationship between employment and inflation. As we shall see, supply shocks are more complicated.

The key to finding order in the randomness of Figure 1 is to filter the data in two ways. Not only must we separate demand and supply shocks, we must also sort out wage shocks (which affect employment and wages through their effect on labor supply) from price shocks (which operate through goods supply on employment and output). This done, there were, I shall argue, two periods in which wage pressure exerted a strong influence on the positive Phillips-curve relationship: in the late 1960s and early 1970s upward pressure on wages displaced the relationship between employment and inflation upwards, and in the mid 1990s downward pressure on wages displaced the relationship downwards. This suggests that high(er) wages have historically exerted a negative influence on the economy, but, in line with the central hypothesis put forward by Bhaduri and me 25 years ago, this result is contextual. Both instances of wage pressure took place under conditions of high employment and, presumably, high investment demand - precisely the conditions under which Bhaduri and I argued that higher wages would not improve aggregate outcomes.

This leaves open the possibility that under conditions of slack, such as characterize global capitalism since the financial crisis that inaugurated the Great Recession, the impact of higher wages would be very different from 20 or 40 years ago. Higher wages would indeed stimulate the economy.

\section{BACKGROUND}

The question of how wages, prices, and employment are related did not begin or end with Keynes, but The General Theory (henceforth GT) provided a framework in which it became possible to analyse the impact of the wage rate on aggregate demand. There is some irony here: in the main, the $G T$ argues that the real wage rate is determined endogenously, a thermometer of economic conditions rather than a thermostat. 
Despite Keynes's own relative neglect of the issue, the potential that redistribution from profits and other forms of property income to wages had for stimulating aggregate demand became identified with the $G T$. With good reason: the $G T$ framework was key. On the left, it seemed like a no-brainer. As long as the economy is operating at less than full employment, income redistribution amounts to a free lunch as far as aggregate demand was concerned; shifting income from rich people with low propensities to consume to poorer people with higher consumption propensities would add to aggregate demand. On the right, redistribution was anathema, a threat not only to the free market, but to social order and morality.

The idea that redistribution could stimulate the economy came under attack from two sides. On the one hand, Friedman's permanent-income and Modigliani's lifecycle hypotheses challenged the idea that the propensity to consume is a function of income. And with the rise of supply-side economics, aggregate demand was relegated to being at best a short-run phenomenon of frictions and market imperfections.

There was a minority view: the left Keynesians who took inspiration from Joan Robinson $(1956 ; 1962)$ and Michał Kalecki (1971) continued to argue that aggregate demand was a problem that ran much deeper than frictions and imperfections, and Robinson devoted much effort to building long-run models in which outcomes depend on aggregate demand. The distributional issue remained central in these models.

Bob Rowthorn (1982) formalized the argument that redistributing income from rich to poor would increase aggregate demand. A novel aspect of Rowthorn's argument was that higher demand would be self-reinforcing through its effects on investment demand. Higher demand implies higher employment and a more intense utilization of existing capacity; higher capacity utilization implies a higher rate of profit; and a higher rate of profit implies higher investment demand.

Bhaduri and I challenged Rowthorn's treatment of the impact of the wage rate on investment demand. We argued that the two factors that together determine the profit rate, namely the share of profits in GDP and the rate of capacity utilization, should be treated separately because each has a distinct impact on investment demand. The profit share reflects the prospects for making money from new capacity, whereas the rate of capacity utilization reflects the likelihood of selling additional goods. When the influence of the profit share is important, the negative impact of higher wages on the profit share may outweigh the positive impact on capacity utilization. The ensuing reduction in investment demand may then outweigh the positive impact of higher wages on consumption demand. Our conclusion was that growth can be stimulated by higher wages under some circumstances, and by higher profits - lower wages under others.

The intention was to change the debate about the impact of the wage rate on growth from a theoretical one to an empirical one. Judging from the voluminous literature that has appeared in the past quarter century, we succeeded.

Nonetheless I have come to view our work as deficient, particularly in our focus on comparative statics and our corresponding neglect of dynamics. The version of our argument that appeared in the Cambridge Journal of Economics ends with the observation:

The recognition that quantities (capacity utilization) and prices (the real wage) may adjust simultaneously in a more general dynamic model raises a deeper conceptual issue regarding the interpretation of the IS-curve itself. It can be treated either as the locus of stationary capacity utilization ... as has been implicitly assumed in our ... analysis, or as the locus of stationary price level ... . Ultimately it boils down to one of the most important unsettled questions of modern macroeconomics: does excess demand for commodities lead primarily to quantity or 
to price adjustment? We cannot pretend to have an answer; but dynamic analysis cannot be undertaken without addressing this important, and as yet unsettled, question. (Bhaduri and Marglin 1990, p. 390)

I offer no definitive answer to the question of how prices and quantities adjust out of equilibrium. But the analysis that follows makes progress on developing the dynamic model we need in order to understand the data on employment and inflation. And in turn these data shed light on dynamics, especially if we separate wage and price adjustment rather than combining the two in the level of the mark-up.

There is another problem with the analysis Bhaduri and I offered in 1990: we lumped all investment together, implicitly assuming that investment takes place solely to expand capacity, an assumption that goes back to Roy Harrod $(1939 ; 1948)$. Outputenhancing investment, capital widening in an older literature, is important, but it is not the only kind of investment. In addition to enhancing output, investment takes place in order to cut costs, by substituting capital for labor, energy, or other inputs - capital deepening for short.

Capital deepening has a different logic from capital widening, in particular a very different relationship to wages and profits. For capital widening, the lower the real wage, the better: lower real wages mean, ceteris paribus, higher profits. By contrast we would expect capital deepening, specifically labor-saving investment, to respond positively to higher wages: the higher the real wage, the greater the savings in labor costs from a given investment.

The difference between capital widening and capital deepening is particularly important because the salience of the two types of investment is likely to differ markedly over the cycle. Since 2008, for example, there has been considerable excess capacity, and consequently relatively little demand for capital widening. It follows that the lion's share of investment since 2008 has been for the purpose of cutting costs. A recession thus enhances the case for wage-led growth since high wages not only stimulate consumption demand directly, they also will stimulate investment demand. If capacity utilization is at 90 percent, there may be little interest in output-enhancing investment, but cutting costs on 90 percent of maximum output is only 10 percent less worthwhile than cutting costs on 100 percent.

When - I suppose I should say if - bust is replaced by boom, capital widening will again come into its own. In boom situations, the positive relationship between low wages and investment profitability bolsters the argument for profit-led growth.

To situate these arguments, this paper elaborates a series of long-run models in which aggregate demand is one element that determines economic outcomes. In these models the capitalist economy is assumed to be perfectly competitive in the sense that no agent has market power. Besides market power, real-world features such as frictions are absent. The point, evidently, is not to provide a faithful description of the world as it is, but to forestall the objection that the results would not hold in the absence of one imperfection or another because it is only imperfections that make aggregate demand matter at all. ${ }^{1}$

This said, I am not willing to go to the extreme of rational expectations in which all agents know how the economy works and this knowledge saves them the trouble of groping (in Walras's famous turn of phrase) towards equilibrium. Not only does

1. The goods-supply schedule that I deploy is a locus of points at which price is equal to marginal cost, that is, as a supply schedule in a perfectly competitive product market, but it can be understood as a relationship between price and employment reflecting the market power of oligopolistic firms. The analytics are the same either way. 
this aspect of rational expectations make unreasonable if not insane demands on agents, a trial-and-error adjustment process is necessary for resolving the over determination inherent in $G T$-inspired models. As we shall see, the adjustment process defines the equilibrium.

\section{UNLIMITED SUPPLIES OF LABOR: THE ROAD NOT TAKEN}

A key assumption of the present model is that capitalism operates in a world of unlimited supplies of labor. This assumption connects my model both to W. Arthur Lewis's seminal 1954 paper, and, in an odd way, to Harrod's pioneering attempt to apply Keynes's conceptual framework to a growing economy. It might not have surprised Harrod or Lewis that China has been able to sustain a remarkable rate of growth by virtue, among other things, of its huge agricultural sector from which to draw labor for industry. But neither thought the model applicable to advanced capitalism. Lewis confined the argument to the poor 'developing' world, and Harrod explicitly rejected the argument once this particular pool of labor is exhausted. Harrod (1948, p. 19) entertained 'the proposition that the supply of labour is infinitely elastic at a certain real wage,' but he discarded this hypothesis as irrelevant to the rich countries. For the rich countries, Harrod argued, it is more appropriate to take the labor supply as exogenously given. Harrod's choice has become the standard assumption about labor supply in growth models. In this respect, the present essay follows the road not taken.

The idea of unlimited supplies of labor is counterintuitive because we normally focus on the supply of labor to an entire economy and society closed to immigration. In such a setting it is natural to think of labor supply in terms of population, and to think of population as given by the net reproduction rate. The facts tell a different story. With the exception of Japan, labor supplies in the rich countries have been augmented by immigration for the better part of a century, and in the US from the first permanent European settlement. Innumerable battalions of the reserve army live outside the country until they are mobilized as wage labor.

Moreover, there is no analytic reason to focus on the entire economy. Indeed it is tendentious to argue that any single model can explain all economic behavior in all settings; and in practice growth models implicitly assume that production is guided by profit maximization and that labor is a commodity, wage labor. In short, the focus of the present inquiry, like the focus of virtually all growth economics, is the behavior of a capitalist economy. What is novel is to take seriously the fact that the capitalist sector is always embedded in a larger economic formation which includes other sectors that follow a logic different from the logic of capitalism.

In particular we can distinguish a 'family enterprise' sector in which production is oriented towards the market but most if not all of the labor is supplied by family members who are not paid wages. The family farm is the most important case in point, and this is the sector that Lewis and other theorists of unlimited supplies of labor had in mind. But it is not the only source of labor supply for the capitalist sector. We can also distinguish a 'household' sector in which not only is wage labor minimal but production is for the immediate satisfaction of wants and needs, unmediated by the market. Food is prepared, clothes washed, children driven to football or piano practice - mostly by women - with nary a dollar, euro, pound, or yen changing hands.

Both these sectors have historically been important constituents of the internal reserve army. At the beginning of the last century the agricultural sector, mostly family farms, contained some 40 percent of the labor force in the US. By mid-century, 40 percent 
had fallen to 10 percent, and by 1970 to less than 5 percent. Agriculture's share of the labor force is currently less than 2 percent. Most of what is now the rich capitalist world lagged behind but eventually caught up. As late as 1960 some 30 percent of the labor force in Japan and Italy and close to 25 percent of the French labor force were engaged in agriculture. But these countries are now more or less where the US is; in none of them is the figure above 5 percent today.

The household sector similarly provided a steady stream of recruits to the capitalist sector; women didn't necessarily leave the kitchen altogether; most added paid labor to their domestic duties. Female 'participation rates,' so-called, have risen in the US from 35 percent in 1950 to 60 percent, declining slightly since the beginning of the recession in 2008. Today, women's and men's participation rates differ by only 10 percentage points.

These internal recruits have complemented the external reserve army, the immigrant population that has served as a reliable if politically contentious source of labor, especially for those jobs that native populations have been reluctant to fill at going rates of pay. The time pattern of immigration into the United States is especially revealing. After an abrupt fall in the wake of the First World War, a decline which lasted for almost half a century, immigration picked up around 1970, just as domestic agriculture dried up as a source of labor - see Figure 2.

The reserve army had a huge impact on the growth of the labor force in the US. Whereas the native-born population grew at an annual rate of 1.3 percent over the twentieth century, paid private employment outside agriculture was able to grow half again as fast, at a rate of more than 2 percent.

The important point is that the reserve army is not a fixed body of men and women, but a source of labor that is constituted and reconstituted in terms of the needs of the capitalist economy: as one source of labor, domestic agriculture, dried up, other spigots were opened. In practical terms, labor supply has been unlimited, not only in the poor countries, but in the rich countries as well. ${ }^{2}$

What, then, determines the wage? Having assumed the labor supply is endogenous, we cannot appeal to the mainstream assumptions of an exogenous labor supply and full employment to determine the wage by the marginal productivity of labor.

The classical economists - Smith, Ricardo, and Marx - were on the right track in emphasizing subsistence as the determinant of wages though they have been misunderstood by later generations who took subsistence to mean a minimal standard of living that would ensure the reproduction of the labor force. (This presumably was Harrod's understanding of the term and for him a reason to reject the whole idea of an unlimited labor supply.) Neither Smith nor Ricardo nor Marx conceived of subsistence solely in biological terms. For all three, there were historical, cultural, and institutional dimensions that entered the determination of real wages. Marx, not surprisingly, emphasized class power, but this emphasis did not preclude a recognition that class power is

2. This century may see the end of the labor-surplus economy. Even China, which only a few years ago was the poster child for a labor-surplus economy, is now approaching the time when the supply of workers from its hinterland will be exhausted (Cai and Wang 2011). The percentage of the labor force employed in agriculture is less than 30 percent (World Bank 2016). The female participation rate is the highest in the world and close to the male participation rate, so there is not much left of that reserve army (Bureau of Labor Statistics 2012, p. 16). And China is unlikely to be willing or able to tap the reserves of foreign workers. India is much further behind in terms both of the ratio of employment in agriculture (approximately half the labor force) and of female participation rates (barely one-quarter), according to World Bank data. 


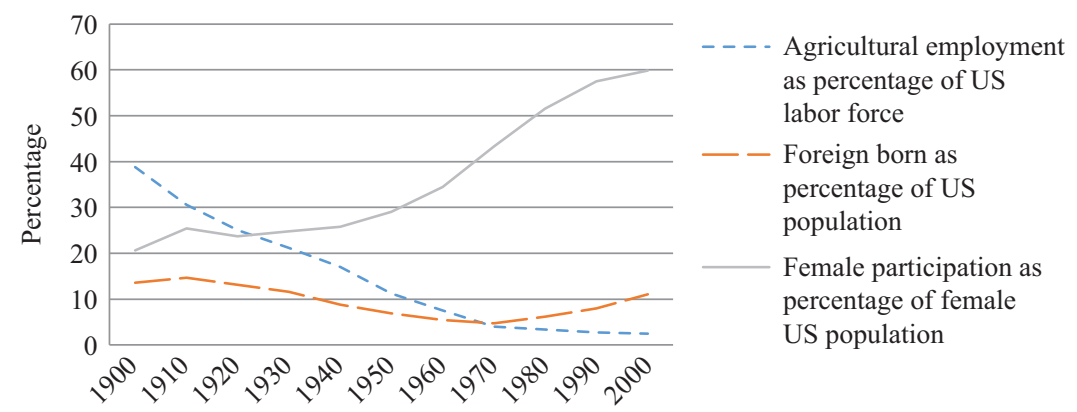

Figure 2 Sources of the reserve army in twentieth-century America

situated in a matrix of culture and history. Workers are better able to press their claims to the extent that public opinion is on their side. Subsistence, in short, is a social norm. ${ }^{3}$

To summarize: the long-run theory of labor supply that I am proposing reverses the mainstream relationship between the supply of labor and the real wage. Competitive profit maximization on the part of producers continues to ensure that the marginal productivity of labor is equal to the real wage, but the wage is not determined by the marginal productivity of labor. Instead of an exogenous labor supply and an endogenous real wage, as the mainstream would have it, I here posit an endogenous labor supply and an exogenous real wage. To avoid confusion, I shall label this wage not a subsistence wage but a conventional wage, conventional referring to both the customary and the contractual elements that enter into wage determination. In a dynamic setting the conventional wage is perhaps better understood as a target wage, the wage that the working class aims for in order to achieve norms of consumption conventionally conceived and understood if not unanimously agreed upon.

None of this is to say that productivity is irrelevant to wage determination even if we necessarily must reject the idea that the wage is determined by the marginal productivity of labor. Productivity determines the size of the pie that the contending parties struggle over. Nineteenth-century British output had to be of a certain size before workers could obtain a share large enough to permit them to buy refined white bread rather than the coarse grains to which the lower classes had accommodated themselves in earlier times; twentieth-century American production had to be of a certain size before workers could successfully struggle for a share large enough to include an automobile as part of the wage packet. But a productive technology did not guarantee that either the nineteenth-century British pie or the twentieth-century American pie would

3. Pigou endorsed the idea of a conventional wage and the key role of public opinion in determining its level: 'Public opinion in a modern civilised State builds up for itself a rough estimate of what constitutes a reasonable living wage' (Pigou 1933, p. 255). This, for Pigou, was one reason why the real wage might persist at a level higher than the market-clearing wage, resulting in persistent unemployment.

The decline of unions is one index of the shift in public opinion against the working class. Freeman and Medoff (1984) argued that workers themselves were more likely to organize the better the public image of unions (cited in Surowiecki 2011). 
be sliced in a way that would allow workers to achieve their aims. For this to happen, certain community standards, social norms, were essential.

These community standards underlie, for example, the very idea of a legal minimum wage - and the erosion of community underlies the erosion of the minimum wage in the US over the last 5 decades. Nor is it just the minimum that is at issue. The last half-century has also witnessed an ever-widening gap between workers in the middle of the wage distribution and the richest 1 percent of the income distribution, which includes both top managers and large stockholders. There is no longer even the pretense that we are all in it together, that the United States is a community when it comes to matters economic.

Not only is productivity relevant to wage determination, so are rates of price increases or decreases. Workers, as Keynes insists, may bargain in money terms, but they are bargaining about real wages, so that inflation or deflation play an important role in determining the bargains that are struck.

Unemployment also matters. The ability of workers to achieve their ambitions in the sphere of wages, or to hold onto a level of wages already achieved, depends on the state of the labor market. In the short period, in which wage claims are made (and contested), unemployment is a fact of life and may be the dominant fact, even if the labor force is endogenous in the long run.

Making the unemployment rate one among other determinants of changes in wages (rather than the sole determinant) resolves another problem. The idea that wages respond to unemployment, and unemployment alone, provides a tolerably good account of wage behavior in the early years of the Great Depression, but not since, as Table 1 shows. In 1933 wages stopped falling even though unemployment remained high. During the post-1933 recovery wages picked up even though unemployment never fell below 10 percent until the outbreak of the Second World War.

Clearly a simple model of wages responding to the unemployment level will not do even if the long run is as limited as the transition from depression to recovery. In fact, if we look at the entire period from 1929 to 2011, a regression equation that accounts

Table 1 Relationship between unemployment rate and changes in money wages, 1930-1941

\begin{tabular}{ccc}
\hline & $\begin{array}{c}\text { Unemployment, not counting } \\
\text { 'federal emergency workers' as employed }\end{array}$ & $\begin{array}{c}\text { Year-on-year change in } \\
\text { hourly manufacturing wage }\end{array}$ \\
\cline { 2 - 2 } 1930 & Percent & Percent \\
1931 & 9.00 & -1.80 \\
1932 & 16.30 & -7.30 \\
1933 & 24.10 & -13.70 \\
1934 & 25.20 & 0.00 \\
1935 & 22.00 & 20.50 \\
1936 & 20.29 & 1.90 \\
1937 & 17.03 & 1.90 \\
1938 & 14.32 & 12.70 \\
1939 & 19.05 & 0.00 \\
1940 & 17.17 & 1.60 \\
1941 & 14.59 & 4.80 \\
& 9.94 & 10.60 \\
\hline
\end{tabular}

Source: Historical Statistics of the United States, Millennial Edition Online, available at: http://hsus.cambridge. org/HSUSWeb/toc/hsusHome.do (accessed 31 August 2012 and 27 June 2013). 
for wage changes in terms of a conventional wage share, ${ }^{4}$ changes in the price level, and unemployment provides a good fit to the data: ${ }^{5}$

$$
\begin{aligned}
& \frac{\Delta W}{W_{-1}}=47.36-77.53\left(\frac{W}{Y}\right)_{-1}+0.5368\left(\frac{\Delta P}{P}\right)_{-1}+0.09168 \frac{\Delta P^{e n}}{P_{-1}^{e n}}+0.4614 \frac{\Delta \text { Prod }}{\text { Prod }_{-1}}-0.2878 \text { UNRATE }+1.011 \text { DUM1 }-3.106 \text { DUM2 } \\
& \begin{array}{lllllll}
(18.00)(31.42) & (0.1142) & (0.0159) & (0.1349) & (0.0848) & (0.7955) & (0.9284)
\end{array}
\end{aligned}
$$

\begin{tabular}{|c|c|c|c|c|c|}
\hline Variable & & Mean & Std dev. & Min. & Max. \\
\hline$\frac{\Delta W}{W_{-1}}$ & Percentage change in money wages & 4.739877 & 4.062962 & -13.209900 & 17.539040 \\
\hline$\left(\frac{W}{Y}\right)_{-1}$ & Lagged share of wages & 0.560050 & 0.018159 & 0.514063 & 0.595732 \\
\hline$\left(\frac{\Delta P}{P}\right)_{-1}$ & Lagged change in consumer prices & 2.980698 & 3.787021 & -11.479300 & 12.577830 \\
\hline$\frac{\Delta P^{e n}}{P^{e n}-1}$ & Change in price of fuel (PPIENG) & 4.635366 & 11.848660 & -26.000000 & 55.200000 \\
\hline$\frac{\Delta \text { Prod }}{\text { Prod }_{-1}}$ & Change in output per employee hour & 2.215437 & 2.391377 & -6.641120 & 12.551870 \\
\hline $\begin{array}{l}\text { UNRATE } \\
\text { DUM1 }\end{array}$ & $\begin{array}{l}\text { Unemployment rate } \\
=0 \text { for years before } 1970, \\
=1 \text { thereafter }\end{array}$ & 7.241463 & 4.849283 & 1.200000 & 24.900000 \\
\hline DUM2 & $\begin{array}{l}=0 \text { for years before } 1994, \\
=1 \text { thereafter }\end{array}$ & & & & \\
\hline
\end{tabular}

The conventional-wage share emerges from the model. We assume that money-wage dynamics, without the control variables, are given by

$$
\frac{\Delta W}{W_{-1}}=\theta\left[\left(\frac{W}{Y}\right)^{*}-\left(\frac{W}{Y}\right)_{-1}\right]
$$

where $\left(\frac{W}{Y}\right)^{*}$ is the conventional wage and $\theta$ is the speed of adjustment. In a regression equation we have

$$
\frac{\Delta W}{W_{-1}}=a_{0}+a_{1}\left(\frac{W}{Y}\right)_{-1} \equiv-a_{1}\left[\frac{a_{0}}{-a_{1}}-\left(\frac{W}{Y}\right)_{-1}\right] .
$$

Thus $\theta=-a_{1}$ and $\left(\frac{W}{Y}\right)^{*}=\frac{a_{0}}{-a_{1}}$. In the above regression this gives $\left(\frac{W}{Y}\right)^{*}=0.61(\mathrm{se}=$ 0.018 , computed by the delta method). Note for future reference that coefficients of

4. The conventional wage is formulated as a share of product rather than as a wage rate. In the theoretical models of this paper, we can assume the conventional wage is a rate because there is no productivity growth to propel wage expectations. But this will hardly do for empirical tests.

5. Blanchard and Katz (1999) present a similar econometric analysis but with a very different interpretation of the variable that I interpret as a conventional wage. 
DUM1 and DUM2 imply that after 1970 the conventional-wage share rises to 0.62 , and after 1993 it falls to 0.58 .

\section{THEORY: A LONG-RUN MODEL IN THE SPIRIT OF THE GENERAL THEORY}

The basic model, depicted in Figure 3, relates the real price level $\frac{P}{W}$ to the labor-capital ratio, $l \equiv \frac{L}{K}$.

At any moment of time, the capital stock is given, so in the short run $l$ is a measure of employment. Since by assumption there is no technical change, the same production function holds sway now and forever:

$$
Y=F(L, K) .
$$

The assumption of constant returns to scale allows us to write:

$$
f(l) \equiv F\left(1, \frac{L}{K}\right) .
$$

There are three relationships of which the model must take account: an aggregatedemand (AD) schedule defined by the equality of expenditure and income; a goodssupply (GS) schedule given by profit maximization on the part of perfectly competitive producers; and a labor-supply (LS) schedule given by the conventional wage.

Observe that the real price is simply the inverse of the real wage, and the goodssupply schedule is at the same time a demand schedule for labor. The difference between the goods-supply and aggregate-demand schedules is the basis of the demand that each measures. On the AD schedule demand reflects the spending decisions of agents. On the GS schedule demand for labor reflects profit-maximizing decisions of firms.

The reason to frame the model in terms of the relationship between $\frac{P}{W}$ and $l$ instead of a relationship between the real price and the level of output or employment is to

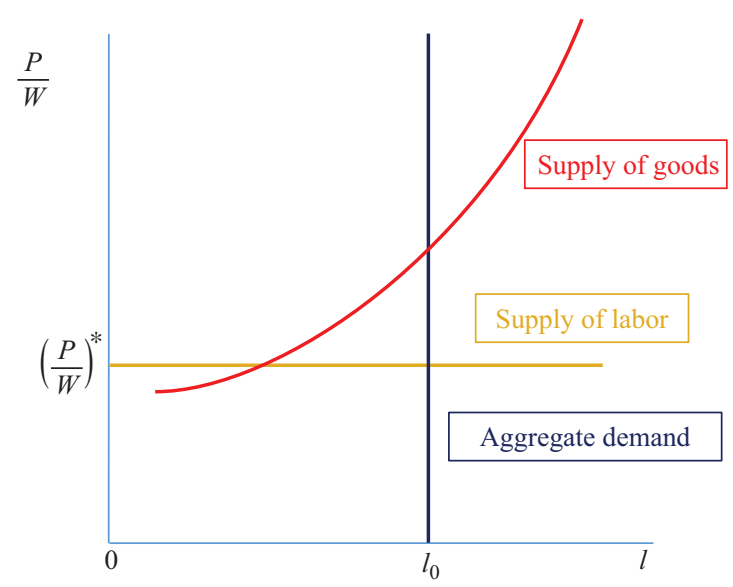

Figure 3 Aggregate demand, goods supply, and unlimited labor supply 
avoid having to deal with schedules that move over time. Stationary schedules are necessary if hardly sufficient for an equilibrium - defined as stationary values of the state variables - to exist.

Consider first aggregate demand, defined as the locus of combinations of $\frac{P}{W}$ and $l$ for which expenditure equals income. The textbook Keynesian short-run investmentdemand function $\left(I_{D}\right)$ is a negative function of a hurdle rate of interest, and desired saving $\left(S_{D}\right)$ is a constant fraction of output, with aggregate demand defined by the equality $I_{D}=S_{D}$. An even simpler formulation takes the level of investment as given.

In the context of an evolving economy, however, investment changes over time. The simplest long-run story replaces the assumption of a fixed level of investment by the assumption of a fixed ratio of desired investment to the capital stock, which is to say a given desired rate of growth of the capital stock $i$. We have $i=I_{D} / K$.

With regard to saving, we don't need to make any change at all when moving from the short to the long run. We write $S_{D} / K=s Y / K=s f(l)$.

Aggregate demand is now defined by $I_{D}=S_{D}$ or $i=s Y / K$, which is to say $f(l)=\frac{i}{s}$. Aggregate demand is thus stationary in the space $\frac{P}{W} \times l$ provided that investment demand per unit of capital $(i)$ and the propensity to save $(s)$ do not change over time.

Similarly, goods supply GS $\left(\frac{P}{W}\right)$ is invariant over time as long as there is no technological change, and no inputs other than labor and capital. (We will presently drop the second assumption in order to examine supply-side shocks.) The GS schedule is defined by equality between the real price and real marginal cost, which is to say equality between the real wage and the marginal productivity of labor:

$$
\left(\frac{P}{W}\right)^{-1}=f^{\prime}(l) .
$$

So defined, the GS schedule is stationary as long as the production function is stationary.

This leaves labor supply. The assumption of unlimited supplies of labor and a conventional wage mean the LS function is a horizontal line with an intercept on the vertical axis at

$$
\frac{P}{W}=\left(\frac{P}{W}\right)^{*},
$$

where $\left(\frac{P}{W}\right)^{*}$ is the inverse of the conventional wage. This schedule is evidently stationary, but once again technological progress would change the story.

\subsection{Equilibrium depends on dynamics}

The model in Figure 3 is overdetermined. Any two of the three schedules are sufficient to determine employment and the real price. All three together make the usual concept of equilibrium quite irrelevant. We can make sense of Figure 3 only if we shift the focus to the dynamics of adjustment.

More than one adjustment model is possible. I assume that deviations from the conventional wage drive money wages up or down, according to whether the actual real price is above or below the conventional real price. What, then, drives goods prices and employment? Keynes appears to have thought in Marshallian terms, according to which the goods-supply schedule is a locus of stationary output and employment, 
which in the present case means that change takes place only if real price and marginal cost diverge. When price exceeds marginal cost, which corresponds to a positive vertical gap between the goods-supply schedule and the current labor-capital ratio, the signal to producers seeking maximum profits is to expand. Conversely, marginal cost in excess of price is a signal to reduce operations. If price and marginal cost drive output and employment, aggregate demand must drive the nominal price level. When expenditure exceeds income, prices rise; when expenditure falls short of income, prices fall. The direct connection between the balance of income and expenditure and price changes led John Hicks (1974) to label this a 'flexprice' adjustment process.

The evolution of prices and wages is described by

$$
\begin{gathered}
\dot{W}=\theta_{3}\left[\frac{P}{W}-\left(\frac{P}{W}\right)^{*}\right] W \\
\dot{P}=\theta_{1}(i-s f(l)) P .
\end{gathered}
$$

So the adjustment of the real price is given by

$$
\left(\frac{P}{W}\right)^{\bullet} \equiv\left[\frac{\dot{P}}{P}-\frac{\dot{W}}{W}\right] \frac{P}{W}=\left\{\theta_{1}(i-s f(l))-\theta_{3}\left[\frac{P}{W}-\left(\frac{P}{W}\right)^{*}\right]\right\} \frac{P}{W} .
$$

Employment is assumed to be driven by the marginal profitability of hiring or firing workers:

$$
\dot{l}=\theta_{2}\left(\frac{P}{W}-f^{\prime}(l)^{-1}\right) .
$$

The picture is given in Figure 4. The stationary real-price locus is defined by $\left(\frac{P}{W}\right)^{\bullet}=0$, which is to say

$$
\theta_{1}(i-s f(l))=\theta_{3}\left[\frac{P}{W}-\left(\frac{P}{W}\right)^{*}\right]
$$

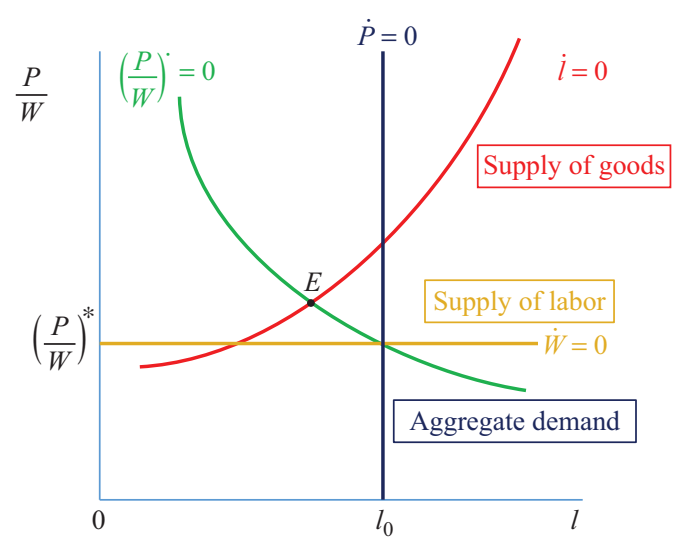

Figure 4 Equilibrium with flexprice dynamics 
The equilibrium at $E$, where both employment per unit of capital and the real price are stationary, is one with perennial excess demand, the result of which is price and wage inflation. Aggregate expenditure exceeds aggregate income, so prices rise. And because the equilibrium real wage is below the conventional wage $\frac{P}{W}>\left(\frac{P}{W}\right)^{*}$, there is constant inflationary pressure on wages. At $E$ wage inflation and price inflation take place at the same percentage rate, so that the real price remains stationary over time. ${ }^{6}$ It is easy to verify that the equilibrium at $E$ is stable since the trace and the determinant of the matrix of partial derivatives of $\dot{l}$ and $\left(\frac{P}{W}\right)^{\cdot}$ with respect to $l$ and $\frac{P}{W}$ are respectively negative and positive.

Hicks contrasted flexprice adjustment with fixprice adjustment. 'Fixprice' is misleading since prices are not fixed; rather the direct impact of an excess or shortfall of expenditure relative to income is on output and employment; prices (and wages) are affected only indirectly. This is to say that changes in employment are driven by how fast goods are moving off (or piling up on) the shelves. This adjustment process is described by the equation

$$
\dot{l}=\theta_{1}(i-s f(l)) l
$$

Prices adjust according to the distance (at the going real price) between actual employment per unit of capital and the profit-maximizing level of employment

$$
\dot{P}=\theta_{2}\left[l-\mathrm{GS}\left(\frac{P}{W}\right)\right] P .
$$

Wages, as with flexprice adjustment, change according to

$$
\dot{W}=\theta_{3}\left[\frac{P}{W}-\left(\frac{P}{W}\right)^{*}\right] W .
$$

Consequently the real price adjusts according to

$$
\left(\frac{P}{W}\right)^{\bullet}=\left\{\theta_{2}\left[l-\mathrm{GS}\left(\frac{P}{W}\right)\right]-\theta_{3}\left[\frac{P}{W}-\left(\frac{P}{W}\right)^{*}\right]\right\} \frac{P}{W} .
$$

This process defines the equilibrium in Figure 5. Since the GS schedule is now a locus of stationary prices and the LS schedule is the locus of stationary money wages, the stationary real price locus, $\left(\frac{P}{W}\right)^{\bullet}=0$, lies between them.

The equilibrium in Figure 5, like the equilibrium in Figure 4, is characterized by inflation: producers raise prices because they are losing money at the margin, while workers, who find themselves making do with less than the conventional wage, put pressure on wages. At $E$ the pressure on prices and pressure on wages just balance, so that while both are rising the real price remains stationary. Like the equilibrium in Figure 4, the equilibrium in Figure 5 is stable.

6. Equilibrium deflation is also possible: if the aggregate-demand schedule lies to the left of the intersection of the goods-supply and labor-supply schedules, the stationary real-price schedule and aggregate-demand schedule will intersect at a point where prices and wages are falling at the same rate, as in the Great Depression. 


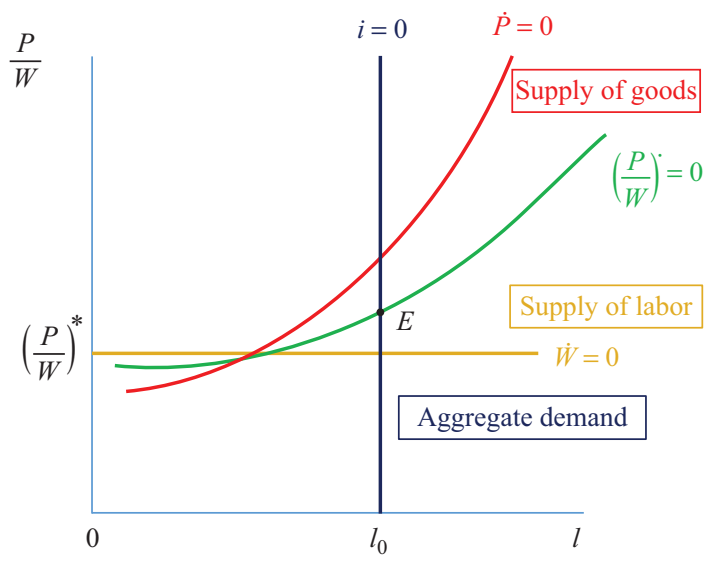

Figure 5 The model with fixprice dynamics

\subsection{Some comparative statics: Phillips and anti-Phillips curves}

Figures 4 and 5 make it clear that the equilibrium depends on the adjustment process. The same underlying AD, GS, and LS schedules lead to different stationary values of the state variables. Equilibrium is defined by the process of getting there.

Moreover, the comparative statics of displacing one or another schedule differ in the two models. We can define Phillips and anti-Phillips outcomes according to whether employment and inflation move in the same direction or in opposite directions.

\subsubsection{Aggregate-demand shocks}

Look first at what happens when aggregate demand changes, as in Figures $6 \mathrm{a}$ and $6 \mathrm{~b}$. In both cases the increase in aggregate demand leads to an increase in economic activity accompanied by higher inflation, that is, a Phillips effect. An older literature referred to this as 'demand-pull' inflation.

\subsubsection{Goods-supply shocks}

As David Colander observed over 20 years ago (Colander 1995), a change in production conditions will not only shift the goods-supply schedule, but will normally move the aggregate-demand schedule as well. A change in output is at the same time a change in income and will thus shift the balance between expenditure and income.

With flexprice dynamics, the results from a joint movement of demand and supply are ambiguous. An upward shift in the GS schedule produces a higher price level and higher inflation, but it may increase or decrease the level of employment depending on how rapidly prices and wages adjust. Thus a Phillips effect, with higher employment and higher inflation, is a possible outcome of an upward shift in the supply schedule, but so is an anti-Phillips effect, coupling lower employment with higher inflation. In the case of fixprice dynamics, we always get a Phillips effect since it requires more 


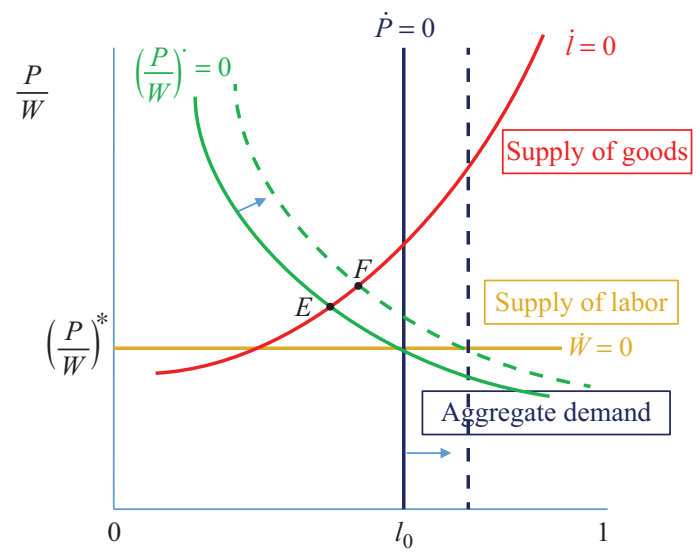

(a) Flexprice dynamics

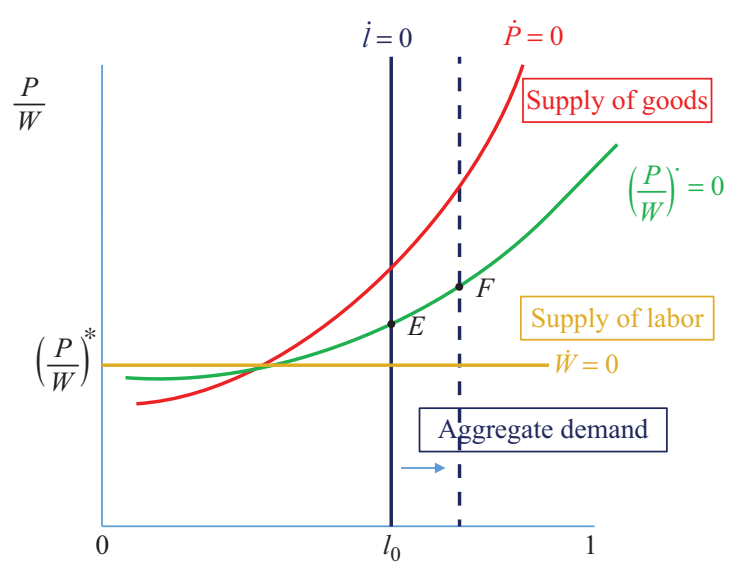

(b) Fixprice dynamics

Figure 6 An aggregate-demand shock

workers to produce the same output, and (for the present) output and employment are determined solely by demand in a fixprice regime.

The simplest way of seeing this is to expand the production function to include a third variable, say, energy $(E)$. We write:

$$
Y=F(K, L, E)
$$

and continue to assume constant returns to scale, so that

$$
\frac{Y}{K}=F(1, l, e)=f(l, e),
$$

where $e=\frac{E}{K}$. We further assume that energy is purchased on a competitive market at the real price $\xi . \xi=\frac{P_{E}}{P}$, where $P_{E}$ is the nominal price of energy. The effects of a change in the price of energy depend on whether energy is produced domestically 
or imported. The simplest story is that energy is entirely imported and paid for by transferring goods abroad. $h(l, \xi)$ is then the output-capital ratio net of the cost of energy inputs:

$$
h(l, \xi)=\max _{e}[f(l, e)-\xi e]=f(l, e(l, \xi))-\xi e(l, \xi),
$$

where $e=e(l, \xi)$ is the amount of energy per unit of capital which, for given $l$ and $\xi$, maximizes the expression $f(l, e)-\xi e$.

We can now represent a supply-side shift by a change in $\xi$. Denoting partial derivatives by subscripts and assuming that the profit-maximizing level of energy involves an interior solution (the marginal productivity of energy equal to its price), we have

$$
\begin{gathered}
h_{l}=f_{l} \\
f_{e}=\xi \\
h_{\xi}=-e \\
e_{\xi}=f_{e e}^{-1} \\
e_{l}=-f_{e l} f_{e e}^{-1} \\
h_{l l}=f_{l l}+f_{l e} e_{l}=f_{l l}-f_{l e}^{2} f_{e e}^{-1}=f_{e e}^{-1}\left(f_{l l} f_{e e}-f_{l e}^{2}\right) \\
h_{l \xi}=f_{l e} e_{\xi}=f_{l e} f_{e e}^{-1} .
\end{gathered}
$$

We assume diminishing returns to each input, so both $f_{l l}$ and $f_{e e}$ are negative. We also assume that energy and labor are complements, with the result that $f_{e l}\left(=f_{l e}\right)$ is positive. $h_{l l}$ must be negative; otherwise equality between the marginal productivity of labor and the real wage

$$
h_{l}=f_{l}=\left(\frac{P}{W}\right)^{-1}
$$

characterizes minimum rather than maximum profits. In other words, the assumption of an interior solution to the profit-maximization problem implies that diminishing returns to each input outweigh the complementarity of the two inputs.

Formally, the effect on the GS schedule of a change in energy price is obtained by calculating the derivatives $\left(\frac{d l}{d \xi}\right)_{\mathrm{GS}}$ and $\left(\frac{d \frac{P}{d \xi}}{d \xi}\right)_{\mathrm{GS}}$. Assuming an interior solution to the profit-maximization problem, we have

$$
\begin{gathered}
h_{l l}\left(\frac{d l}{d \xi}\right)_{\mathrm{GS}}+h_{l \xi}=f_{e e}^{-1}\left(f_{l l} f_{e e}-f_{l e}^{2}\right)\left(\frac{d l}{d \xi}\right)_{\mathrm{GS}}+f_{l e} f_{e e}^{-1}=0 \\
\left(\frac{d l}{d \xi}\right)_{\mathrm{GS}}=-\frac{h_{l \xi}}{h_{l l}}=\frac{-f_{l e}}{\left(f_{l l} f_{e e}-f_{l e}^{2}\right)}
\end{gathered}
$$


and

$$
\begin{aligned}
h_{l \xi}=f_{l e} e_{\xi}=f_{l e} f_{e e} & =-\left(\frac{P}{W}\right)^{-2}\left(\frac{d \frac{P}{W}}{d \xi}\right)_{\mathrm{GS}} \\
\left(\frac{d \frac{P}{W}}{d \xi}\right)_{\mathrm{GS}} & =-\frac{f_{l e} f_{e e}}{\left(\frac{P}{W}\right)^{-2}} .
\end{aligned}
$$

We are not done. As has been observed, a change in the price of energy also affects the aggregate-demand schedule since expenditure and income depend on output. Under the assumption that energy is imported and paid for in goods, the AD equation is:

$$
i-s h(l, \xi)=i-s[f(l, e(l, \xi))-\xi e(l, \xi)]=0
$$

so

$$
\left(\frac{d l}{d \xi}\right)_{\mathrm{AD}}=-\frac{h_{\xi}}{h_{l}}=\frac{e}{f_{l}}>0 .
$$

Figure 7 shows the combined effects of an increase in the price of energy on aggregate demand and goods supply. ${ }^{7}$

The effect on equilibrium depends on the adjustment process. With flexprice adjustment, the stationary loci are

$$
\begin{gathered}
\frac{P}{W}-h_{l}(l, \xi)^{-1}=0 \\
i-\operatorname{sh}(l, \xi)-\frac{\theta_{3}}{\theta_{1}}\left[\frac{P}{W}-\left(\frac{P}{W}\right)^{*}\right]=0
\end{gathered}
$$

and, denoting the derivatives of equilibrium levels of $l$ and $\frac{P}{W}$ with respect to $\xi$ by $l_{\xi}$ and $\left(\frac{P}{W}\right)_{\xi}$, the results are

$$
l_{\xi}=\frac{\frac{h_{l \xi}}{\left(\frac{P}{W}\right)^{-2}}-\frac{\theta_{1}}{\theta_{3}} s h_{\xi}}{-\left(\frac{h_{l l}}{\left(\frac{P}{W}\right)^{-2}}-\frac{\theta_{1}}{\theta_{3}} s h_{l}\right)}=\frac{h_{l \xi}-\frac{\theta_{1}}{\theta_{3}} s h_{l}^{2} h_{\xi}}{-\left(h_{l l}-\frac{\theta_{1}}{\theta_{3}} s h_{l}^{3}\right)}
$$

7. If energy is domestically produced with the income staying in the country, the equation remains

$$
i-s f(l, e(l, \xi))=0
$$

and

$$
\left(\frac{d l}{d \xi}\right)_{\mathrm{AD}}=-\frac{f_{e} f_{e e}^{-1}}{f_{l}+f_{e}\left(-f_{e l} f_{e e}^{-1}\right)}>0
$$

so the results are qualitatively similar to the results of assuming all energy is imported. 


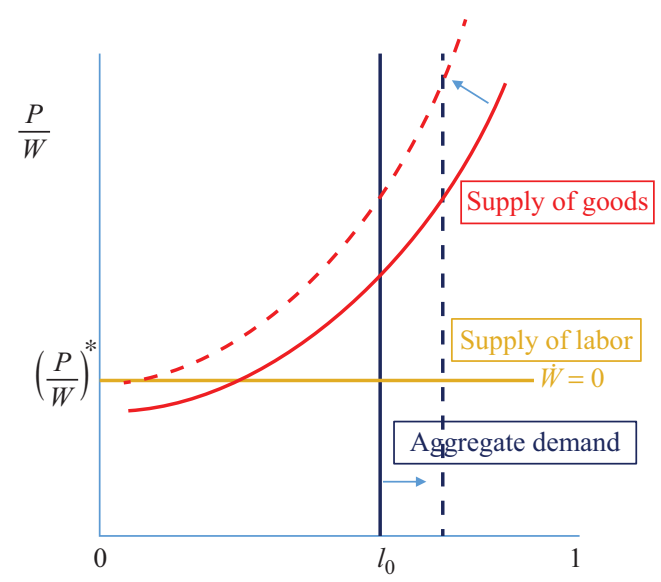

Figure 7 The impact of an increase in energy price

$$
\left(\frac{P}{W}\right)_{\xi}=\frac{-\frac{\frac{\theta_{1}}{\theta_{3}}}{\left(\frac{P}{W}\right)^{-2}} s\left(h_{l} h_{l \xi}-h_{\xi} h_{l l}\right)}{-\left(\frac{h_{l l}}{\left(\frac{P}{W}\right)^{-2}}-\frac{\theta_{1}}{\theta_{3}} s h_{l}\right)}=\frac{-\frac{\theta_{1}}{\theta_{3}} s\left(h_{l} h_{l \xi}-h_{\xi} h_{l l}\right)}{-\left(h_{l l}-\frac{\theta_{1}}{\theta_{3}} s h_{l}^{3}\right)}
$$

The expressions on the far right incorporate the equilibrium condition

$$
h_{l}(l, \xi)^{-1}=\frac{P}{W} .
$$

$\left(\frac{P}{W}\right)_{\xi}$ is necessarily positive since the numerator and denominator are both negative. So inflation rises. But now the cause of the increase in inflation is an upward displacement of the GS schedule, which leads to a distinction between 'cost-push' inflation that has its origins on the supply side from the demand-pull of an outward shift in the AD schedule.

By contrast, the sign of $l_{\xi}$ is ambiguous because there are two contradictory forces at work. Two possibilities are shown in Figures $8 \mathrm{a}$ and $8 \mathrm{~b}$. When the price of energy rises, the marginal productivity of labor falls (remember, labor and energy are complements), so producers contract output and employment. At the same time, output net of energy costs, $h(l, \xi)$, falls, and therefore so does saving. Because investment is assumed to be given, aggregate expenditure rises relative to aggregate income, and this causes the price level to rise. This makes production more profitable at the margin, which induces an increase in output and employment. However, the rise in prices reduces real wages and this leads to wage pressure, which counters the positive effect of higher prices on output and employment. How these conflicting tendencies resolve depends, among other things, on the relative adjustment speeds $\theta_{1}$ (the speed of price adjustment) and $\theta_{3}$ (the speed at which wages adjust).

An energy price hike always poses a burden on workers. But how much the burden takes the form of lower real wages and how much it takes the form of lower employment depends on whether prices or wages adjust more rapidly. 


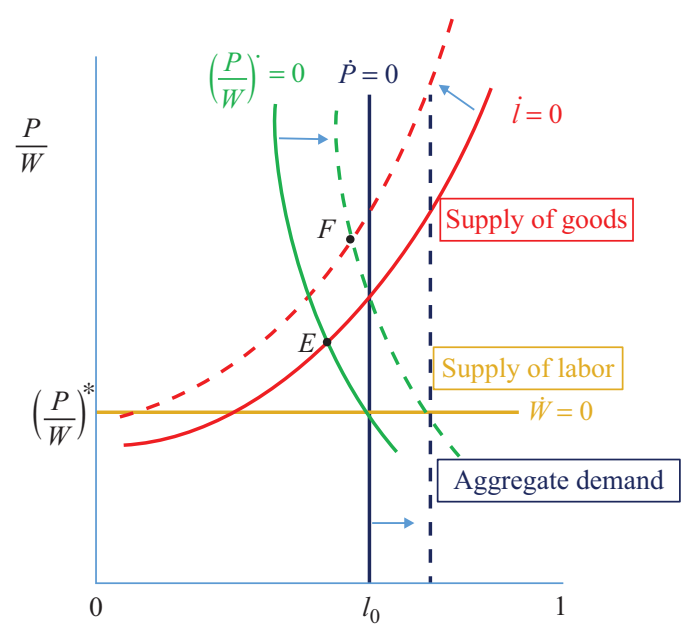

(a) Rapid price adjustment

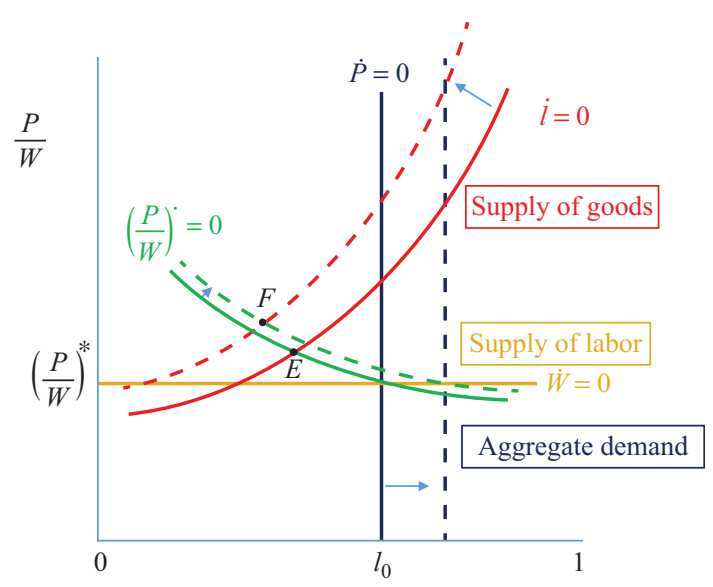

(b) Slow price adjustment

Figure 8 Increase in energy price with flexprice dynamics

The contradictory effects of supply shocks are made clearer by looking at the limiting cases of rapid price adjustment and sluggish price adjustment. In the first case, which is Keynes's case of money-wage rigidity, and therefore real-wage flexibility, we have

$$
\lim _{\frac{\theta_{3}}{\theta_{1}} \rightarrow 0} l_{\xi}=-\frac{h_{\xi}}{h_{l}}
$$

the right-hand side representing the relationship between changes in $\xi$ and $l$ when $h(l, \xi)$ remains constant, which it does along the aggregate-demand equation if $i$ and 
$s$ remain constant. In this limiting case, the wage equation drops out as a determinant of equilibrium, which is now characterized by the two equations:

$$
\begin{gathered}
\frac{P}{W}-h_{l}(l, \xi)^{-1}=0 \\
i-\operatorname{sh}(l, \xi)=0 .
\end{gathered}
$$

That is, in the limit as $\frac{\theta_{3}}{\theta_{1}} \rightarrow 0$ the stationary real-price locus coincides with the AD schedule, and a higher real price - a lower real wage - makes it profitable to employ more workers. At this limit, there is no mechanism for countering the real effects of the adjustment of the price level, and workers feel the burden of a higher energy price in lower real wages. The wage-equation does not drop out as a determinant of inflation since the stationary-price equation

$$
\left(\frac{P}{W}\right)^{\bullet} \equiv\left[\frac{\dot{P}}{P}-\frac{\dot{W}}{W}\right] \frac{P}{W}=\left\{\theta_{1}(i-\operatorname{sh}(l, \xi))-\theta_{3}\left[\frac{P}{W}-\left(\frac{P}{W}\right)^{*}\right]\right\} \frac{P}{W}
$$

continues to hold as we pass to the limit as $\theta_{1} \rightarrow \infty$ for fixed $\theta_{3}$; this is consistent with a non-zero but finite value for $\frac{\dot{P}}{P}$ and $\frac{\dot{W}}{W}$ since $i-\operatorname{sh}(l, \xi) \rightarrow 0$ as $\theta_{1} \rightarrow \infty$. The new equilibrium induced by an energy-price increase is associated with a higher rate of inflation.

At the other extreme, where money wages are infinitely flexible, negative employment effects replace negative real-wage effects. In this case, the real wage is rigid and we have

$$
\lim _{\frac{\theta_{1}}{\theta_{3}} \rightarrow 0} l_{\xi}=-\frac{h_{l \xi}}{h_{l l}}
$$

which reflects the relationship between changes in $\xi$ and $l$ along the goods-supply equation. The stationary-price locus now coincides with the labor-supply schedule. As in the previous case, there is a permanently higher rate of inflation.

The two limiting cases are shown in Figure 9. In Figure 9a we have the Phillips effect, coupling higher employment and higher inflation; in Figure 9b, we have an anti-Phillips, stagflationary, effect, coupling lower employment and higher inflation.

The analysis suggests a fissure in the working class with regard to a supply-side shock. If asked to choose between taking a hit in the form of reduced wages or in the form of reduced employment, different workers have different interests. Those with secure employment, or good job prospects in the face of job loss, might be expected to opt for rigid real wages. Those with only marginal employment opportunities might opt for rigid money wages, preferring to take the hit in the form of lower real wages than in the form of reduced employment.

With fixprice dynamics, the stationary loci are

$$
\begin{gathered}
i-\operatorname{sh}(l, \xi)=0 \\
l-\mathrm{GS}\left(\frac{P}{W}, \xi\right)-\frac{\theta_{3}}{\theta_{2}}\left[\frac{P}{W}-\left(\frac{P}{W}\right)^{*}\right]=0 .
\end{gathered}
$$




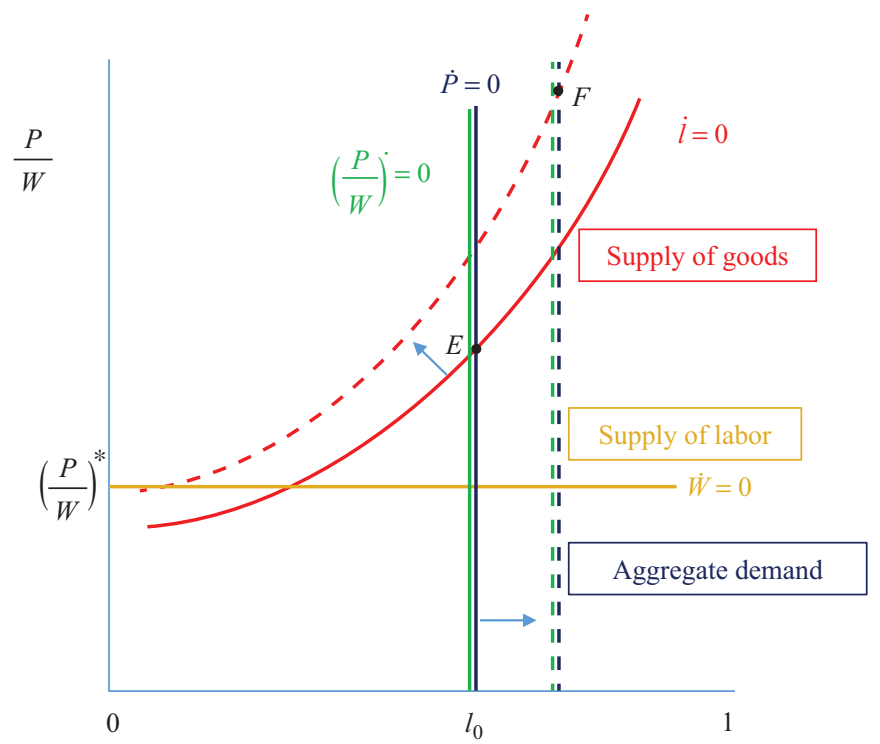

(a) Rapid price adjustment (flexible real wages)

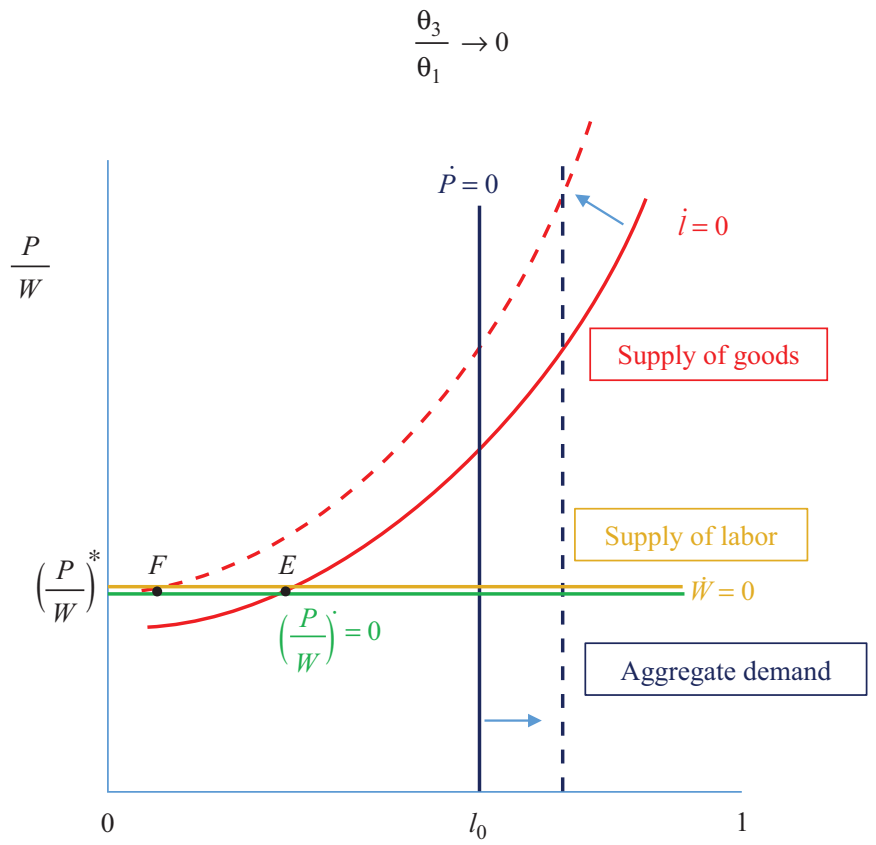

(b) Rapid wage adjustment (rigid real wages)

$$
\frac{\theta_{1}}{\theta_{3}} \rightarrow 0
$$

Figure 9 Increase in energy price with flexprice dynamics: limiting cases 
The equilibrium values of $l_{\xi}$ and $\left(\frac{P}{W}\right)_{\xi}$ are now

$$
\begin{gathered}
l_{\xi}=-\frac{h_{\xi}}{h_{l}}>0 \\
\left(\frac{P}{W}\right)_{\xi}=\frac{-\mathrm{GS}_{\xi}-\frac{h_{\xi}}{h_{l}}}{\mathrm{GS}_{\frac{P}{W}}+\frac{\theta_{3}}{\theta_{2}}}>0
\end{gathered}
$$

with the derivatives of the goods-supply schedule given by

$$
\begin{gathered}
\mathrm{GS}_{\xi}=\left(\frac{d l}{d \xi}\right)_{\mathrm{GS}}=-\frac{h_{l \xi}}{h_{l l}}<0 \\
\mathrm{GS}_{\frac{P}{W}}=\left(\frac{d l}{d\left(\frac{P}{W}\right)}\right)_{\mathrm{GS}}=-\frac{h_{l}^{2}}{h_{l l}}>0 .
\end{gathered}
$$

The picture is in Figure 10. In words, an increase in the price of energy increases employment while lowering real wages and increasing the equilibrium level of inflation. Employment increases because more workers are required to produce the same output; with fixprice dynamics equilibrium is always on the AD schedule. Real wages fall because producing this output is profitable only at a higher real price; inflation increases because workers increase the pressure on money wages as the real wage falls.

In the fixprice case, there is no ambiguity. A shock to the GS schedule consistently produces a Phillips-curve result - higher inflation coupled with higher employment regardless of whether wages or prices adjust more rapidly.

The results of varying the conventional wage $\left(\frac{P}{W}\right)^{*}$ are similar to the results of a supply shock - without any ambiguity in the effect on employment. As Figure 11a shows, in the flexprice case an increase in the conventional wage, which is to say a fall in $\left(\frac{P}{W}\right)^{*}$, leads to an increase in inflation (except in the limiting case of rigid money wages); in the fixprice case, Figure $11 \mathrm{~b}$, there is also an increase in the equilibrium

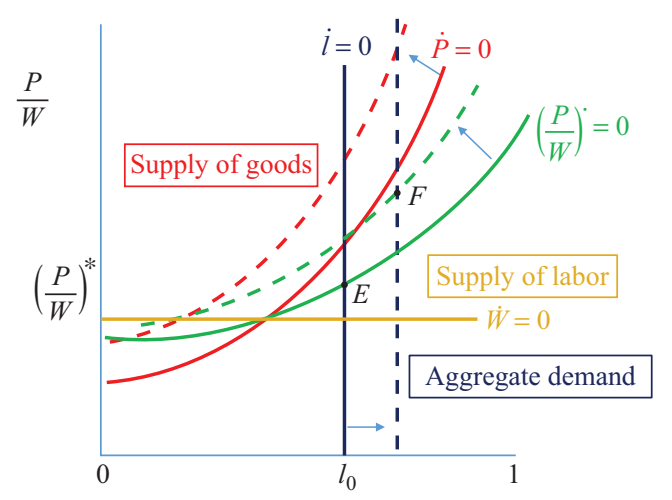

Figure 10 An energy-price shock with fixprice dynamics 


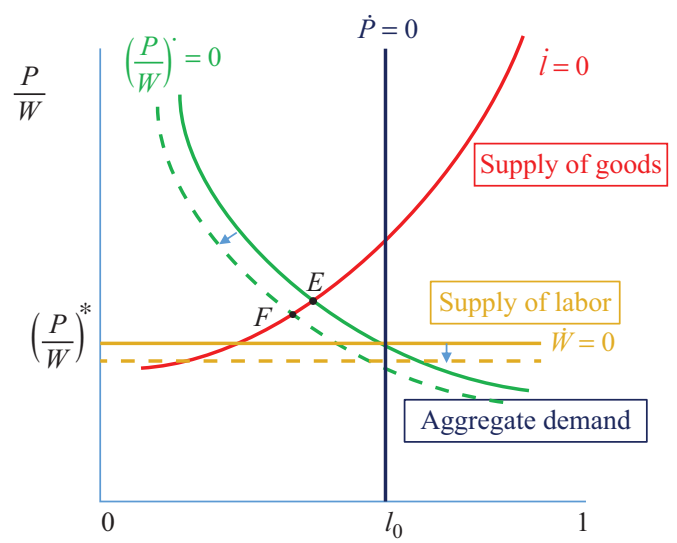

(a) Flexprice dynamics

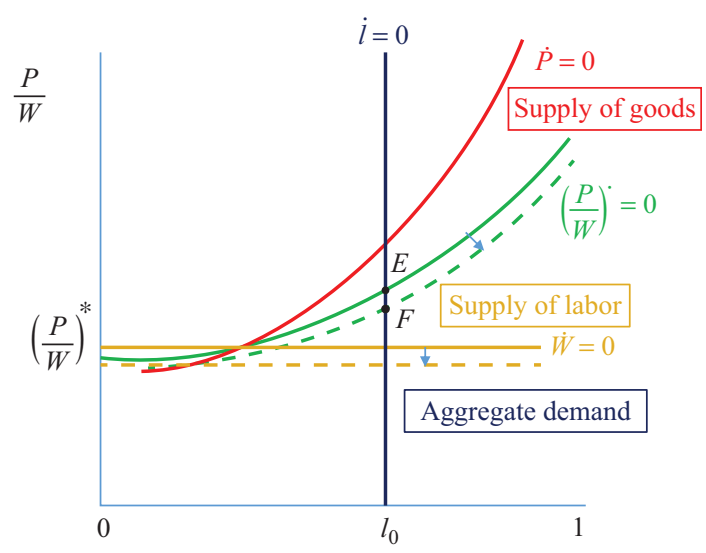

(b) Fixprice dynamics

Figure 11 An increase in the conventional wage

rate of inflation. This is another case of cost-push inflation; indeed wage pressure was practically synonymous with cost-push before the oil shocks of the 1970s.

Observe that an increase in the conventional wage leads to a reduction in employment in the flexprice case, but employment is unaffected in the fixprice model. This comes from assuming a vertical AD schedule. In turn, the vertical AD schedule is the consequence of assuming, first, that saving is a constant fraction of income, and, second, that investment demand is exogenously given. We relax these simplifying assumptions one at a time.

\subsection{Demand and supply shocks with the Cambridge saving equation}

A model with a uniform propensity to save is clearly not the right model for bringing out the left-Keynesian argument that the redistribution involved in higher wages will shift the AD schedule outwards and thus lead to higher employment. The focus of this 
story was on consumption demand, which (at least until the intellectual triumph of permanent income and life-cycle hypotheses) was believed to increase as a proportion of income the farther one went down the income scale.

A pre-Keynesian view of consumption and saving assumed that working people simply lacked the economic capacity to save and that the rich were responsible for whatever saving the community was able to muster. In the nineteenth century economists were not reluctant to associate saving and class: capitalists saved a substantial share of their profits while workers, with meager wages, had all they could do to keep body and soul together. In the book which catapulted him from the middle ranks of the civil service to world-renowned public intellectual, The Economic Consequences of the Peace (1919), Keynes himself made a class-based argument about saving, attributing the remarkable growth of capital and income between 1870 and the First World War to a tacit social bargain which allowed capitalists to call the lion's share of the national product their own - on condition that they plowed it back into capital formation.

The class-based view of saving was revived by economists who, some of them at least, had been among Keynes's closest disciples and who, each and every one, thought himself or (especially) herself as the true defender of the true faith. In the simplest form of the so-called 'Cambridge saving equation,' saving is proportional to total profit, $S_{D}=s_{\pi} \Pi, s_{\pi}$ representing capitalists' propensity to save and $\Pi$ total profits. Expressing saving as a percentage of the capital stock $K$, and noting that desired saving represents a desired increment in the capital stock, the growth rate of capital desired by savers is proportional to the rate of profit:

$$
r=\frac{\Pi}{K}=f(l, e)-\left(\frac{P}{W}\right)^{-1} l-\xi \mathrm{e}=h(l, \xi)-\left(\frac{P}{W}\right)^{-1} l .
$$

That is,

$$
\frac{S_{D}}{K}=s_{\pi} r=s_{\pi} \pi h(l, \xi)
$$

where

$$
\begin{gathered}
r=h(l, \xi)-\left(\frac{P}{W}\right)^{-1} l \\
\pi=\frac{\Pi}{Y}=1-\left(\frac{P}{W}\right)^{-1} h(l, \xi)^{-1} l .
\end{gathered}
$$

If we continue to assume investment demand per unit of capital, $i=\frac{I_{D}}{K}$, is constant, the aggregate-demand schedule is now defined by

$$
i=s_{\pi} r .
$$

In panel (a) of Figure 12, the aggregate-demand equilibrium is unique, but this uniqueness translates into multiple equilibria when the vertical axis measures $l$ rather than $r$, as it does in panel (b). Observe that all the equilibria in panel (b), for various levels of the real price, correspond to the same rate of profit and the same rate of saving and investment: $l_{1}$ and $l_{4}$ are points where desired saving and investment are equal with the price level $\left(\frac{P}{W}\right)_{0}, l_{2}$ and $l_{3}$ with $\left(\frac{P}{W}\right)_{1}$. 
a) Investment and saving as

$$
\frac{I_{D}}{K}, \frac{S_{D}}{K} \mid \frac{I_{D}}{K}, \frac{S_{D}}{K}
$$

functions of the rate of profit

(b) Investment and saving

holding real price constant

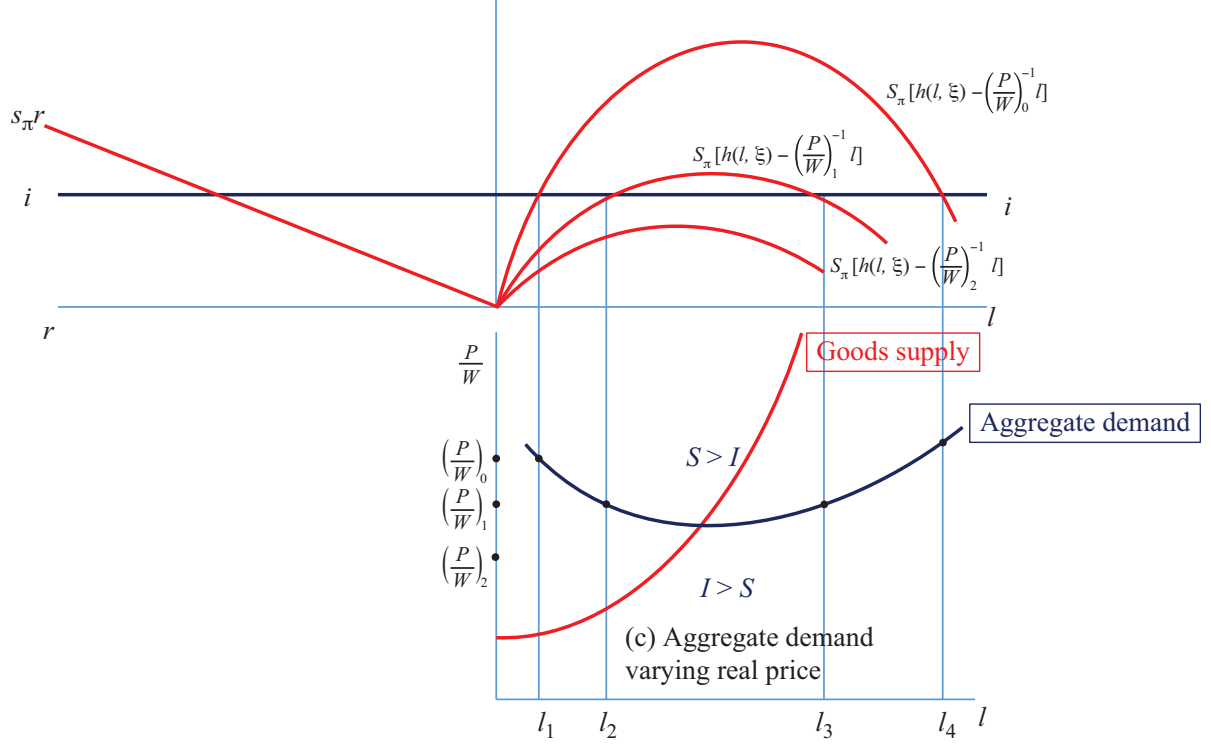

Figure 12 Aggregate demand with the Cambridge saving equation

Multiple equilibria arise in Figure $12 \mathrm{~b}$ because, for a given price level, profits and therefore saving rise as long as the marginal productivity of labor exceeds the real wage, and then fall. Panel (c) shows the implications for aggregate demand in $\frac{P}{W} \times l$ space. For relatively high real prices, like $\left(\frac{P}{W}\right)_{0}$ and $\left(\frac{P}{W}\right)_{1}$, the two intersections of the corresponding desired-saving schedule and the desired-investment schedule in panel (b) translate into two points on the aggregate-demand schedule in panel (c). For a relatively low price, like $\left(\frac{P}{W}\right)_{2}$, there is no level of employment that generates profit sufficient to balance the desired level of investment.

Observe that the goods-supply schedule goes through the minimum point of the aggregate-demand schedule. This is because, for any given real price, maximum saving corresponds to the point of profit maximization, which in turn defines the goodssupply schedule. At the minimum of the aggregate-demand schedule, there is only one level of employment - namely the profit-maximizing level - that generates enough profit and saving to cover the given amount of desired investment.

Class-based saving changes the analysis of equilibrium. Figure 13a illustrates a flexprice equilibrium and Figure $13 \mathrm{~b}$ a pair of fixprice equilibria. With saving coming from profits, flexprice dynamics are governed by

$$
\left(\frac{P}{W}\right)^{\bullet}=\left\{\theta_{1}\left(i-s_{\pi} \pi h(l, \xi)\right)-\theta_{3}\left[\frac{P}{W}-\left(\frac{P}{W}\right)^{*}\right]\right\} \frac{P}{W}
$$


386 Review of Keynesian Economics, Vol. 5 No. 3

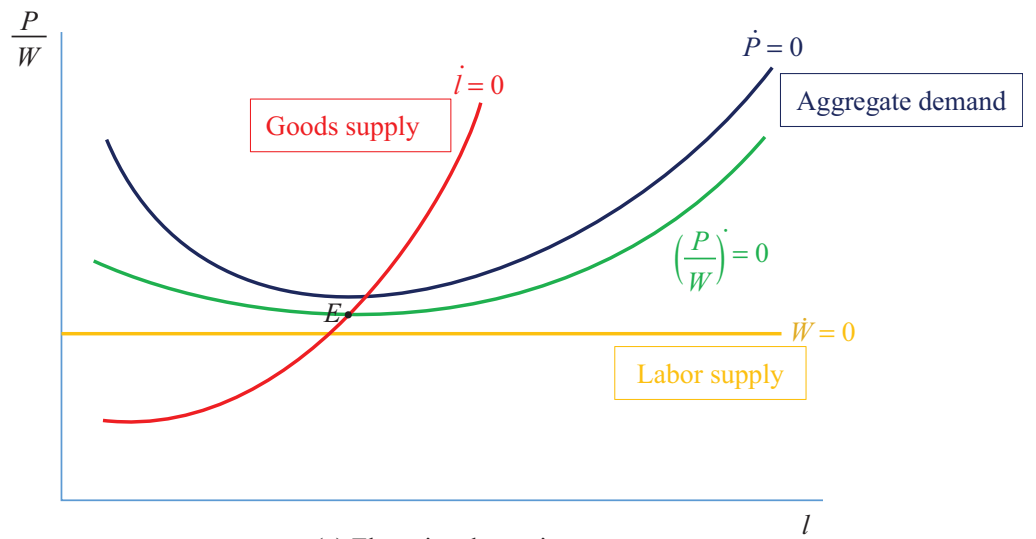

(a) Flexprice dynamics

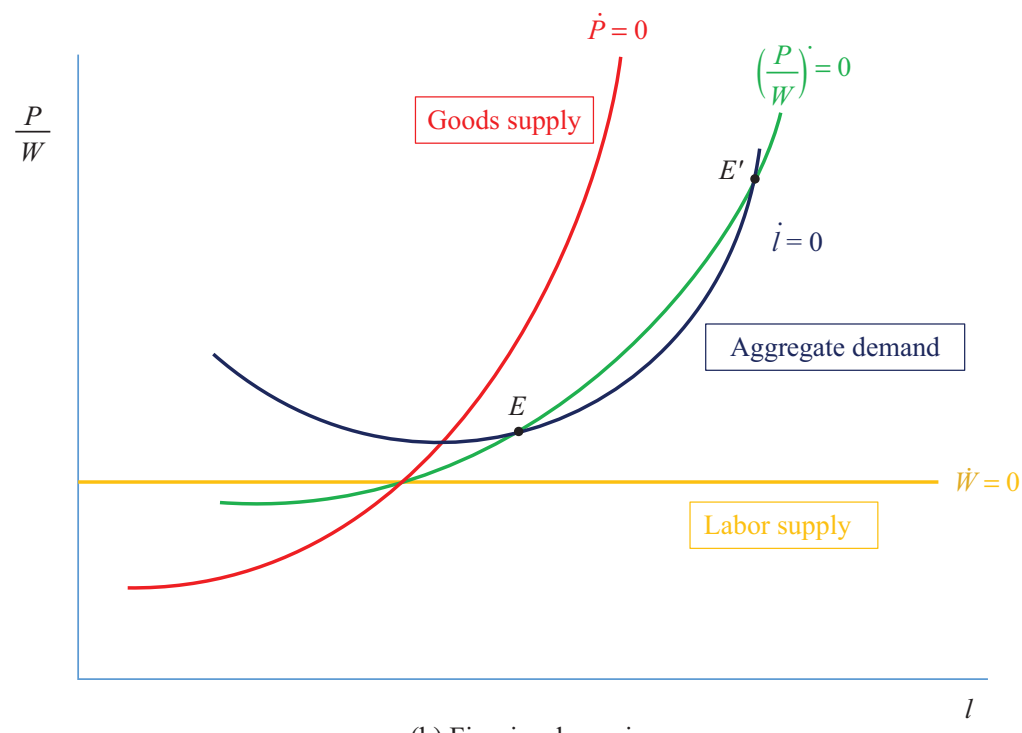

(b) Fixprice dynamics

Figure 13 Equilibria with Cambridge saving equation

$$
\dot{l}=\theta_{2}\left(\frac{P}{W}-h_{l}(l, \xi)^{-1}\right) l
$$

and fixprice dynamics by

$$
\begin{gathered}
\left(\frac{P}{W}\right)^{\bullet}=\left\{\theta_{2}\left[l-\mathrm{GS}\left(\frac{P}{W}, \xi\right)\right]-\theta_{3}\left[\frac{P}{W}-\left(\frac{P}{W}\right)^{*}\right]\right\} \frac{P}{W} \\
i=\theta_{1}\left(i-s_{\pi} \pi h(l, \xi)\right) l
\end{gathered}
$$


The flexprice Jacobian is

$$
\begin{aligned}
& J=\left[\begin{array}{cc}
\frac{\partial\left(\frac{P}{W}\right)^{\bullet}}{\partial \frac{P}{W}} & \frac{\partial\left(\frac{P}{W}\right)^{\bullet}}{\partial l} \\
\frac{\partial \dot{l}}{\partial \frac{P}{W}} & \frac{\partial \dot{l}}{\partial l}
\end{array}\right]=\left[\begin{array}{cc}
-\theta_{1} s_{\pi}\left(\frac{P}{W}\right)^{-2} l-\theta_{3} & -\theta_{1} s_{\pi}\left[h_{l}-\left(\frac{P}{W}\right)^{-1}\right] \\
\theta_{2} & \theta_{2} h_{l}^{-2} h_{l l}
\end{array}\right] \\
& \operatorname{sgn}\left[\begin{array}{cc}
\frac{\partial\left(\frac{P}{W}\right)}{\partial \frac{P}{W}} & \frac{\partial\left(\frac{P}{W}\right)^{\cdot}}{\partial l} \\
\frac{\partial i}{\partial \frac{P}{W}} & \frac{\partial i}{\partial l}
\end{array}\right]=\left[\begin{array}{cc}
- & 0 \\
+ & -
\end{array}\right]
\end{aligned}
$$

so the trace is negative and the determinant is positive. Thus the equilibrium is stable.

In contrast, the fixprice Jacobian is

$$
J=\left[\begin{array}{cc}
\frac{\partial\left(\frac{P}{W}\right)^{\bullet}}{\partial \frac{P}{W}} & \frac{\partial\left(\frac{P}{W}\right)^{\bullet}}{\partial l} \\
\frac{\partial \dot{l}}{\partial \frac{P}{W}} & \frac{\partial \dot{l}}{\partial l}
\end{array}\right]=\left[\begin{array}{cc}
\theta_{2} \frac{h_{l}^{2}}{h_{l l}}-\theta_{3} & \theta_{2} \\
-\theta_{1} s_{\pi}\left(\frac{P}{W}\right)^{-2} & -\theta_{1} s_{\pi}\left[h_{l}-\left(\frac{P}{W}\right)^{-1}\right]
\end{array}\right]=\left[\begin{array}{cc}
- & + \\
- & +
\end{array}\right]
$$

with $\frac{h_{l}^{2}}{h_{l l}}$ in the expression

$$
\theta_{2} \frac{h_{l}^{2}}{h_{l l}}-\theta_{3}
$$

calculated on the goods-supply schedule. At $E$, the determinant is positive since the slope of the AD schedule relative to the price axis is greater than the slope of the stationary-price locus. That is,

$$
\left(\frac{d l}{d\left(\frac{P}{W}\right)}\right)_{\left(\frac{P}{W}\right)^{\cdot}=0}=-\frac{\frac{\partial\left(\frac{P}{W}\right)^{\bullet}}{\partial \frac{P}{W}}}{\frac{\partial\left(\frac{P}{W}\right)^{\bullet}}{\partial l}} \text { and }\left(\frac{d l}{d\left(\frac{P}{W}\right)}\right)_{\mathrm{AD}}=-\frac{\frac{\partial l}{\partial \frac{P}{W}}}{\frac{\partial l}{\partial l}}
$$


so

$$
\begin{gathered}
\left(\frac{d l}{d\left(\frac{P}{W}\right)}\right)_{\mathrm{AD}}>\left(\frac{d l}{d\left(\frac{P}{W}\right)}\right)_{\left(\frac{P}{W}\right)^{\bullet}=0} \Leftrightarrow-\frac{\frac{\partial \dot{l}}{\partial \frac{P}{W}}}{\frac{\partial \dot{l}}{\partial l}}>-\frac{\frac{\partial\left(\frac{P}{W}\right)^{\bullet}}{\partial \frac{P}{W}}}{\frac{\partial\left(\frac{P}{W}\right)^{\bullet}}{\partial l}} \\
\Leftrightarrow \operatorname{det} J=\frac{\partial\left(\frac{P}{W}\right)^{\bullet}}{\partial \frac{P}{W}} \frac{\partial \dot{l}}{\partial l}-\frac{\partial \dot{l}}{\partial \frac{P}{W}} \frac{\partial\left(\frac{P}{W}\right)^{\bullet}}{\partial l}>0 .
\end{gathered}
$$

But the trace is of indefinite sign: it will be negative - and the equilibrium will be stable - if prices adjust much more rapidly than quantities, and it will be positive implying instability - if quantities adjust more rapidly than prices. The indeterminacy is clearest when the economy is below the AD schedule. In this region an excess of expenditure over income drives the economy away from equilibrium while the adjustment of prices and wages drives the economy towards equilibrium. The outcome depends on which force is stronger, which determines whether the economy spirals inward, towards $E$ in Figure 13b, or outward, away from $E$.

At $E^{\prime}$, the situation is different. In the fixprice case, if an equilibrium like $E$ exists, it must coexist with another equilibrium. With the elasticity of substitution in production less than 1, the slope of the AD schedule relative to the price axis approaches 0 as $\frac{P}{W} \rightarrow \infty$, while the slope of the stationary real-price equation approaches $\frac{\theta_{3}}{\theta_{2}}$. This second equilibrium is necessarily unstable. At $E^{\prime}$ the $\mathrm{AD}$ schedule cuts the stationary-price locus from below, so the determinant is negative, which precludes stability.

What happens when the parameters change? We examine, successively, aggregatedemand, goods-supply, and conventional-wage shocks.

\subsubsection{Aggregate-demand shocks}

An increase in $i$ or a decline in $s_{\pi}$ will displace the AD schedule upward, as in Figure 14. The equilibria in Figures $12 \mathrm{~b}$ and $12 \mathrm{c}$ move closer together for each value of $\frac{P}{W}$ and thus move the entire AD schedule in Figure 12c upward. Employment increases along with the equilibrium rate of inflation.

The algebra is straightforward. Consider a change in the propensity to save. The $\mathrm{AD}$ schedule is defined by

so

$$
i-s_{\pi} \pi h(l, \xi)=i-s_{\pi}\left(h(l, \xi)-\left(\frac{P}{W}\right)^{-1} l\right)=0
$$

$$
\left(\frac{d l}{d s_{\pi}}\right)_{\mathrm{AD}}=\frac{-\left(h(l, \xi)-\left(\frac{P}{W}\right)^{-1} l\right)}{s_{\pi}\left(h_{l}-\left(\frac{P}{W}\right)^{-1}\right)},
$$

which is negative to the left of the intersection of the AD and GS schedules (because $h_{l}-\left(\frac{P}{W}\right)^{-1}$ is positive) and positive to the right of the intersection (since $h_{l}-\left(\frac{P}{W}\right)^{-1}$ changes sign). We also have

$$
\left(\frac{d \frac{P}{W}}{d s_{\pi}}\right)_{\mathrm{AD}}=\frac{-\left(h(l, \xi)-\left(\frac{P}{W}\right)^{-1} l\right)}{s_{\pi}\left(h_{l}-\left(\frac{P}{W}\right)^{-2}\right)},
$$




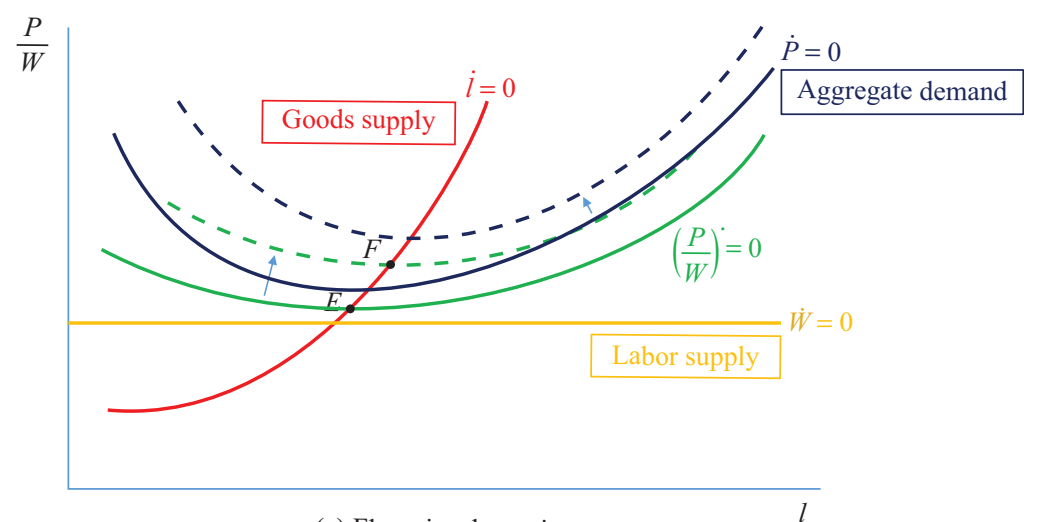

(a) Flexprice dynamics

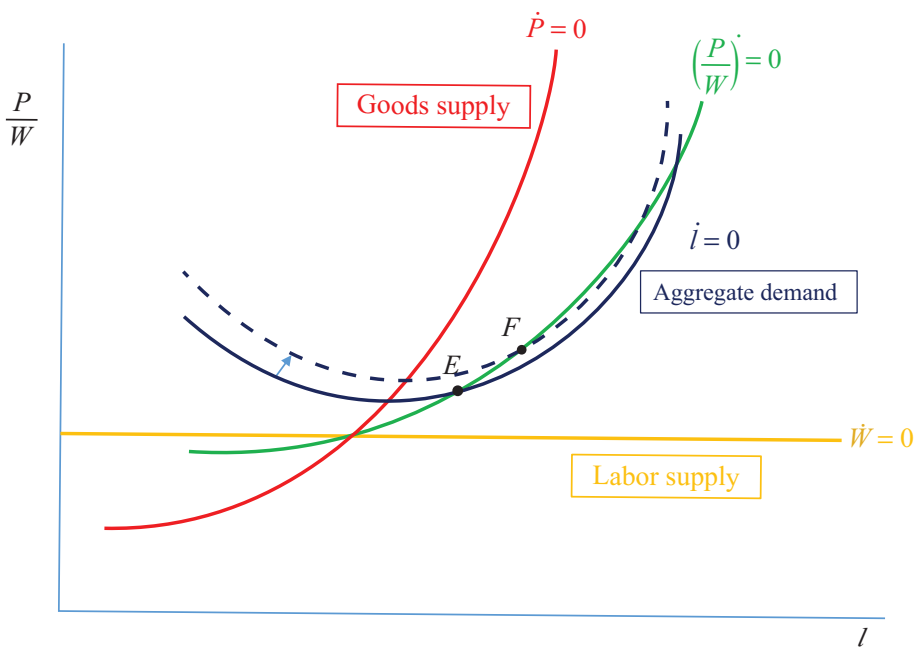

(b) Fixprice dynamics

Figure 14 A rise in investment demand or a fall in the propensity to save with Cambridge saving equation

which is negative for all values of $l$. A similar analysis applies to shifts in investment demand, so the algebra need not be repeated. To sum up: a decrease in desired saving or an increase in desired investment have the effect of expanding demand and employment whichever adjustment mechanism is in place.

\subsubsection{Goods-supply shocks}

A shift in the goods-supply schedule is more complicated. As before, the analysis of a shift in the GS schedule must now include the effects of changes in supply-side conditions on aggregate demand. $\left(\frac{d l}{d \xi}\right)_{\mathrm{AD}}$ and $\left(\frac{d_{W}^{P}}{d \xi}\right)_{\mathrm{AD}}$ are calculated from the equation

$$
i-s_{\pi} \pi h(l, \xi)=i-s_{\pi}\left(h(l, \xi)-\left(\frac{P}{W}\right)^{-1} l\right)=0
$$


with these results:

$$
\begin{gathered}
\left(\frac{d l}{d \xi}\right)_{\mathrm{AD}}=-\frac{-s_{\pi} h_{\xi}}{s_{\pi}\left(h_{1}-\left(\frac{P}{W}\right)^{-1}\right)}=\frac{e}{\left(h_{l}-\left(\frac{P}{W}\right)^{-1}\right)} \\
\left(\frac{d \frac{P}{W}}{d \xi}\right)_{\mathrm{AD}}=-\frac{-s_{\pi} h_{\xi}}{-s_{\pi}\left(\frac{P}{W}\right)^{-2} l}=\frac{e}{\left(\frac{P}{W}\right)^{-2} l} .
\end{gathered}
$$

As with a shift caused by a change in saving or investment propensities, the effect on $l$ depends on whether $l$ is greater or less than its value at the intersection of the AD and GS schedules; it is positive to the left and negative to the right. The effect on the real price is unambiguously positive.

As before, to find the effect on equilibrium we differentiate the equations for the two stationary loci. In the flexprice case, these loci are

$$
\begin{gathered}
\frac{P}{W}-h_{l}(l, \xi)^{-1}=0 \\
\theta_{1}\left[i-s_{\pi} \pi h(l)\right]-\theta_{3}\left[\frac{P}{W}-\left(\frac{P}{W}\right)^{*}\right]=0 .
\end{gathered}
$$

The results are

$$
\begin{gathered}
l_{\xi}=\frac{\frac{h_{l \xi}}{\left(\frac{P}{W}\right)^{-2}}\left(1+s_{\pi}\left(\frac{P}{W}\right)^{-2} l \frac{\theta_{1}}{\theta_{3}}\right)-s_{\pi} h_{\xi} \frac{\theta_{1}}{\theta_{3}}}{-\frac{h_{l l}}{\left(\frac{P}{W}\right)^{-2}}\left(1+s_{\pi}\left(\frac{P}{W}\right)^{-2} l \frac{\theta_{1}}{\theta_{3}}\right)} \\
\left(\frac{P}{W}\right)_{\xi}=\frac{s_{\pi} h_{\xi} \frac{\theta_{1}}{\theta_{3}}}{1+s_{\pi}\left(\frac{P}{W}\right)^{-2} l \frac{\theta_{1}}{\theta_{3}}} .
\end{gathered}
$$

$\left(\frac{P}{W}\right)_{\xi}$ is positive; the equilibrium real price rises along with the price of energy provided $\theta_{1}$ is not vanishingly small relative to $\theta_{3}$. Along with the real price the equilibrium rate of inflation also rises. In contrast, the sign of $l_{\xi}$ is ambiguous for the same reasons that made $l_{\xi}$ ambiguous in the previous case of a uniform rate of saving. The two limiting cases of (infinitely) rapid price and wage adjustment provide bounds on the response of employment to the price of energy:

$$
\begin{gathered}
\lim _{\frac{\theta_{3}}{\theta_{1}} \rightarrow 0} l_{\xi}=\frac{h_{l \xi} l-h_{\xi}}{-h_{l l} l}=-\frac{\sigma h_{\xi}}{h_{l}} \\
\lim _{\frac{\theta_{1}}{\theta_{3}} \rightarrow 0} l_{\xi}=-\frac{h_{l \xi}}{h_{l l}}
\end{gathered}
$$

where $\sigma$ is the elasticity of substitution in production. With $\sigma<1$, the effect on employment in the limiting case of rigid money wages is reduced relative to the benchmark of a uniform saving rate out of all income. 
In the fixprice case equilibrium is characterized by the AD schedule and the stationaryprice locus defined by the GS and LS schedules:

$$
\begin{gathered}
i-s_{\pi} \pi h(l)=0 \\
\theta_{2}\left[l-\mathrm{GS}\left(\frac{P}{W}, \xi\right)\right]-\theta_{3}\left[\frac{P}{W}-\left(\frac{P}{W}\right)^{*}\right]=0 .
\end{gathered}
$$

Employment and real price change with $\xi$ according to the formulas

$$
\begin{gathered}
l_{\xi}=\frac{-\theta_{2} \theta_{1} s_{\pi}\left(\frac{P}{W}\right)^{-2} l \frac{h_{l \xi}}{h_{l l}}+\theta_{1}\left(\theta_{2} \frac{h_{l}^{2}}{h_{l l}}-\theta_{3}\right) s_{\pi} h_{\xi}}{\operatorname{det} J}=\frac{-\theta_{2} \theta_{1} s_{\pi}\left(\frac{P}{W}\right)^{-2}\left(l \frac{h_{l \xi}}{h_{l l}}-\frac{h_{\xi}}{h_{l l}}+\frac{\theta_{3}}{\theta_{2}} \frac{h_{\xi}}{\left(\frac{P}{W}\right)^{-2}}\right)}{\operatorname{det} J} \\
\left(\frac{P}{W}\right)_{\xi}=\frac{\theta_{2} \theta_{1} s_{\pi}\left[h_{l}-\left(\frac{P}{W}\right)^{-1}\right] \frac{h_{l \xi}}{h_{l l}}-\theta_{1} \theta_{2} s_{\pi} h_{\xi}}{\operatorname{det} J}=\frac{\theta_{2} \theta_{1} s_{\pi}\left(\left[h_{l}-\left(\frac{P}{W}\right)^{-1}\right] \frac{h_{l \xi}}{h_{l l}}-h_{\xi}\right)}{\operatorname{det} J},
\end{gathered}
$$

with $\frac{h_{l \xi}}{h_{l l}}$ and $\frac{h_{l}^{2}}{h_{l l}}$ evaluated along the goods-supply schedule. The second of these two derivatives, $\left(\frac{P}{W}\right)_{\xi}$, is positive, whereas the change in the labor-capital ratio, $l_{\xi}$, is of indefinite sign. With a constant-elasticity-of-substitution production function

$$
\begin{gathered}
f(l, e)=A\left(\lambda_{1}+\lambda_{2} l^{\zeta}+\lambda_{3} e^{\zeta}\right)^{\frac{1}{\zeta}} \\
l_{\xi} \rightarrow \frac{-\theta_{2} \theta_{1} s_{\pi}\left(\frac{P}{W}\right)^{-2}}{h_{l l}} \frac{e \lambda_{1}}{\lambda_{1}+\lambda_{2} l^{\zeta}}
\end{gathered}
$$

in the limit as $\theta_{3}$ goes to 0 . But as $\theta_{3}$ approaches the maximum value for which an equilibrium exists (where the stationary-price locus is tangent to the aggregate-demand schedule),

$$
l_{\xi} \rightarrow-\theta_{2} \theta_{1} s_{\pi}\left(\left[h_{l}-\left(\frac{P}{W}\right)^{-1}\right] \frac{h_{l \xi}}{h_{l l}}-h_{\xi}\right),
$$

which is of indefinite sign. The general picture for both flexprice and fixprice dynamics is in Figure 15. Figure 15b omits the unstable equilibrium.

\subsubsection{Conventional-wage shocks}

The impact of an increase in the conventional wage is supply-driven in the flexprice case and demand-driven in the fixprice case. When adjustment takes place according to flexprice rules, the effect of an increase in the conventional wage and the resulting increase in pressure on wages is to raise costs and reduce profitability. The consequence is a reduction in employment and output and an increase in the rate of inflation. In a fixprice regime an increase in the conventional wage has the opposite effect on employment and output. Wage pressure reduces the profit share and thus saving per unit of output, but with investment fixed, the effect of this redistribution is to move the economy to the right on the AD schedule. As in the flexprice case, inflation rises. Figure 16 shows the differences. 
392 Review of Keynesian Economics, Vol. 5 No. 3

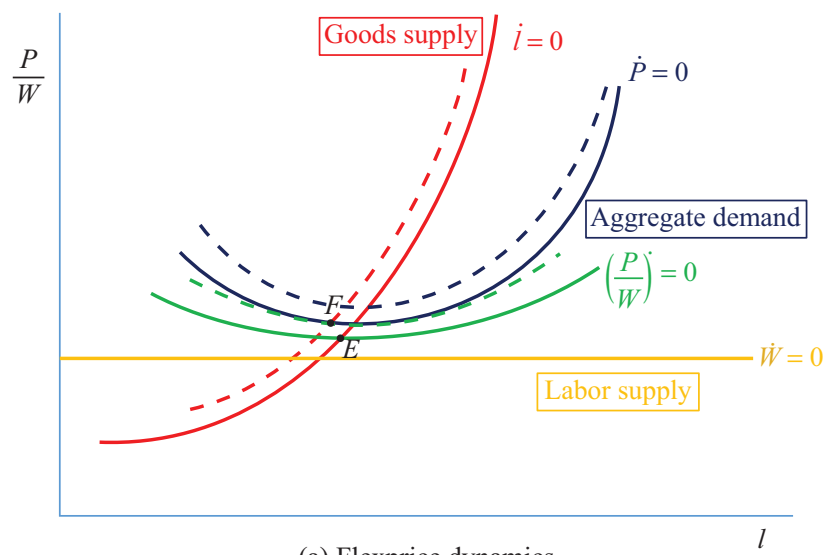

(a) Flexprice dynamics

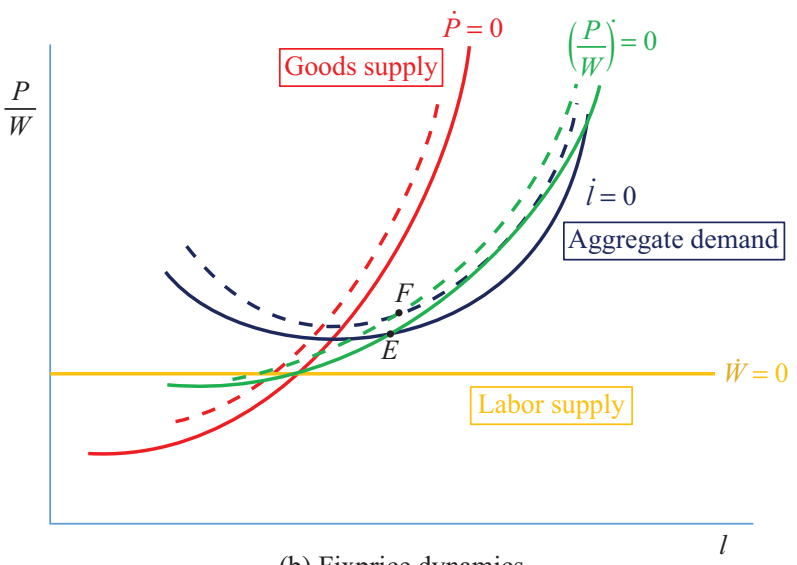

(b) Fixprice dynamics

Figure 15 An increase in the price of energy with Cambridge saving equation

The fixprice result reflects the original left-Keynesian view alluded to earlier: an increase in wages stimulates (consumption) spending. And in consequence output and employment. A positive impact on employment is thus one possible outcome of an increase in the conventional wage, but the broader lesson - that special assumptions are needed to reach this result - is worth reiterating. The opposite result is also possible even when, as in the present case, investment demand is independent of profits. If flexprice adjustment is assumed, then even the most diehard left-Keynesian has to admit the possibility that high wages are not good for employment.

\subsection{Investment and real wages}

Assuming an exogenously fixed investment demand is a useful simplification for understanding the role of dynamics, as well as for exploring different assumptions about saving. But a fixed investment demand is a strong assumption, and some of 


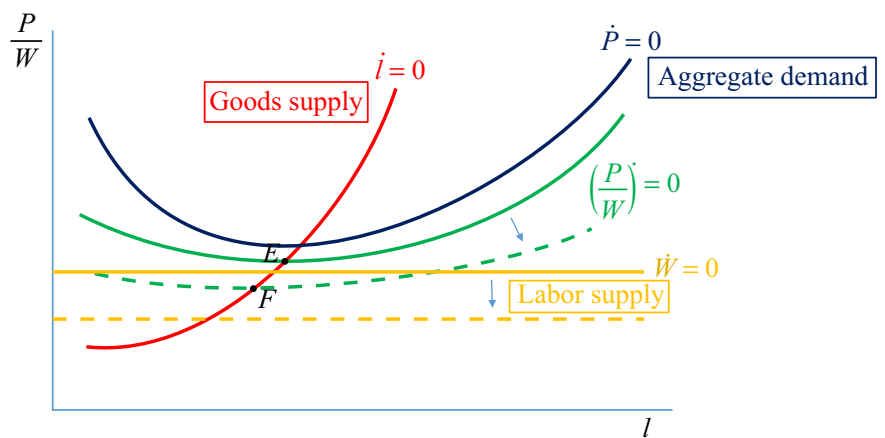

(a) Flexprice dynamics

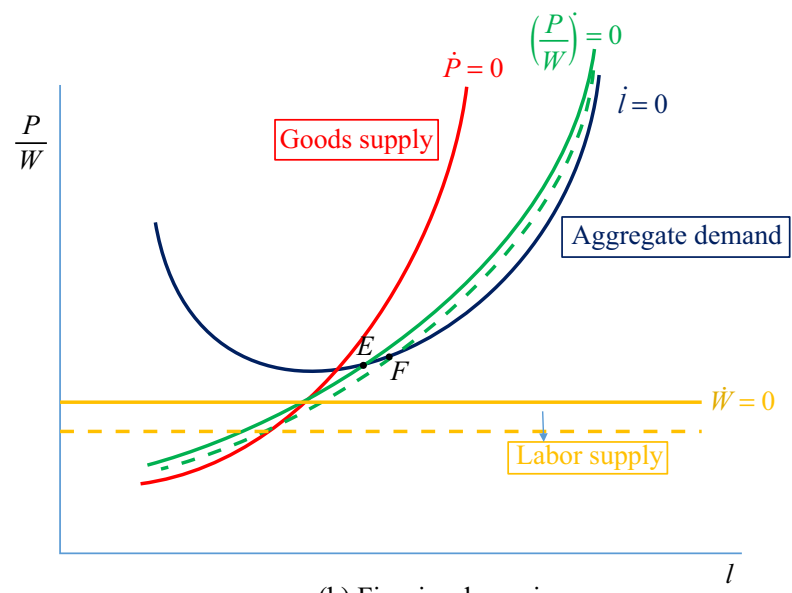

(b) Fixprice dynamics

Figure 16 An increase in the conventional wage with Cambridge saving equation

the results obtained so far do not hold when this assumption is relaxed. An important first step is to recognize a role for profits in determining investment demand, as Joan Robinson did in her pioneering studies of growth (1956; 1962). But this is hardly sufficient. Bhaduri and I argued that it is important to go beyond a simple dependence of investment on the rate of profit (and thus on the real wage), because the two components of the profit rate - the profit share and the rate of capacity utilization - can interact differently depending on the state of the economy. In particular, investment demand may be more responsive to the rate of profit when capacity utilization is (or is expected to be) high, but much less responsive under slack business conditions, the difference being due to business perceptions of how likely it is that they will be able to sell more goods and thus realize the prospective profits from adding to productive capacity.

In this essay I add a new dimension, distinguishing between two very different types of investment, capital widening, which is to say investment that takes place to expand capacity, and capital deepening, investment which substitutes capital for labor. Though the distinction between widening and deepening is an old one, the 
growth theories spawned by Harrod three-quarters of a century ago have neglected capital deepening.

The reason for introducing capital deepening is that Bhaduri and I didn't go far enough in our critique of investment theory. Yes, indeed, the responsiveness of investment demand to the rate of profit may vary pro-cyclically, but in our model it was still true that the response was always positive, or at least non-negative. But that assumption makes sense only for capital widening. By contrast, capital deepening responds negatively to the rate of profit. The benefits of substituting capital for labor, unlike the benefits of capital widening, vary directly with the real wage. Another reason why high wages might be good for employment. ${ }^{8}$

Moreover, there is good reason to expect that the attractiveness of capital deepening will be much less influenced by the business cycle than is capital widening. At a capacity utilization rate of 90 percent, capital widening may have little attraction at all. At a capacity utilization rate of 90 percent, capital deepening may be only 10 percent less profitable than when the economy is running at 100 percent of capacity. And the importance of this distinction is borne out empirically. Alex Field (2011) has documented the importance of capital deepening even in the depths of the Great Depression. By 1936, the US economy was back to the level of real GDP in 1929, but it could produce the same level of output with so many fewer workers that the unemployment rate was 17 percent in 1936, as against 3.2 percent in 1929.

In this section we take up capital widening and capital deepening successively.

\subsubsection{Capital widening}

We write investment demand for capacity expansion as

$$
i=\psi\left(\Omega(l)\left[h(l, \xi)-\left(\frac{P}{W}\right)^{-1} l\right]-\rho_{h}\right) .
$$

The expression within parentheses on the right-hand side is the quasi-rent per unit of investment taking account of the (subjective) probability that the additional capacity is utilized and the additional production is sold. $\rho_{h}$, the hurdle rate of return, is the capital cost on the assumption that capital lasts forever. $\Omega(l)$ is the probability of finding a market for the additional output, which is assumed to be an increasing function of $l$, with $\Omega(0)=0$ and $\Omega(l) \leq 1$. Finally, $\psi$ reflects the level of animal spirits, the degree of optimism that determines the responsiveness of investment demand to anticipated returns.

This expression for investment demand derives from the general expression for the real return to an investment equal to $\dot{K}$, namely:

$$
\frac{\partial Y}{\partial K} \dot{K}+\frac{\partial Y}{\partial L} \dot{L}-\rho_{h} \dot{K}-\left(\frac{P}{W}\right)^{-1} \dot{L},
$$

8. At least in the short run: capital deepening involves kicking the unemployment can down the road. If nothing is done to maintain aggregate demand, today's jobs building robots may mean job loss tomorrow when those robots come into service. This is not necessarily problematic: in principle, productivity gains can be taken out in shorter work weeks or shorter working lives, but in practice a good deal of the reduced employment attendant to capital deepening takes the form of involuntary unemployment. 
where $\frac{\partial Y}{\partial K} \dot{K}$ measures the direct contribution of the additional capital and $\left(\frac{P}{W}\right)^{-1} \dot{L}$ measures the prospective change in labor costs associated with the investment. In the mainstream conception of equilibrium the above expression vanishes. With capital a homogeneous, undifferentiated mass, the marginal productivity of capital equals the hurdle rate of interest at equilibrium

$$
\frac{\partial Y}{\partial K}=\rho_{h}
$$

And with employment dictated by profit maximization, the marginal productivity is equal to the real wage

$$
\frac{\partial Y}{\partial L}=\left(\frac{P}{W}\right)^{-1}
$$

Here, in contrast, even though capital is written as an aggregate $K$, the capital stock is not assumed to consist of legos which can be dismantled and recombined in new shapes. I rather assume investment to involve a commitment to a particular form of capital. In the absence of lego capital there can be a persistent gap between the marginal productivity of capital and the hurdle rate of interest. Indeed it is precisely an assumed positive value of the difference

$$
\frac{\partial Y}{\partial K}-\rho_{h}
$$

that in The General Theory is assumed to drive capital formation. As for the labor costs associated with new capital, the difference

$$
\frac{\partial Y}{\partial L}-\left(\frac{P}{W}\right)^{-1}
$$

is not necessarily equal to 0 - it vanishes at a flexprice equilibrium but not under a fixprice regime.

How do we get from the generic expression for investment returns to the specific formula for capital widening? First, separate the capital cost from the quasi-rent and multiply the quasi-rent by the probability of selling the additional goods to obtain the flow of returns per unit of investment: ${ }^{9}$

$$
\Omega(l)\left(\frac{\partial Y}{\partial K}+\frac{\partial Y}{\partial L} \frac{\dot{L}}{\dot{K}}-\left(\frac{P}{W}\right)^{-1} \frac{\dot{L}}{\dot{K}}\right)-\rho_{h} .
$$

Now factor in the animal spirits of capitalists, measured by $\psi$, to obtain the following expression for investment demand:

$$
i=\psi\left(\Omega(l)\left[\left(\frac{\partial Y}{\partial K}+\frac{\partial Y}{\partial L} \frac{\dot{L}}{\dot{K}}-\left(\frac{P}{W}\right)^{-1} \frac{\dot{L}}{\dot{K}}\right)-\rho_{h}\right]\right)
$$

9. The implicit assumption behind multiplying the quasi-rent rather than the entire return by $\Omega(l)$ is that if there is no market for the additional output, there is no additional production, even with the new capital in place. So the firm incurs no current cost for labor and energy, but the interest cost incurred by the idle capital remains a charge. 
The next step is to determine the incremental labor-capital ratio $\frac{\dot{L}}{\tilde{K}}$. The simplest assumption is that when considering capacity-augmenting investment, capitalists extrapolate the current labor-capital ratio, which is to say that one additional unit of capital requires $l$ workers:

$$
\frac{\dot{L}}{\dot{K}}=\frac{L}{K}=l
$$

Since

$$
\left(\frac{\partial Y}{\partial K} K+\frac{\partial Y}{\partial L} L\right) \frac{1}{K}=\frac{Y}{K}=h(l, \xi)
$$

when we substitute the equivalent expressions for $\frac{\dot{L}}{\dot{K}}$ and $\left(\frac{\partial Y}{\partial K} K+\frac{\partial Y}{\partial L} L\right) \frac{1}{K}$, we obtain the capital-widening formula

$$
i=\psi\left(\Omega(l)\left[h(l, \xi)-\left(\frac{P}{W}\right)^{-1} l\right]-\rho_{h}\right) .
$$

To draw the aggregate-demand schedule, plot the investment-demand schedule together with the saving schedule in the manner of Figure 12. For simplicity let saving revert to being a constant fraction of income, and Figure 12 becomes Figure 17.

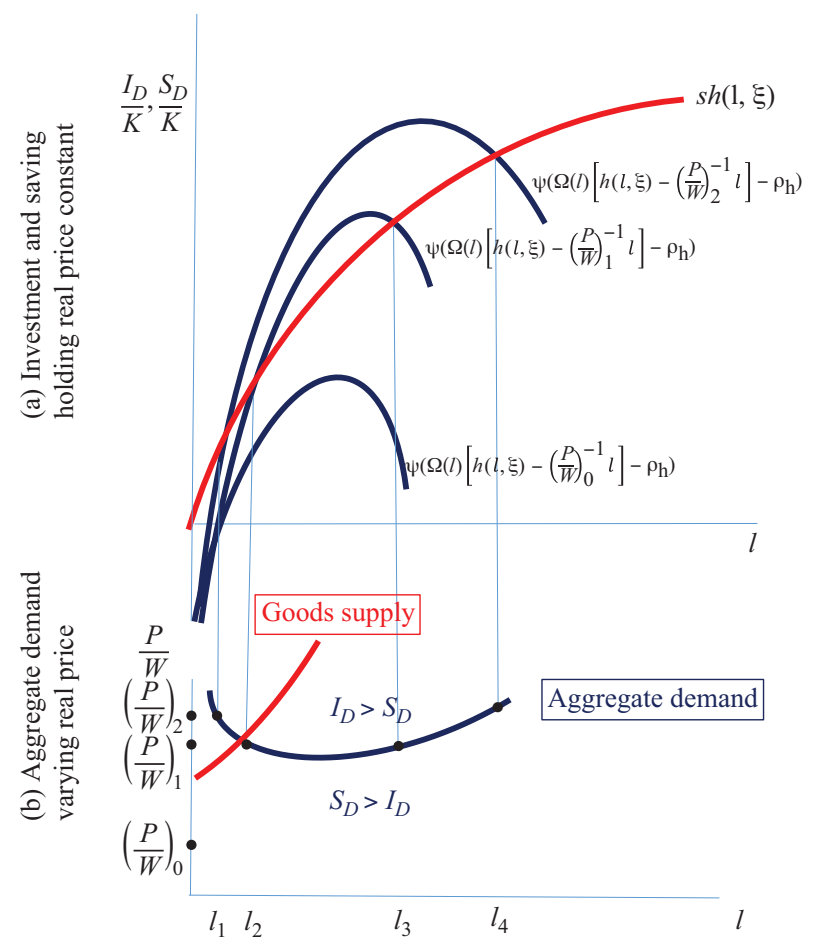

Figure 17 Aggregate demand with capital widening 
There is an obvious superficial resemblance between Figure 17b and Figure 12c. But the superficial resemblance conceals significant differences. In the first place, in contrast with Figure 12, there is no reason for the AD schedule generated by Figure 17a to intersect the GS schedule at its minimum point relative to the $l$ axis. More important, the dynamics of Figure 17b are the opposite of the dynamics of Figure 12c. Here, between any two points generated by a given real price, say, $l_{2}$ and $l_{3}$ generated by $\left(\frac{P}{W}\right)_{1}$, there is an excess of investment demand over desired saving, whereas in Figure $12 \mathrm{c}$ the same interval is characterized by excess desired saving. For this reason stability and the comparative statics of parameter changes do not carry over from the earlier analysis.

Consider Figure 18, in which AD, GS, and LS schedules look similar to the corresponding schedules in Figure 13a. The results are very different. In the flexprice case, the stationary-price locus itself changes, and there are now three equilibria instead of one. There are two distinct regions of the stationary-price locus, one below the LS schedule along which downward pressure on prices is just balanced by downward pressure on wages. A second region, above the LS schedule, defines a set of points for which upward price pressure balances upward wage pressure. In the interior of these loci the real price rises because price pressure exceeds wage pressure; everywhere else wage pressure exceeds price pressure and the real price falls.

With flexprice adjustment, change is now governed by

$$
\begin{gathered}
\left(\frac{P}{W}\right)^{\cdot}=\left(\theta_{1}\left\{\psi\left(\Omega(l)\left[h(l, \xi)-\left(\frac{P}{W}\right)^{-1} l\right]-\rho_{h}\right)-\operatorname{sh}(l, \xi)\right\}-\theta_{3}\left[\frac{P}{W}-\left(\frac{P}{W}\right)^{*}\right]\right) \frac{P}{W} \\
i=\theta_{2}\left(\frac{P}{W}-h_{l}(l, \xi)^{-1}\right) l .
\end{gathered}
$$

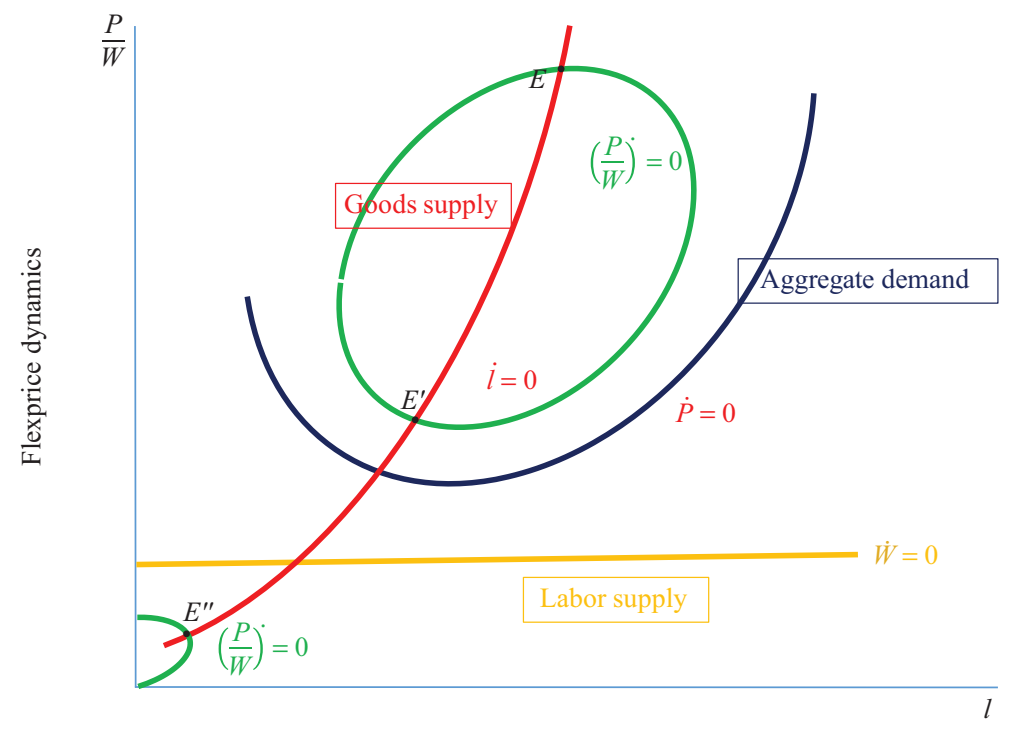

Figure 18 Equilibrium with capital widening 
The Jacobian matrix is

$$
\begin{gathered}
{\left[\begin{array}{cc}
\frac{\partial\left(\frac{P}{W}\right)^{\cdot}}{\partial \frac{P}{W}} & \frac{\partial\left(\frac{P}{W}\right)^{\bullet}}{\partial l} \\
\frac{\partial i}{\partial \frac{P}{W}} & \frac{\partial l}{\partial l}
\end{array}\right]} \\
=\left[\begin{array}{cc}
\theta_{1} \psi \Omega(l)\left(\frac{P}{W}\right)^{-2} l-\theta_{3} & \left.\theta_{1}\left(\psi\left\{\Omega^{\prime}(l)\left[h(l, \xi)-\left(\frac{P}{W}\right)^{-1} l\right]+\Omega(l)\left[h_{l}-\left(\frac{P}{W}\right)^{-1}\right]\right\}-s h_{l}\right)\right] \\
\theta_{2} & \theta_{2} h_{l}^{-2} h_{l l}
\end{array}\right] .
\end{gathered}
$$

Since $h_{u}$ is negative, a sufficient condition for a negative trace is that the expression

$$
\theta_{1} \psi \Omega(l)\left(\frac{P}{W}\right)^{-2} l-\theta_{3}
$$

be negative. This condition holds at $E^{\prime \prime}$ and $E$, as we can see from the expression for the slope of the stationary-price locus. This slope is given by

$$
\left(\frac{d\left(\frac{P}{W}\right)}{d l}\right)_{\left(\frac{P}{W}\right)^{\cdot}=0}=-\frac{\psi\left\{\Omega^{\prime}(l)\left[h(l, \xi)-\left(\frac{P}{W}\right)^{-1} l\right]+\Omega(l)\left[h_{l}-\left(\frac{P}{W}\right)^{-1}\right]\right\}-s h_{l}}{\psi \Omega\left(\frac{P}{W}\right)^{-2} l-\frac{\theta_{3}}{\theta_{1}}}
$$

and is negative at $E^{\prime}$ and positive at $E$ and $E^{\prime \prime}$. The numerator is positive at $E$ and $E^{\prime}$ because increasing $l$ from its value at either point moves the economy from the boundary of the stationary-price locus, where $\left(\frac{P}{W}\right)^{\bullet}=0$, into the interior, where $\left(\frac{P}{W}\right)^{\bullet}>0$. In other words at both $E$ and $E^{\prime \prime}$

$$
\frac{\partial\left(\frac{P}{W}\right)^{\bullet}}{\partial l}=\psi\left\{\Omega^{\prime}(l)\left[h(l, \xi)-\left(\frac{P}{W}\right)^{-1} l\right]+\Omega(l)\left[h_{l}-\left(\frac{P}{W}\right)^{-1}\right]\right\}-s h_{l}
$$

is positive. Since $\left(\frac{d\left(\frac{P}{W}\right)}{d l}\right)_{\left(\frac{P}{W}\right)^{\cdot}=0}$ is positive at $E$ and negative at $E^{\prime}$, it follows that the denominator must be negative at $E$ and positive at $E^{\prime}$. At $E^{\prime \prime}$ the numerator is negative, so the denominator is also negative. Consequently the trace is necessarily negative at $E^{\prime \prime}$ and $E$, but sign indefinite at $E^{\prime}$. The determinant, however, is negative at $E^{\prime}$. This establishes that there are two stable equilibria, $E^{\prime \prime}$ and $E$; the middle one, at $E^{\prime}$, is unstable.

In Figure 18 the stability of the equilibrium at $E$ is unaffected if the intersection of the GS schedule and the stationary-price locus takes place to the right of the maximum of the stationary-price locus. Because the GS schedule is more steep than the stationary-price locus relative to the $l$-axis, the determinant of the Jacobian is unaffected. Since both the slope of the stationary-price locus and the numerator change sign 
relative to the case we just considered, the denominator continues to be negative. Likewise, the equilibrium at $E^{\prime}$ continues to be unstable if the intersection is to the right of the minimum point on the stationary-price locus.

As we have done with earlier models, we ask what happens when one or another of the parameters shifts. The results are presented in the three panels of Figure 19. We focus on the stable equilibrium at $E$. (For the most part the stable equilibrium at $E^{\prime \prime}$ responds similarly.)

Start with the AD schedule. An increase in investment demand - an improvement either in animal spirits or in the confidence of being able to utilize additional capacity shifts the AD schedule downward. As does a fall in the propensity to save. Note the contrast with the case where profits drive saving and investment is fixed. The AD schedule has the same U-shape in the two cases; but in the present case the downward-sloping portion of the AD schedule reflects a situation where, as the economy approaches the AD schedule from the left, investment catches up to saving, and the upward-sloping segment reflects a situation where investment falls to the level of saving. It takes less output to generate the requisite amount of saving when the investment propensity rises or the saving propensity falls, so the downward-sloping segment is displaced to the left. By the same logic, the upward-sloping segment is displaced to the right. In the case of the Cambridge saving equation, in which investment is fixed and saving is proportionate to profits, the downward-sloping portion is associated with saving catching up to investment and the upward-sloping segment with saving falling to investment. So an increase in investment demand or a fall in the saving propensity - see Figure 14 - increases the amount of output necessary for saving to catch up with investment and thus displaces the downward-sloping segment to the right. Again the same logic means the upward-sloping piece is displaced to the left.

Now the new equilibrium involves greater employment per unit of capital and a higher real price, which is to say a lower equilibrium real wage. The new rate of inflation at $F$, which can be measured by the distance from the equilibrium to the (unchanging) conventional-wage schedule, is higher than the old rate.

Supply-side shocks affect equilibrium similarly to the previous flexprice models. In Figure 19b, an increase in the price of energy reduces the marginal productivity of labor, which in turn reduces output (net of energy costs) and reduces profitability. The reduction in the marginal productivity of labor directly shifts the GS schedule to the left and, because the effect on profitability is stronger than the effect on output, shifts the AD schedule inward. The result is a downward shift in equilibrium employment per unit of capital and in the equilibrium real price. Inflation is reduced.

Figure 19c shows the effect of an increase in the conventional wage. Observe that the stationary-price locus shrinks. Why? The reason is that a decrease in $\left(\frac{P}{W}\right)^{*}$ raises wage pressure, which, with price pressure unchanged, has the effect of reducing the real price. To restore the balance between price and wage pressure, it is necessary to increase $l$. For as $l$ increases, the difference between investment demand and desired saving also increases (since the derivative

$$
\psi\left\{\Omega^{\prime}(l)\left[h(l, \xi)-\left(\frac{P}{W}\right)^{-1} l\right]+\Omega(l)\left[h_{l}-\left(\frac{P}{W}\right)^{-1}\right]\right\}-s h_{l}
$$

is positive at both $E$ and $E^{\prime}$ ), and this increases price pressure while wage pressure remains constant. As $l$ increases, wage pressure and price pressure once again become equal, on the new (dashed) stationary-price locus. At $E^{\prime \prime}$ the above derivative is negative, so it would be necessary to dial back employment per unit of capital in order to 
400 Review of Keynesian Economics, Vol. 5 No. 3
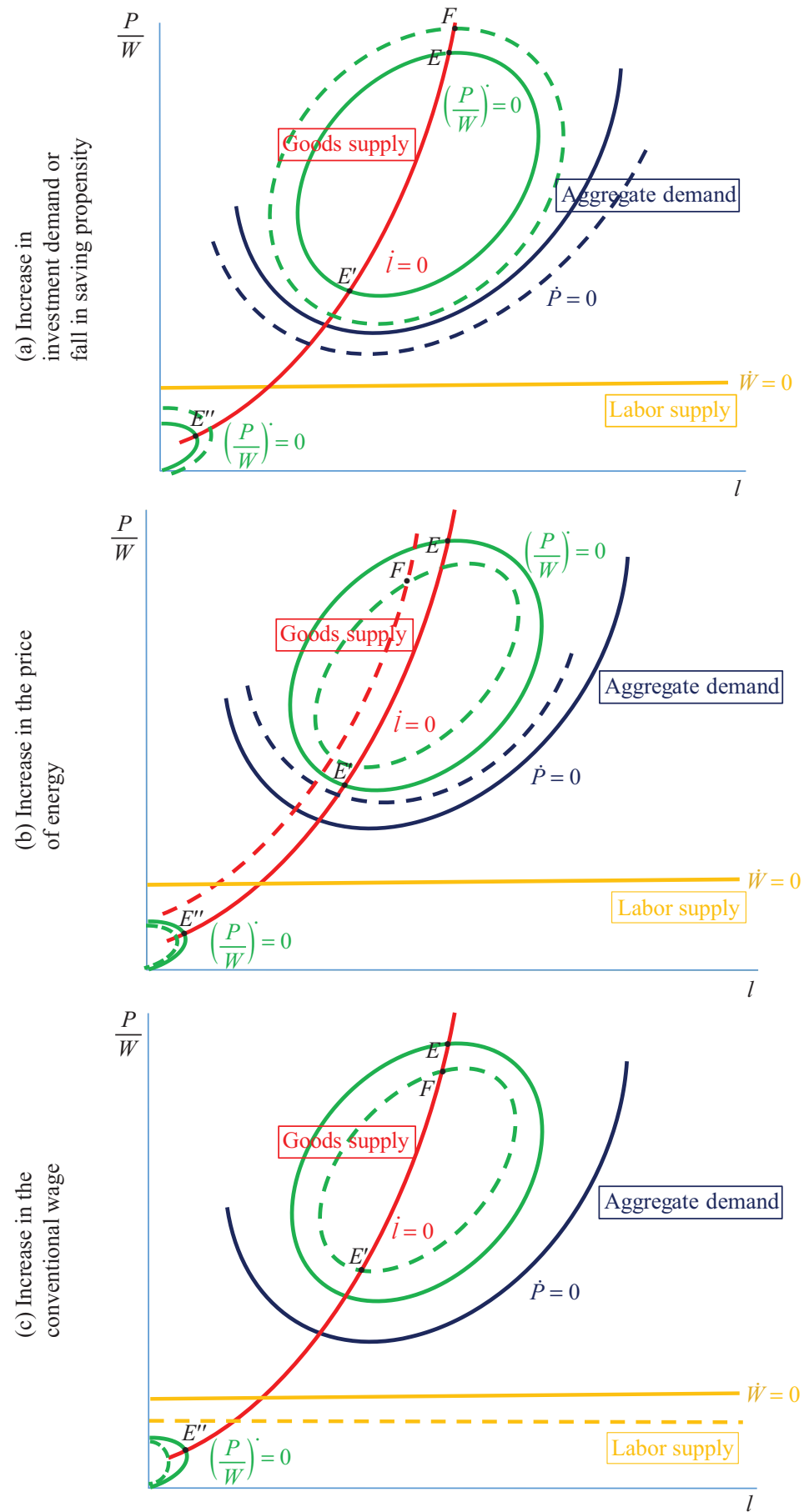

Figure 19 Flexprice comparative statics with capital widening 
increase price pressure sufficiently to balance the changed level of wage pressure. The shift in the equilibrium from $E$ to $F$ reflects the contraction of the stationary-price locus and the consequent fall in the real wage which makes employment less profitable at the margin and leads capitalists to curtail the level of employment.

In the situation described by Figure 19c, wage stimulus loses its luster. An increase in the conventional wage raises the equilibrium real wage but it leads to a decrease in employment and growth, and a very high conventional wage might make it impossible for the economy to grow at all. Similarly real-wage resistance, the ability of the working class to defend itself against erosion of the conventional wage, may defeat the possibility for a growth equilibrium to exist at all.

There is a clear pattern in these displacements of equilibrium. Both a shift of the AD schedule and a shift of the LS schedule are movements along a stationary GS schedule. Along this schedule the real price moves in the same direction as employment, Figure 19a is evidently consistent with a Phillips curve since the conventional wage remains fixed and inflation is proportional to the distance between the equilibrium $\frac{P}{W}$ and $\left(\frac{P}{W}\right)^{*}$. This is true in Figure 19b as well. In Figure 19b the displacement of the GS schedule adds to the effect of the shift along this schedule. In Figure 19c, the increase in the conventional wage moves the LS schedule and the equilibrium real price in the same direction, so to determine the impact of a change in the conventional wage on inflation we need to calculate the derivative $\frac{d\left(\frac{P}{W}\right)}{d\left(\frac{P}{W}\right)^{*}}$, where $\frac{P}{W}$ is the equilibrium price. We have

$$
\frac{d\left(\frac{P}{W}\right)}{d\left(\frac{P}{W}\right)^{*}}=\frac{\frac{\theta_{3}}{\theta_{1}}}{\frac{\left(\frac{P}{W}\right)^{-2}}{h_{l l}}\left(\psi \Omega^{\prime}(l)\left[h(l, \xi)-\left(\frac{P}{W}\right)^{-1} l\right]-s h_{l}\right)-\psi \Omega l\left(\frac{P}{W}\right)^{-2}+\frac{\theta_{3}}{\theta_{1}}} .
$$

The denominator is positive at a stable equilibrium because a condition of stability is that the determinant of the Jacobian is positive, and the denominator is the determinant after dividing through by $\theta_{2} \theta_{1}$. For an upward shift in the conventional wage to be inflationary the derivative $\frac{d\left(\frac{P}{W}\right)}{d\left(\frac{P}{W}\right)^{*}}$ must be less than unity. Since $h_{l l}<0$, a necessary condition for this inequality is that

$$
\psi \Omega^{\prime}(l)\left[h(l, \xi)-\left(\frac{P}{W}\right)^{-1} l\right]-s h_{l}
$$

be positive, which is to say that at equilibrium investment must be more responsive to additional output and employment than is saving.

Consider now the alternative, fixprice, adjustment mechanism. In the fixprice case, the picture is qualitatively the same as for the Cambridge saving equation, except for the fact that the GS schedule does not go through the minimum point of the AD schedule. That is, Figure 20 looks like Figure 13b. But the disequilibrium relationship of investment and saving is reversed, and as a result stable and unstable equilibria change places: $E^{\prime}$ is now unstable, while $E$ is stable.

The equations describing the dynamics of a fixprice regime are

$$
\left(\frac{P}{W}\right)^{\bullet}=\left\{\theta_{2}\left[l-\mathrm{GS}\left(\frac{P}{W}, \xi\right)\right]-\theta_{3}\left[\frac{P}{W}-\left(\frac{P}{W}\right)^{*}\right]\right\} \frac{P}{W}
$$


402 Review of Keynesian Economics, Vol. 5 No. 3

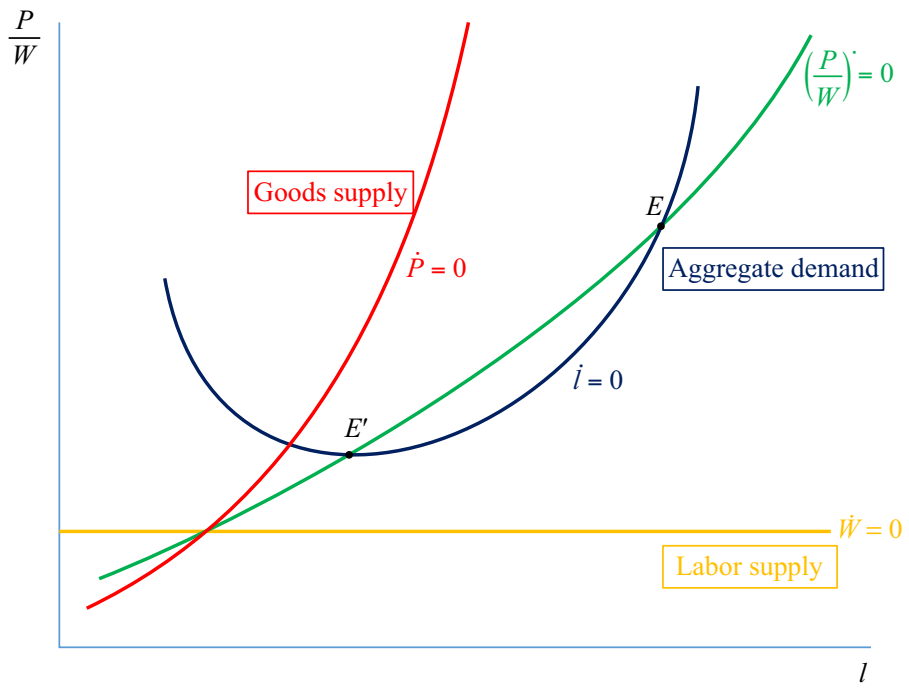

Figure 20 Fixprice equilibrium with capital widening

$$
\dot{l}=\theta_{1}\left\{\psi\left(\Omega(l)\left[h(l, \xi)-\left(\frac{P}{W}\right)^{-1} l\right]-\rho_{h}\right)-\operatorname{sh}(l, \xi)\right\} l .
$$

The Jacobian matrix is

$$
\begin{aligned}
& {\left[\begin{array}{cc}
\frac{\partial\left(\frac{P}{W}\right)^{\cdot}}{\partial \frac{P}{W}} & \frac{\partial\left(\frac{P}{W}\right)^{\prime}}{\partial l} \\
\frac{\partial i}{\partial \frac{P}{W}} & \frac{\partial l}{\partial l}
\end{array}\right]^{\cdot}=\left[\begin{array}{cc}
\theta_{2} \frac{h_{l}^{2}}{h_{l l}}-\theta_{3} & \theta_{2} \\
\theta_{1} \psi \Omega\left(\frac{P}{W}\right)^{-2} l & \theta_{1}\left(\Psi\left\{\Omega^{\prime}(l)\left[h(l, \xi)-\left(\frac{P}{W}\right)^{-1} l\right]+\Omega(l)\left[h_{l}-\left(\frac{P}{W}\right)^{-1}\right]\right\}-s h_{l}\right)
\end{array}\right]} \\
& \operatorname{sgn}\left[\begin{array}{cc}
\frac{\partial\left(\frac{P}{W}\right)^{\cdot}}{\partial \frac{P}{W}} & \frac{\partial\left(\frac{P}{W}\right)^{\cdot}}{\partial l} \\
\frac{\partial i}{\partial \frac{P}{W}} & \frac{\partial i}{\partial l}
\end{array}\right]=\left[\begin{array}{cc}
- & + \\
+ & -
\end{array}\right]
\end{aligned}
$$

The trace of the Jacobian is negative but the determinant is sign-indefinite. The determinant is positive at $E$, where the $\mathrm{AD}$ schedule cuts the stationary-price locus from below, and negative at $E^{\prime}$, where the $\mathrm{AD}$ schedule cuts the stationary-price locus from above.

The comparative statics of shifting the underlying schedules are shown in Figure 21. With one exception, these comparative-statics exercises yield results that are 

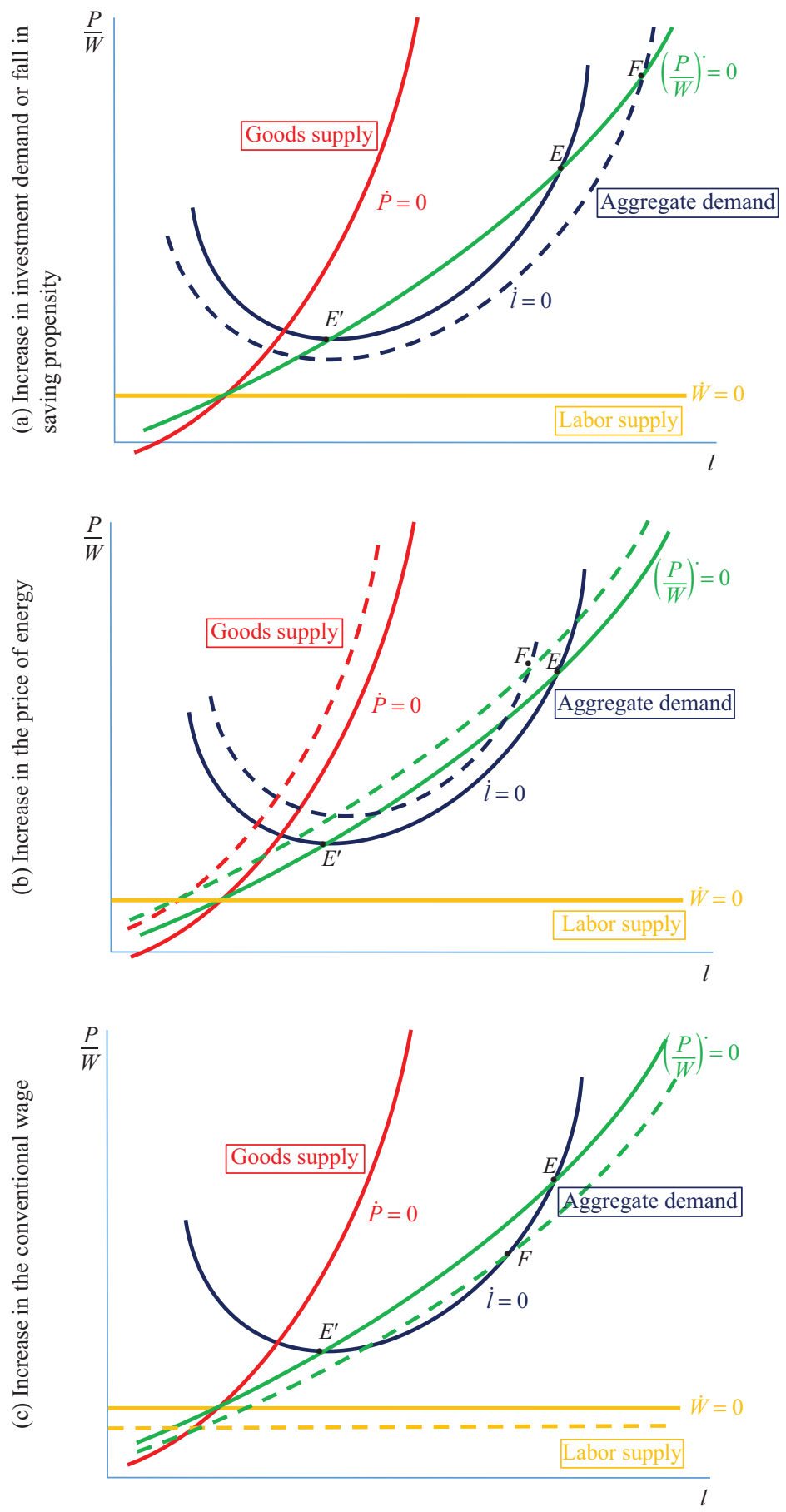

Figure 21 Fixprice comparative statics with capital widening 
qualitatively the same as in a flexprice regime. A decrease in desired saving or an increase in investment demand, pictured in panel (a), increases both employment and inflation. An increase in the conventional wage, as in panel (c), reduces employment but has ambiguous effects on inflation. ${ }^{10}$ This, like the corresponding flexprice result, supports the conclusion that Bhaduri and I reached to the effect that investment responsiveness to profitability provides a channel through which higher wages depress employment.

The only exception to the previous pattern is a change in the price of energy. As in the flexprice case, an increase in the price of energy shifts the goods-supply schedule to the left and the aggregate-demand schedule inwards. But, unlike the flexprice case,

10. As in the case of flexprice adjustment, the effect of a change in the conventional wage on inflation depends on whether the derivative $\frac{d\left(\frac{P}{W}\right)}{d\left(\frac{P}{W}\right)^{*}}$ is greater or less than 1 . In the fixprice case, we have

$$
\frac{d\left(\frac{P}{W}\right)}{d\left(\frac{P}{W}\right)^{*}}=\frac{\frac{\theta_{3}}{\theta_{2}}}{-\frac{h_{l}^{2}}{h_{l}}+\frac{\psi \Omega\left(\frac{P}{W}\right)^{-2} l}{\psi\left\{\Omega^{\prime}(l)\left[h(l, \xi)-\left(\frac{P}{W}\right)^{-1} l\right]+\Omega(l)\left[h_{l}-\left(\frac{P}{W}\right)^{-1}\right]\right\}-s h_{l}}+\frac{\theta_{3}}{\theta_{2}}}
$$

Since the first term of the denominator, $-\frac{h_{l}^{2}}{h_{l l}}$, is the slope of the GS schedule and the negative of the second term,

$$
\frac{-\psi \Omega\left(\frac{P}{W}\right)^{-2} l}{\psi\left\{\Omega^{\prime}(l)\left[h(l, \xi)-\left(\frac{P}{W}\right)^{-1} l\right]+\Omega(l)\left[h_{l}-\left(\frac{P}{W}\right)^{-1}\right]\right\}-s h_{l}}
$$

is the slope of the AD schedule, the sign of $\frac{d\left(\frac{P}{W}\right)}{d\left(\frac{P}{W}\right)^{*}}-1$ depends on whether the GS schedule is steeper than the $\mathrm{AD}$ schedule relative to the price axis. If

$$
-\frac{h_{l}^{2}}{h_{l l}}+\frac{\psi \Omega\left(\frac{P}{W}\right)^{-2} l}{\psi\left\{\Omega^{\prime}(l)\left[h(l, \xi)-\left(\frac{P}{W}\right)^{-1} l\right]+\Omega(l)\left[h_{l}-\left(\frac{P}{W}\right)^{-1}\right]\right\}-s h_{l}}>0
$$

which is to say that the slope of the GS schedule relative to the price axis is steeper than the slope of the AD schedule, then

$$
\frac{d\left(\frac{P}{W}\right)}{d\left(\frac{P}{W}\right)^{*}}<1
$$

In this case, an increase in the conventional wage is inflationary. In the opposite case, with

$$
-\frac{h_{l}^{2}}{h_{l l}}+\frac{\psi \Omega\left(\frac{P}{W}\right)^{-2} l}{\psi\left\{\Omega^{\prime}(l)\left[h(l, \xi)-\left(\frac{P}{W}\right)^{-1} l\right]+\Omega(l)\left[h_{l}-\left(\frac{P}{W}\right)^{-1}\right]\right\}-s h_{l}}<0
$$

an increase in the conventional wage is deflationary. 
the effect on the real price, inflation, and the level of economic activity is ambiguous. In the fixprice case, as before,

$$
\begin{gathered}
\mathrm{GS}_{\xi}=\left(\frac{d l}{d \xi}\right)_{\mathrm{GS}}=-\frac{h_{l \xi}}{h_{l l}}<0 \\
\mathrm{GS}_{\frac{P}{W}}=\left(\frac{d l}{d\left(\frac{P}{W}\right)}\right)_{\mathrm{GS}}=-\frac{h_{l}^{2}}{h_{l l}}>0
\end{gathered}
$$

and, for capital-widening investment,

$$
\begin{aligned}
\mathrm{AD}_{\frac{P}{W}} & =\left(\frac{d l}{d\left(\frac{P}{W}\right)}\right)_{\mathrm{AD}}=\frac{-\psi \Omega\left(\frac{P}{W}\right)^{-2} l}{\psi\left\{\Omega^{\prime}(l)\left[h(l, \xi)-\left(\frac{P}{W}\right)^{-1} l\right]+\Omega(l)\left[h_{l}-\left(\frac{P}{W}\right)^{-1}\right]\right\}-s h_{l}} \\
\mathrm{AD}_{\xi} & =\left(\frac{d l}{d \xi}\right)_{\mathrm{AD}}=\frac{-(\psi \Omega-s) h_{\xi}}{\psi\left\{\Omega^{\prime}(l)\left[h(l, \xi)-\left(\frac{P}{W}\right)^{-1} l\right]+\Omega(l)\left[h_{l}-\left(\frac{P}{W}\right)^{-1}\right]\right\}-s h_{l}}
\end{aligned}
$$

We have

$$
\left(\frac{P}{W}\right)_{\xi}=\frac{-\mathrm{GS}_{\xi}+\mathrm{AD}_{\xi}}{\mathrm{GS}_{\frac{P}{W}}+\frac{\theta_{3}}{\theta_{2}}-\mathrm{AD}_{\frac{P}{W}}}
$$

The term $\mathrm{GS}_{\xi}$ measures the direct effect of an increase in the price of energy on the goods-supply schedule. This effect is positive: an increase in the price of energy increases the real price associated with any given level of employment. But there is a second effect on $\left(\frac{P}{W}\right)_{\xi}$ via aggregate demand, reflected in the second term of the numerator. This effect is negative since at equilibrium the denominator in the formula for $\mathrm{AD}_{\xi}$

$$
\psi\left\{\Omega^{\prime}(l)\left[h(l, \xi)-\left(\frac{P}{W}\right)^{-1} l\right]+\Omega(l)\left[h_{l}-\left(\frac{P}{W}\right)^{-1}\right]\right\}-s h_{l}=I_{l}-S_{l}
$$

is negative, and the numerator is positive. Figure $21 \mathrm{~b}$ shows the balance of these two effects as positive - the denominator of $\left(\frac{P}{W}\right)_{\xi}, \mathrm{GS}_{\frac{P}{W}}+\frac{\theta_{3}}{\theta_{2}}-\mathrm{AD}_{\frac{P}{W}}$, is necessarily positive as a condition of equilibrium.

As in previous fixprice exercises, however, the sign of the numerator is not guaranteed. Whether the real price goes up or down depends rather on how much the GS schedule shifts relative to how much the AD schedule shifts. An increase in the price of energy initially adds to inflationary pressures on prices and causes $\frac{P}{W}$ to rise. When the marginal propensity to invest (as a function of the labor-capital ratio), $I_{l}$, is much larger than the marginal propensity to save, $S_{l}$, this is pretty much the whole story. At a higher real price profits are higher, and as a result there is greater investment demand.

When the difference between the two propensities is small, the initial inflationary effect is countered by the reduction in income caused by the increase in the 
price of energy. As income falls, so does saving. At the same time, a fall in income leads to a reduction in profit and therefore lower investment demand. With investment demand and saving closely balanced at the margin but with $I_{l}-S_{l}$ being negative, it takes a substantial reduction in output to bring saving and investment back into line with each other. Once again the idea that exogenous price increases cause stagflation - greater inflation and lower output - turns out to be overly simple. This is the outcome in Figure 21b, but a higher energy price can lead also to Phillips-type outcomes in which the real price and inflation, as well as output, move downward together.

A sufficient condition for the change in employment to be negative is that the real price responds negatively to a change in $\xi$. The change in employment is given by

$$
l_{\xi}=\mathrm{AD}_{\xi}+\mathrm{AD}_{\frac{P}{W}}\left(\frac{P}{W}\right)_{\xi}=\mathrm{GS}_{\xi}+\left(\frac{P}{W}\right)_{\xi}\left(\mathrm{GS}_{\frac{P}{W}}+\frac{\theta_{3}}{\theta_{2}}\right)
$$

so that if $\left(\frac{P}{W}\right)_{\xi}$ is negative, so is $l_{\xi}$. Observe that the converse does not hold. $l_{\xi}$ can be negative even if $\left(\frac{P}{W}\right)_{\xi}$ is positive, provided that $\mathrm{GS}_{\xi}$, which is necessarily negative, is sufficiently large in absolute value.

\subsubsection{Capital deepening}

Capital deepening - cost-cutting investment - is an entirely different story. Again we start from the generic formula

$$
\frac{\partial Y}{\partial K} \dot{K}+\frac{\partial Y}{\partial L} \dot{L}-\rho_{h} \dot{K}-\left(\frac{P}{W}\right)^{-1} \dot{L}
$$

but now we assume that output is fixed so

$$
\frac{\partial Y}{\partial K} \dot{K}+\frac{\partial Y}{\partial L} \dot{L}=0
$$

Hence the prospective return to a single unit of investment is

$$
\left(\frac{P}{W}\right)^{-1} \frac{\partial Y}{\frac{\partial K}{\partial L}}-\rho_{h}=\left(\frac{P}{W}\right)^{-1} \frac{h-h_{l} l}{h_{l}}-\rho_{h}
$$

and investment demand becomes

$$
i=\psi\left(\left(\frac{P}{W}\right)^{-1} \frac{h-h_{l} l}{h_{l}}-\rho_{h}\right)
$$

with $\psi$, as before, reflecting animal spirits.

Assuming that saving is a constant fraction of income, the aggregate-demand schedule can be derived in the same manner as we derived Figures 12 and 17. The picture is in Figure 22. 


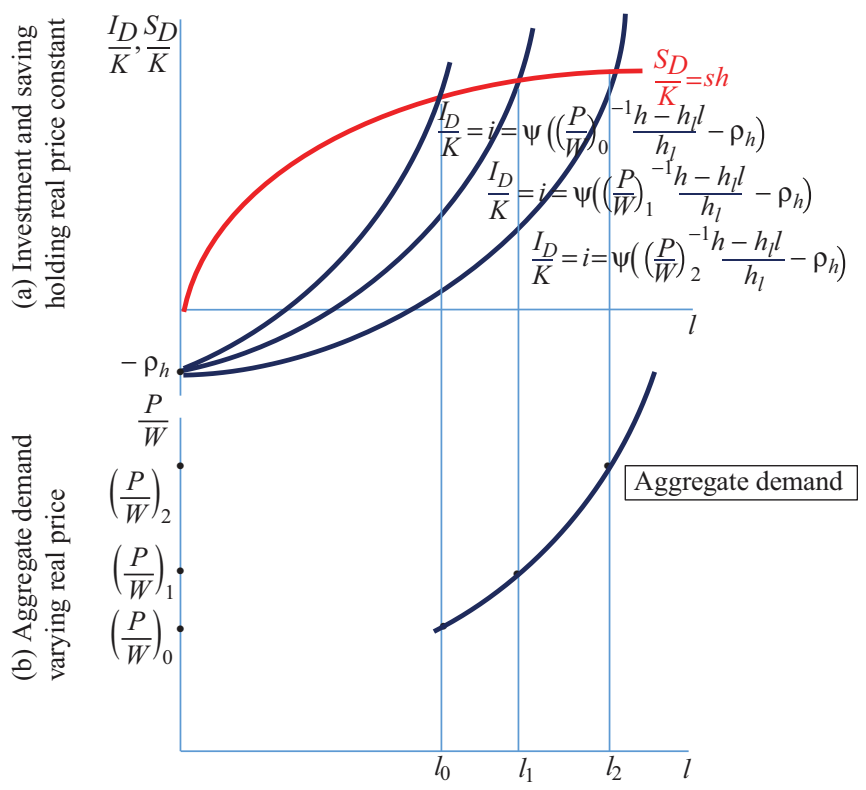

Figure 22 Aggregate demand with capital deepening

There is a new wrinkle. Unlike capacity-augmenting investment, which is assumed to maintain the labor-capital ratio unchanged, cost-cutting investment is specifically intended to reduce the labor-capital ratio. We have

$$
\begin{gathered}
\dot{l}=\left(\frac{\dot{L}}{L}-\frac{\dot{K}}{K}\right) \frac{L}{K} \\
\frac{\dot{L}}{L}=-\frac{h-h_{l} l}{h_{l}} \frac{\dot{K}}{K} \frac{K}{L}=-\frac{h-h_{l} l}{h_{l}} \psi\left(\left(\frac{P}{W}\right)^{-1} \frac{h-h_{l} l}{h_{l}}-\rho_{h}\right) l^{-1} \\
\frac{\dot{K}}{K}=\psi\left(\left(\frac{P}{W}\right)^{-1} \frac{h-h_{l} l}{h_{l}}-\rho_{h}\right)
\end{gathered}
$$

so that

$$
\dot{l}=-\frac{h}{h_{l}} \psi\left(\left(\frac{P}{W}\right)^{-1} \frac{h-h_{l} l}{h_{l}}-\rho_{h}\right) .
$$

Therefore in a flexprice regime the goods-supply schedule by itself no longer determines $\dot{l}$ and is no longer the stationary $l$ locus. Instead we have

$$
i=\theta_{2}\left(h_{l}-\left(\frac{P}{W}\right)^{-1}\right) l-\frac{h}{h_{l}}\left(\psi\left(\frac{P}{W}\right)^{-1} \frac{h-h_{l} l}{h_{l}}-\rho_{h}\right) .
$$


In a fixprice regime the stationary- $l$ locus is no longer the aggregate-demand schedule. Instead we have

$$
\begin{gathered}
i=\theta_{1}\left[\psi\left(\left(\frac{P}{W}\right)^{-1} \frac{h-h_{l} l}{h_{l}}-\rho_{h}\right)-s h\right] l-\frac{h}{h_{l}}\left(\psi\left(\frac{P}{W}\right)^{-1} \frac{h-h_{l} l}{h_{l}}-\rho_{h}\right) \\
=\left(\theta_{1}-\frac{h}{h_{l} l}\right) \psi\left(\left(\frac{P}{W}\right)^{-1} \frac{h-h_{l} l}{h_{l}}-\rho_{h}\right) l-\theta_{1} s h l .
\end{gathered}
$$

The flexprice and fixprice equibria are given in panels (b) and (c) of Figure 23.

In a flexprice regime the stationary- $l$ locus simply shifts to the left, so that it lies above the GS schedule. The shift is more complicated in a fixprice regime: the shift of the stationary- $l$ locus is of ambiguous sign near the origin but unequivocally negative as $l$ increases without bound. So as $l$ increases, the intersection of investment demand and desired saving is no longer single valued for a given value of the real price. Figure 24a shows the displacement of investment demand as a function of $l$, and Figure $24 \mathrm{~b}$ reflects this displacement in $\frac{P}{W} \mathrm{x} l$ space. (The stationary- $l$ locus approaches the aggregate-demand schedule as $l$ goes to zero. The difference between the two schedules becomes infinite as $l$ increases without bound.)

The equilibria in Figures $23 \mathrm{~b}$ and $23 \mathrm{c}$ are strange in that they imply that the boss's right hand does not know what the left hand is doing, and vice versa. ${ }^{11}$ In both a flexprice regime and a fixprice regime, the right hand is substituting capital for labor, presumably because it is cheaper to produce with more capital and less labor. At the same time, in a flexprice regime, the left hand is hiring additional workers because the price of goods exceeds their marginal cost. In a fixprice the left hand is hiring more workers

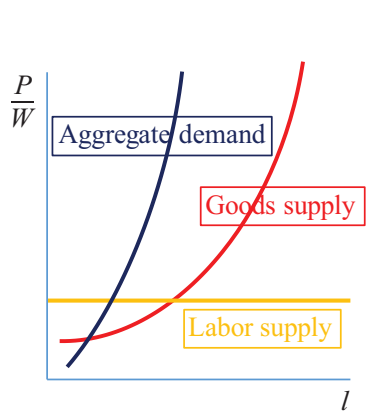

(a) Aggregate demand, goods supply, and labor supply

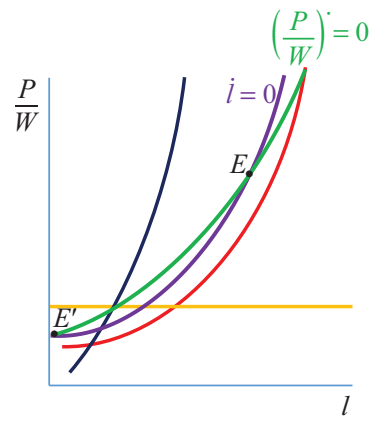

(b) Flexprice equilibrium

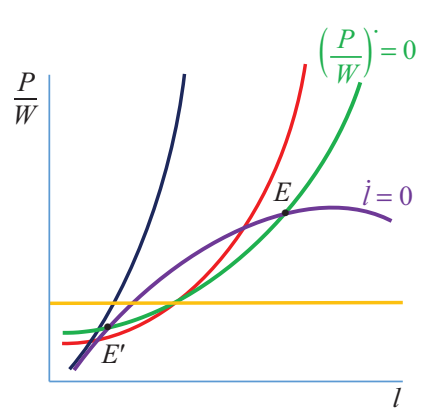

(c) Fixprice equilibrium

\section{Figure 23 Equilibrium with capital deepening}

11. Strange may be the wrong word. What is at issue is the lack of coordination between different decisions. One way of understanding why the right and left hands appear at odds is that they might belong to different agents, the right hand belonging to a capital-expenditure manager and the left to a production manager. 


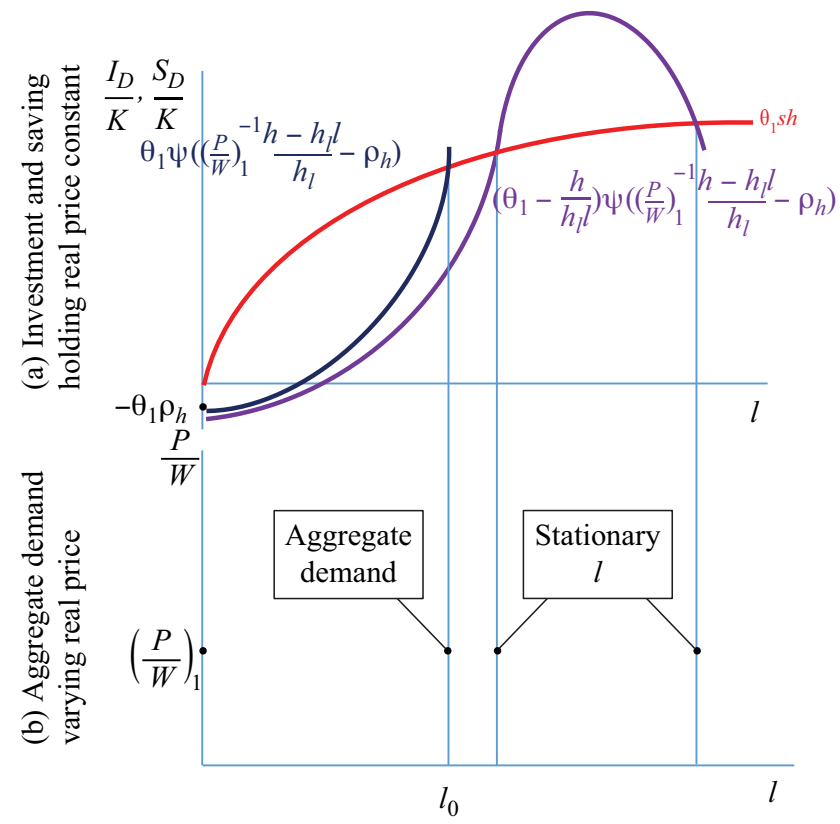

Figure 24 Aggregate demand and stationary 1 with capital deepening

because goods are flying off the shelves. The right and left hands offset each other with the result that at $E$ (and at $E^{\prime}$ ) the labor-capital ratio remains stationary over time even as both employment and the capital stock increase.

Examination of the Jacobian matrices reveals what by now has become a familiar pattern. In the flexprice case we have

$$
\begin{aligned}
J & =\left[\begin{array}{ll}
\frac{\partial\left(\frac{P}{W}\right)^{\cdot}}{\partial \frac{P}{W}} & \frac{\partial\left(\frac{P}{W}\right)^{\bullet}}{\partial l} \\
\frac{\partial l}{\partial \frac{P}{W}} & \frac{\partial l}{\partial l}
\end{array}\right] \\
= & {\left[\begin{array}{cc}
-\theta_{1} \psi\left(\frac{P}{W}\right)^{-2} \frac{h-h_{l} l}{h_{l}}-\theta_{3} & -\theta_{1}\left[\Psi\left(\frac{P}{W}\right)^{-1} \frac{h_{l l}}{h_{l}^{2}}+s h_{l}\right] \\
\theta_{2}\left(\frac{P}{W}\right)^{-2}+\frac{h}{h_{l}} \frac{h-h_{l} l}{h_{l}} \psi\left(\frac{P}{W}\right)^{-2} & \theta_{2} h_{l l}-\frac{h_{l}^{2}-h_{l l} h}{h_{l}^{2}} \psi\left[\left(\frac{P}{W}\right)^{-1} \frac{h-h_{l} l}{h_{l}}-\rho_{h}\right]+\frac{h}{h_{l}} \psi\left(\frac{P}{W}\right)^{-1} \frac{h_{l l} h}{h_{l}^{2}}
\end{array}\right] } \\
= & {\left[\begin{array}{l}
- \\
+
\end{array}\right] }
\end{aligned}
$$

with the result that in Figure $23 \mathrm{~b} E$ is stable and $E^{\prime}$ is unstable. 
In the fixprice case

$$
\begin{aligned}
& J=\left[\begin{array}{cc}
\frac{\partial\left(\frac{P}{W}\right)^{\bullet}}{\partial \frac{P}{W}} & \frac{\partial\left(\frac{P}{W}\right)^{\bullet}}{\partial l} \\
\frac{\partial i}{\partial \frac{P}{W}} & \frac{\partial i}{\partial l}
\end{array}\right] \\
& =\left[\begin{array}{cc}
\theta_{2} \frac{h_{l}^{2}}{h_{l l}}-\theta_{3} & \theta_{2} \\
-\left(\theta_{1}-\frac{h}{h_{l}}\right) \psi\left(\frac{P}{W}\right)^{-2} \frac{h-h_{l} l}{h_{l}} & -\left(\theta_{1}-\frac{h}{h_{l}}\right) \psi\left(\frac{P}{W}\right)^{-1} \frac{h_{l l}}{h_{l}}-\theta_{1} s h_{l}+\left(\frac{h_{l} h}{h_{l}^{2}}-1\right) \psi\left[\left(\frac{P}{W}\right)^{-1} \frac{h-h_{l} l}{h_{l}}-\rho_{h}\right.
\end{array}\right] \\
& =\left[\begin{array}{ll}
- & + \\
- & +
\end{array}\right] .
\end{aligned}
$$

In Figure 23c $E^{\prime}$ is once again unstable whereas $E$ is stable only if the speed of adjustment of prices and wages, reflected in the parameters $\theta_{2}$ and $\theta_{3}$, is sufficiently rapid relative to the speed of adjustment of employment, $\theta_{1}$, that the trace is negative.

The economics behind the new wrinkle deserve some attention. The equilibria in Figures $23 \mathrm{~b}$ and $23 \mathrm{c}$ reflect both the continuing downward pressure on employment caused by the substitution of capital for labor and the continuing incentive to create new jobs resulting from either the excess of price over marginal cost (in a flexprice regime) or the excess of expenditure over income (in a fixprice regime). At equilibrium the pressures to destroy and create jobs are equipoised so that the labor-capital ratio remains stationary.

The comparative statics of parameter changes are similar in most respects to what has already been encountered. Figures 25-27 show, respectively, the effect of a higher level of investment demand (or a lower level of desired saving); the effect of a higher energy price; and, finally, the effect of a higher conventional wage.

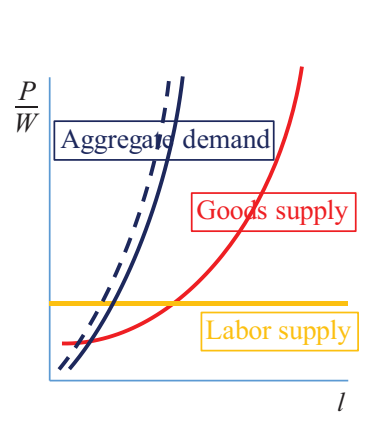

(a) Aggregate demand, goods supply, and labor supply

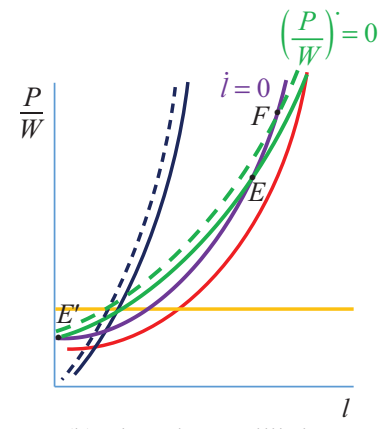

(b) Flexprice equilibrium

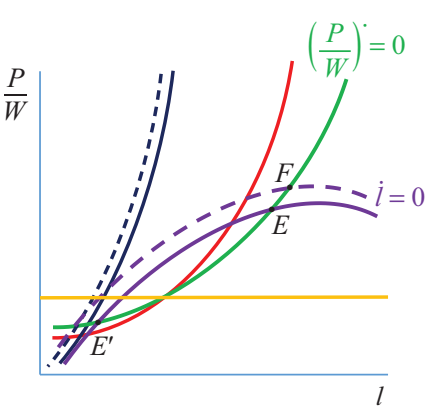

(c) Fixprice equilibrium

Figure 25 Capital deepening: an increase in investment demand or a decrease in desired saving 


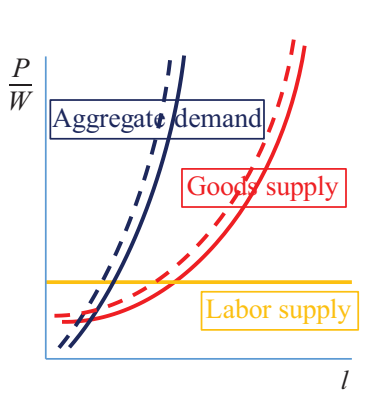

(a) Aggregate demand, goods supply, and labor supply

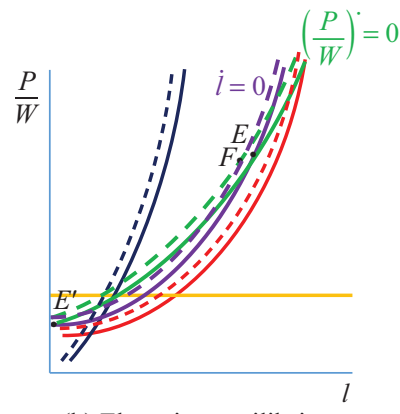

(b) Flexprice equilibrium

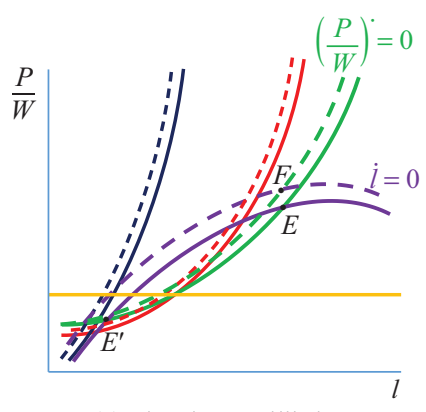

(c) Fixprice equilibrium

Figure 26 Capital deepening: an increase in the price of energy

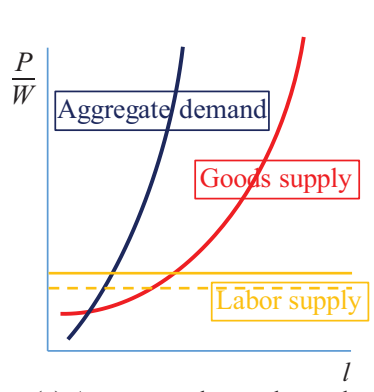

(a) Aggregate demand, goods supply, and labor supply

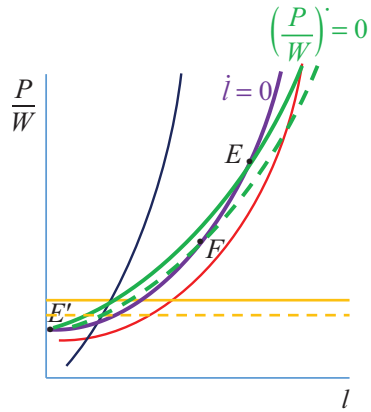

(b) Flexprice equilibrium

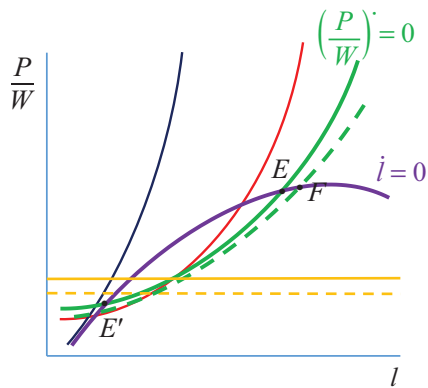

(c) Fixprice equilibrium

Figure 27 Capital deepening: an increase in the conventional wage

As has been the case right along, an increase in investment demand or a decrease in desired saving, pictured in Figure 25, expands employment and output and raises inflation in both flexprice and fixprice regimes. The effect of a higher price of energy also parallels earlier results. In the flexprice case, the outcome is unambiguous, higher energy prices invariably leading to diminished economic activity and a lower rate of inflation, as in Figure 26b. By contrast, in the fixprice regime, both the real price and employment can go up or down. Indeed, $\frac{P}{W}$ and $l$ can move in opposite directions, as in Figure 26c, or they can move together in the same direction.

A change in the conventional wage, pictured in Figure 27, demonstrates the importance of whether investment is capacity-augmenting or cost-cutting. In a flexprice regime, as in Figure 27b, a higher conventional wage is contractionary with respect 
to employment and of ambiguous sign with regard to inflation. ${ }^{12}$ This is the same as the earlier cases. The surprise is that under a fixprice regime, an increase in the conventional wage is associated with a higher level of economic activity. The reason is that a higher conventional wage drives the equilibrium real wage up, and a higher real wage means more investment demand since the higher the real wage the more profitable it is to substitute capital for labor. This is of course the opposite of capital widening, in which investment demand falls as the conventional wage rises and the profit rate falls.

Observe that as Figure 27c is drawn, a higher conventional wage is not only expansionary, it is also inflationary, that is, the new equilibrium $F$ is associated with a higher level of inflation than the original equilibrium $E$. But this is a consequence of assuming that the original equilibrium is on the rising portion of the stationary- $l$ locus. In case the equilibrium lies on the falling portion, a higher conventional wage continues to be expansionary but is now associated with a lower rate of inflation. We have

$$
\frac{d\left(\frac{P}{W}\right)}{d\left(\frac{P}{W}\right)^{*}}=\frac{\left(\theta_{1}-\frac{h}{h_{l}}\right) \psi\left(\frac{P}{W}\right)^{-1} \frac{h_{l}}{h_{l}}+\theta_{1} s h_{l}-\left(\frac{h_{l} h}{h_{l}^{2}}-1\right) \psi\left[\left(\frac{P}{W}\right)^{-1} \frac{h-h_{l} l}{h_{l}}-\rho_{h}\right] \theta_{3}}{\operatorname{det} J}
$$

so

$$
\begin{gathered}
\frac{d\left(\frac{P}{W}\right)}{d\left(\frac{P}{W}\right)^{*}}-1= \\
\frac{\theta_{2}}{\operatorname{det} J}\left\{\left(\theta_{1}-\frac{h}{h_{l}}\right) \Psi\left(\frac{P}{W}\right)^{-1} \frac{h_{l l}}{h_{l}}+\theta_{1} s h_{l}-\left(\frac{h_{l l} h}{h_{l}^{2}}-1\right) \Psi\left[\left(\frac{P}{W}\right)^{-1} \frac{h-h_{l} l}{h_{l}}-\rho_{h}\right] \frac{h_{l}^{2}}{h_{l l}}-\left(\theta_{1}-\frac{h}{h_{l}}\right) \Psi\left(\frac{P}{W}\right)^{-2} \frac{h-h_{l} l}{h_{l}}\right\},
\end{gathered}
$$

which is necessarily negative since

$$
\begin{aligned}
& \operatorname{det} J>0 \\
& -\frac{h_{l}^{2}}{h_{l l}}>0
\end{aligned}
$$

and, as the slope of the stationary- $l$ locus relative to the $l$ axis, the ratio

$$
\frac{-\left(\theta_{1}-\frac{h}{h_{l}}\right) \psi\left(\frac{P}{W}\right)^{-1} \frac{h_{l l}}{h_{l}}-\theta_{1} s h_{l}+\left(\frac{h_{l l} h}{h_{l}^{2}}-1\right) \psi\left[\left(\frac{P}{W}\right)^{-1} \frac{h-h_{l} l}{h_{l}}-\rho_{h}\right]}{\left(\theta_{1}-\frac{h}{h_{l}}\right) \psi\left(\frac{P}{W}\right)^{-2} \frac{h-h_{l} l}{h_{l}}}
$$

is negative along the falling portion.

12. A higher conventional wage is associated with less inflation if at $E$ the slope of the stationary $l$ locus is less steep with respect to the $l$ axis than the slope of an isoquant of a constant margin of investment over saving, that is, if

$$
\left(\frac{d \frac{P}{W}}{d l}\right)_{i=0}<\frac{-\left[\psi\left(\frac{P}{W}\right)^{-2} \frac{h_{l l}}{h_{l}^{2}}+s h_{l}\right]}{\psi\left(\frac{P}{W}\right)^{-2} \frac{h-h_{l} l}{h_{l}}}
$$




\subsection{Wages, prices, and employment: a summary of theoretical results}

The results of the four cases we have analysed are presented in Table 2. These results both confirm and extend the argument made in my joint work with Bhaduri. This essay confirms the central role of investment demand in determining whether high wages or high profits promote employment and growth. It clarifies our original argument by distinguishing the characteristics of investment likely to respond to profitability, namely capital widening, from investment likely to respond to higher wages, capital deepening. The extension of the argument is to model explicitly the responses to demand, supply, and wage shocks under alternative dynamic processes. Whereas the response to shifts in investment demand and the propensity to save are independent of the adjustment process, flexprice and fixprice results differ for both price and wage shocks.

One unexpected result is the variability of the response to an exogenous price shock. The anticipated stagflationary result, in which inflation and employment move in opposite directions, is one possibility, but it is also possible for inflation and employment to move in the same direction. Even more surprising is the possibility that, by stimulating capital deepening, a higher energy price can lead to higher employment along with lower inflation.

Finally, results with respect to the conventional wage both confirm and go beyond received doctrine on the left. When investment demand is fixed and saving depends on profits (the implicit assumption that underlies the argument for higher wages) a higher conventional wage will lead to greater aggregate demand and higher employment via the impact on consumption demand: higher wages mean lower profits and less saving, so it takes more output and employment to generate the saving corresponding to the given level of investment demand. But once the assumption of a fixed investment demand is dropped, the results Bhaduri and I highlighted become possible. If capital widening dominates, then lower profitability leads to lower investment demand and a lower level of employment. By contrast, the profitability of capital deepening is enhanced by higher wages, and this provides a complementary avenue to the consumption-based case for associating higher employment with higher wages.

\section{INFLATION AND EMPLOYMENT EMPIRICS}

How do the models stand up to the data? In particular, does this framework explain the ephemeral aspect of the Phillips curve that has supported the mainstream predilection to limit the policy relevance of a trade-off between price stability and employment? (Such disagreement as exists among mainstream economists is about the short run; there is virtual unanimity that the writ of Phillips does not extend to the long run.)

My models, it must be conceded, are not directly applicable for empirical work since they omit a crucial component of empirical reality, namely technological progress. Were we living in a world without technological change, it would be reasonable to apply the theory to data relating the labor-capital ratio to the real wage (or to the real price of labor) and to translate demand and supply shocks into changes in the labor-capital ratio and changes in the real wage. But in a world of changing technology, the laborcapital ratio will vary independently of demand and supply shocks and so will the real wage rate.

In short, we must be content with a proxy for the state variable $l$ in applying the theory and a proxy for a conventional real wage as the driver of money wages. The simplest proxy for $l$ is the ratio of employment to the labor force, which is to 
414 Review of Keynesian Economics, Vol. 5 No. 3

Table 2 The results of shocks to aggregate demand, goods supply, and the conventional wage

\begin{tabular}{|c|c|c|c|c|}
\hline \multicolumn{5}{|c|}{ Fixed investment and saving a constant fraction of income } \\
\hline & \multicolumn{2}{|c|}{ Flexprice } & \multicolumn{2}{|c|}{ Fixprice } \\
\hline & Inflation & Employment & Inflation & Employment \\
\hline Investment $\uparrow$ or saving $\downarrow$ & $\uparrow$ & $\uparrow$ & $\uparrow$ & $\uparrow$ \\
\hline Price of energy $\uparrow$ & $\uparrow$ & ? & $\uparrow$ & $\uparrow$ \\
\hline Conventional wage $\uparrow$ & $\uparrow$ & $\downarrow$ & $\uparrow$ & 0 \\
\hline \multicolumn{5}{|c|}{ Fixed investment and saving a constant fraction of profit (Cambridge saving equation) } \\
\hline & \multicolumn{2}{|c|}{ Flexprice } & \multicolumn{2}{|c|}{ Fixprice } \\
\hline & Inflation & Employment & Inflation & Employment \\
\hline Investment $\uparrow$ or saving $\downarrow$ & $\uparrow$ & $\uparrow$ & $\uparrow$ & $\uparrow$ \\
\hline Price of energy $\uparrow$ & $\uparrow$ & $?$ & $\uparrow$ & $?$ \\
\hline Conventional wage $\uparrow$ & $\uparrow$ & $\downarrow$ & $\uparrow$ & $\uparrow$ \\
\hline \multicolumn{5}{|c|}{ Capital widening with saving a constant fraction of income } \\
\hline & \multicolumn{2}{|c|}{ Flexprice } & \multicolumn{2}{|c|}{ Fixprice } \\
\hline & Inflation & Employment & Inflation & Employment \\
\hline Investment $\uparrow$ or saving $\downarrow$ & $\uparrow$ & $\uparrow$ & $\uparrow$ & $\uparrow$ \\
\hline Price of energy $\uparrow$ & $\downarrow$ & $\downarrow$ & $\uparrow$ & ? \\
\hline Conventional wage $\uparrow$ & $?$ & $\downarrow$ & $?$ & $\downarrow$ \\
\hline \multicolumn{5}{|c|}{ Capital deepening and saving a constant fraction of income } \\
\hline & \multicolumn{2}{|c|}{ Flexprice } & \multicolumn{2}{|c|}{ Fixprice } \\
\hline & Inflation & Employment & Inflation & Employment \\
\hline Investment $\uparrow$ or saving $\downarrow$ & $\uparrow$ & $\uparrow$ & $\uparrow$ & $\uparrow$ \\
\hline Price of energy $\uparrow$ & $\downarrow$ & $\downarrow$ & $?$ & $?$ \\
\hline Conventional wage $\uparrow$ & $?$ & $\downarrow$ & $\uparrow$ & $\uparrow$ \\
\hline
\end{tabular}

say, $1-u$, where $u$ is the unemployment rate. Despite the endogeneity of the labor force, it is fixed at each moment of time. So variations in the employment ratio will capture the effect of demand and supply shocks that are reflected in variations in $l$ in my theory. The obvious proxy for a conventional wage rate is a conventional wage share.

Despite the omission of technological change, the lessons of the models elaborated in the theoretical section of this essay apply to real-world data. First, the models all agree that positive demand shocks, represented by an increase in investment demand or a reduction in desired saving, lead to an increase in employment and an increase in inflation. In other words, according to the theory presented here, the Phillips curve should be reflected in the long-term data.

Beyond this prediction that the Phillips curve is alive and well, the models suggest that there are a variety of plausible responses to price and wage shocks. Both a negative association between inflation and employment (anti-Phillips stagflation) and a positive association (the Phillips relationship) are possible.

The challenge is then to make sense of the haphazard collection of points in Figure 1, which shows the relationship between the employment ratio and inflation in the US over the period 1955-2011. We begin by looking at the data for the first years of 
this period, when Keynesians believed all too easily that the world, like their models, could be understood in terms of the behavior of demand, with nary a side glance at supply. Figure 28 presents the sub-set of data from Figure 1 for the period 19561969, the core years of the so-called Golden Age. This exercise does not look very promising if the goal is to fit a Phillips curve to the data. We do not need a regression line to see that employment and inflation do not move together even over this limited period.

However, we have not exploited one feature of the models, namely the different implications of the two adjustment processes for lags between changes in employment and changes in the rate of inflation. Flexprice adjustment implies that prices move first, in response to the balance between desired expenditure and output; output and employment adjust later, when the rise in prices makes it profitable to expand production. We can capture this in a simple way by assuming that employment responds with a 1-year lag to inflation, with changes in the rate of inflation in turn triggered by a change in aggregate demand. Figure 29 presents the data for 1956-1969 with this lag structure.

No improvement in the fit would, I believe, be an understatement.

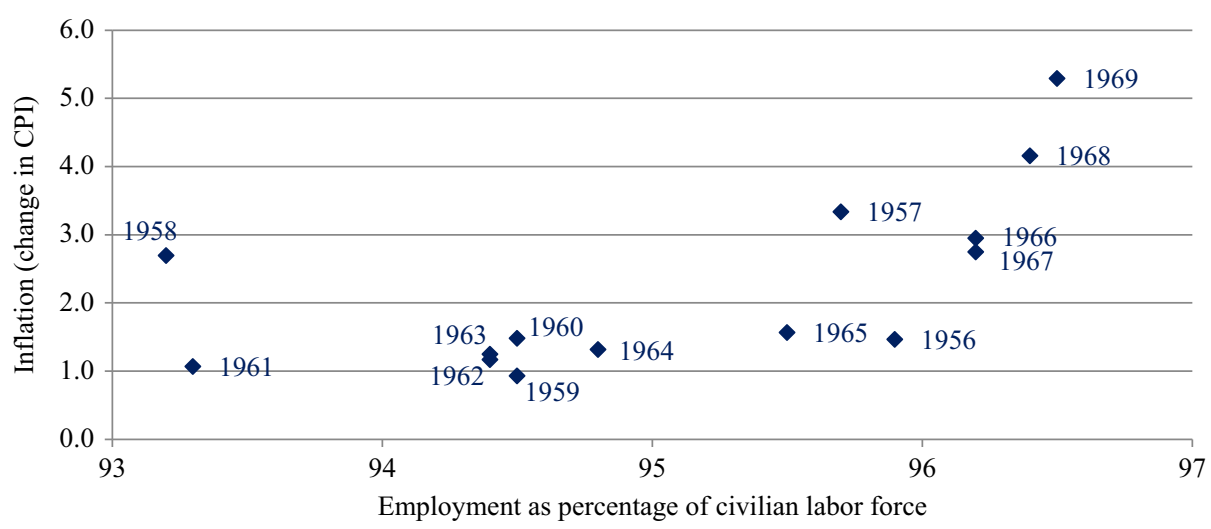

Figure 28 Employment vs inflation, 1956-1969

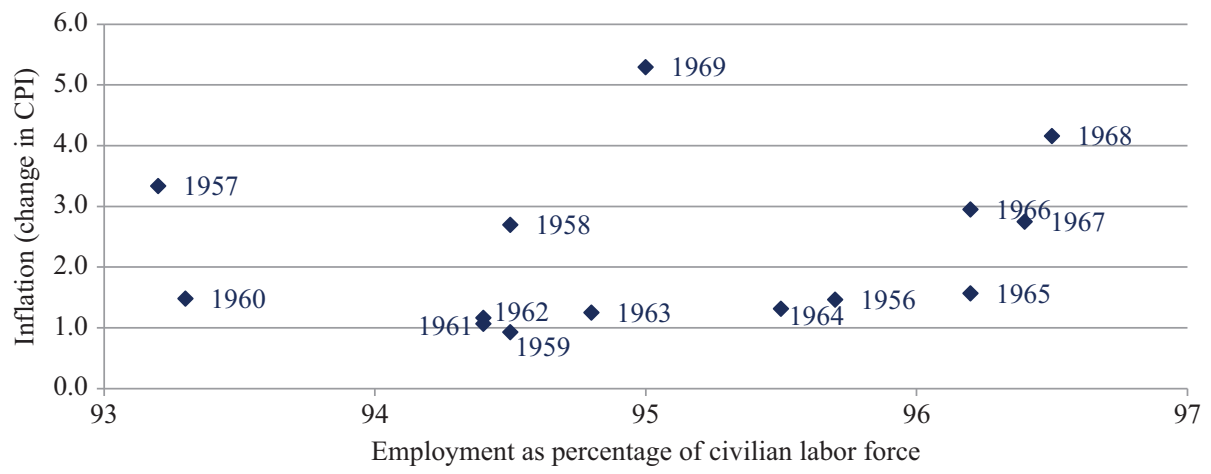

Figure 29 Employment $_{+1}$ vs inflation, 1956-1969 
However, if we assume fixprice adjustment, and thereby impose a lag structure that goes in the opposite direction - first comes the change in output and employment, then comes the change in the rate of inflation - the results look more promising. Figure 30 relates employment to the following year's rate of inflation. The fit is now very much in line with the Phillips curve prediction of the model, but the Phillips curve is really a curve rather than a linear relationship: higher levels of employment lead to more than proportionate changes in the rate of inflation. In fact, a log-linear specification does much better, as in Figure 31, in which a 1-percentage-point additional employment leads to a uniform percentage increase in the inflation rate, regardless of the ratio of employment to the labor force.

But even students with only Economics 101 under their belts know what happens when we extend the range of the data beyond the so-called Golden Age. Keeping to the lag structure suggested by fixprice adjustment, we have Figure 32, in which the years 1969-1975 have been added. The Phillips curve, as was widely noted at the time, falls apart. The post-1969 years have nothing to do with the earlier period.

With a somewhat longer view we can make better sense of the data. Add the period through 1983, and the data sort themselves out differently. In Figure 33, there are two distinct Phillips curves covering, respectively, the periods 1956-1969 and 1973-1983. The Phillips curve is somewhat flatter in the second period, and the intercepts are very different. In between are the years 1970-1972.

Figure 34 brings the story up to the present century. In Figure 34 there is a change in the intercept, and the Phillips-curve trade-off increases moderately in 1997-2001. The period 1994-1996 is a transition period, not belonging to either the earlier or the later era.

Between the 1970s and the late 1990s, changes took place that allowed any given employment ratio to be achieved at a progressively lower rate of inflation. For instance, in 1982, an employment ratio of just over 90 percent (an unemployment rate approaching 10 percent!) coexisted with an inflation rate of 3.1 percent the following year $(\exp (1.13)=3.1)$; approximately a decade later, in 1991 , the employment ratio was over 93 percent with the same rate of inflation as in 1982; by the end of

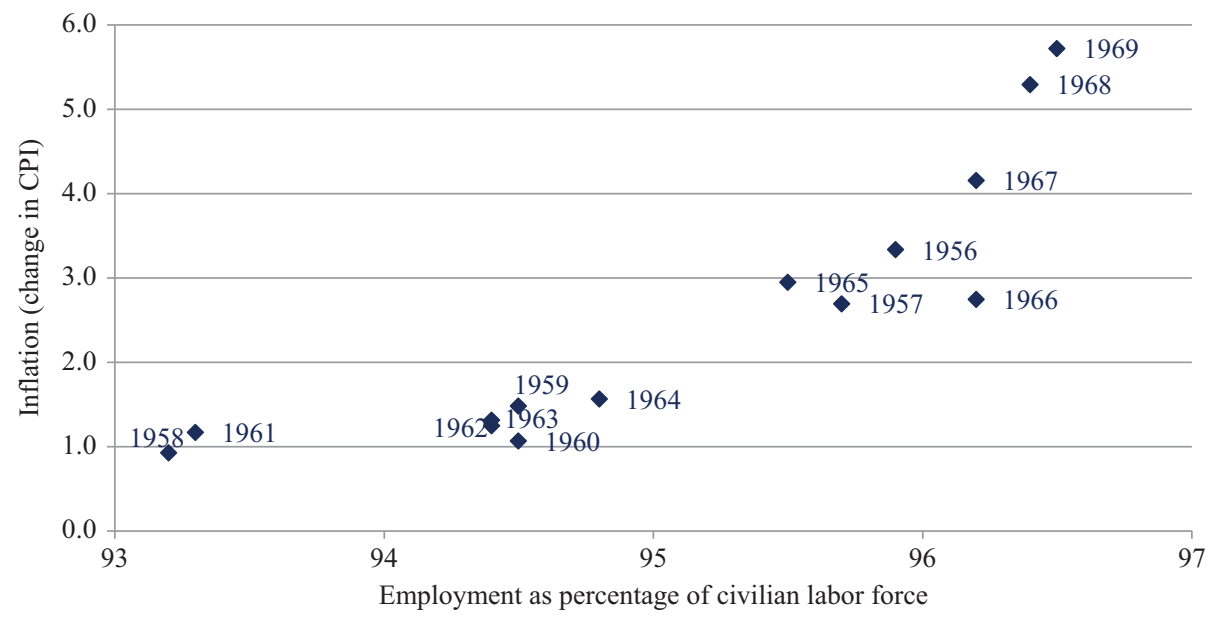

Figure 30 Employment vs inflation $+1,1956-1969$ 


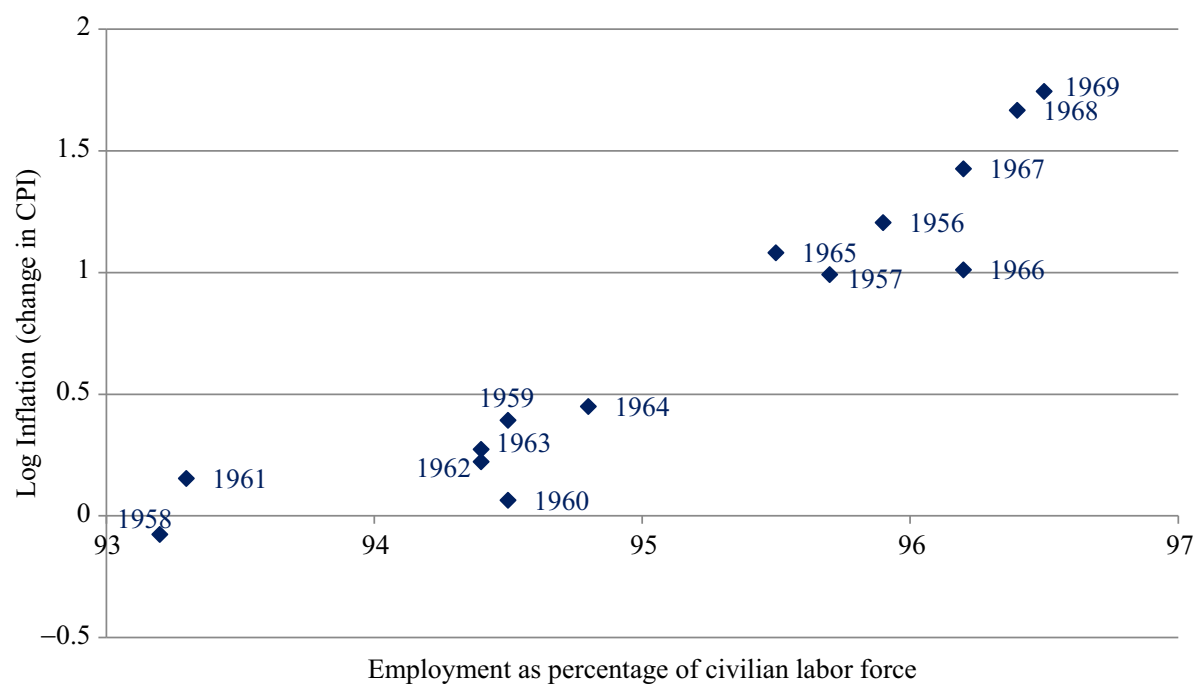

Figure 31 Employment vs log (inflation +1 ), 1956-1969

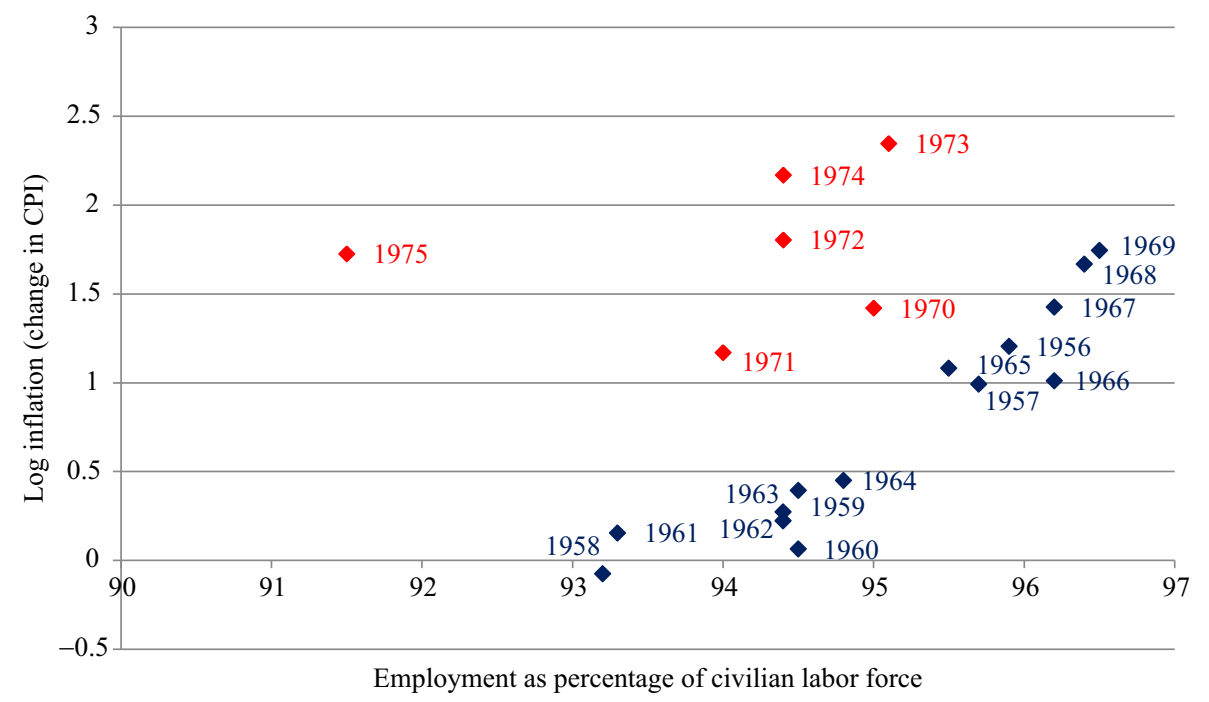

Figure 32 Employment vs log (inflation ${ }_{+1}$ ), 1956-1975

the century, in 2000, the employment ratio was just shy of 96 percent with inflation even less than 3 percent. Indeed, Figure 35 suggests that by the late 1990s the relationship between employment and inflation was back to where it had been in the Golden Age of the 1950s and 1960s. To illustrate, the data points for 1956 and 1999 are virtually indistinguishable; in 1956 as well as in 1999, employment was just under 96 percent and inflation in both 1957 and 2000 was 3.3 percent. 
418 Review of Keynesian Economics, Vol. 5 No. 3

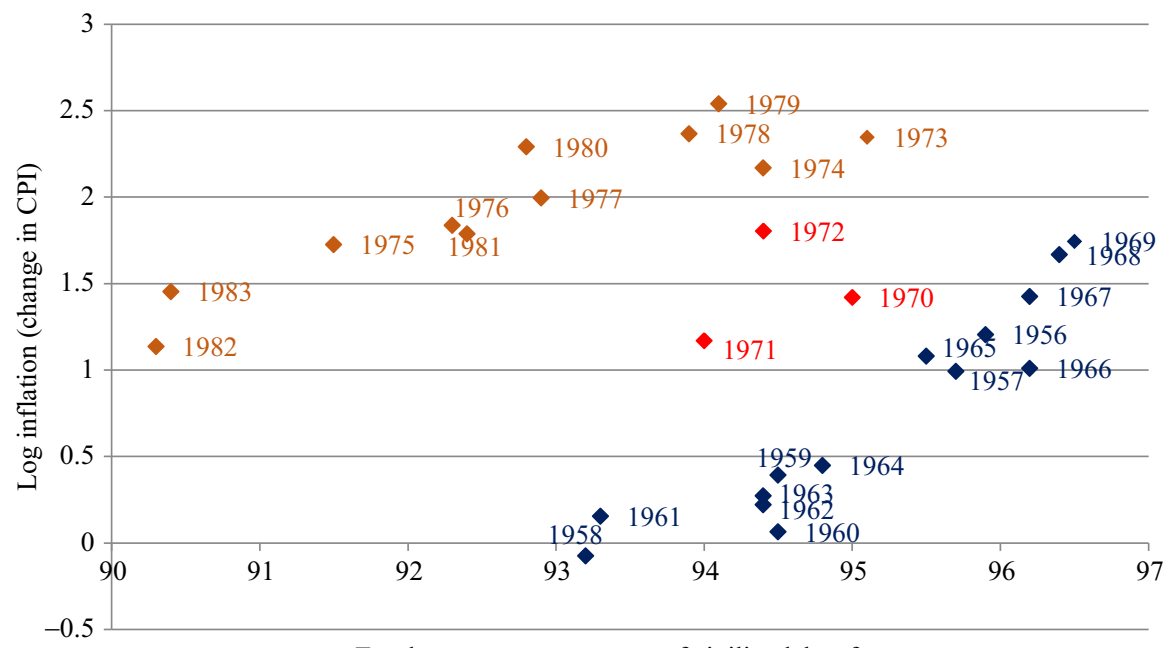

Employment as percentage of civilian labor force

Figure 33 Employment vs log (inflation +1 ), 1956-1983

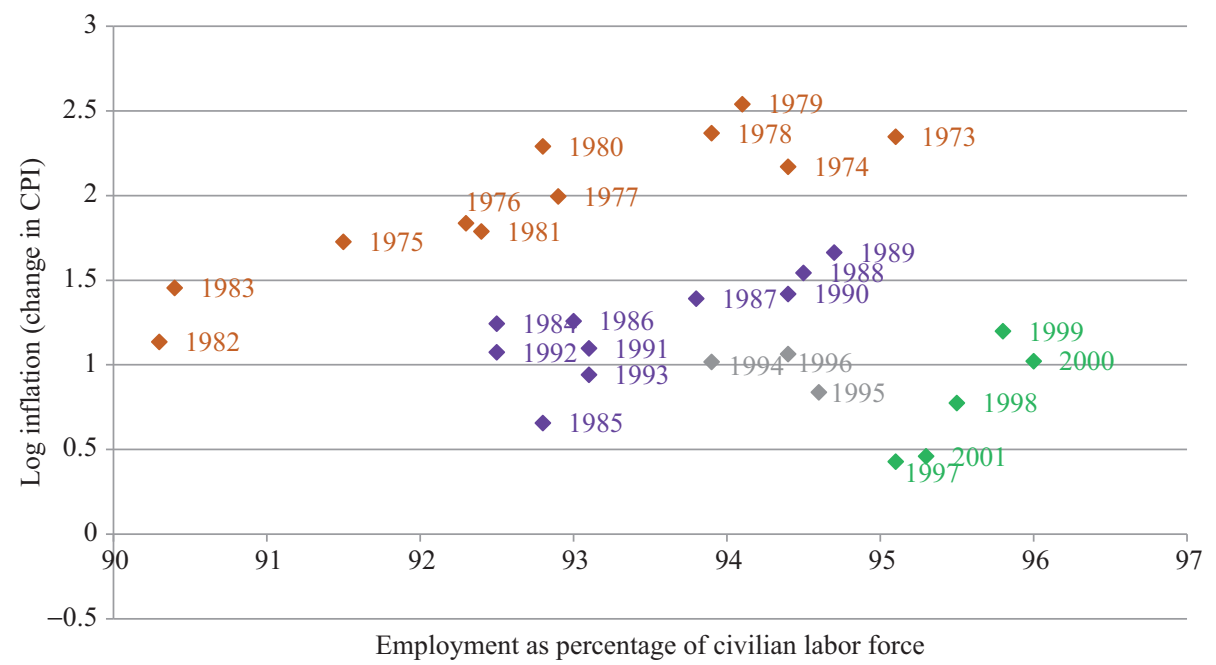

Figure 34 Employment vs log (inflation +1 ), 1973-2001

Figure 36 brings the story up to date. Something new has happened in this century. Not only has the dispersion of the data increased, ${ }^{13}$ but the trade-off between employment and inflation has become much flatter. If the data for the years 2002-2013 define

13. The year 2008 is omitted because inflation was negative and the log of the inflation rate therefore undefined. 2008 is literally off the chart. Evidently including 2008 would increase the dispersion dramatically!. 


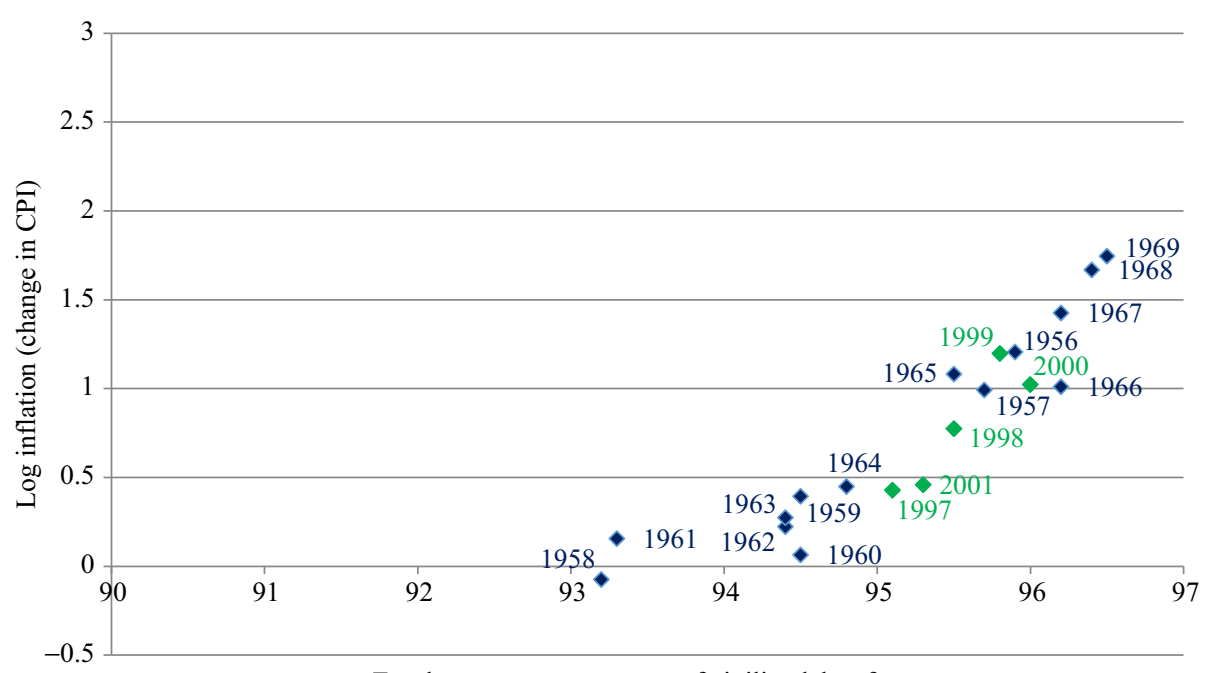

Employment as percentage of civilian labor force

Figure 35 Employment vs log (inflation +1 ), 1956-1969 and 1997-2001

the actual Phillips curve under which the US economy is now operating, it appears we could have much higher employment without touching off much more inflation.

According to the theory laid out in Section 4, the Phillips curve shifts over time because of supply shocks. For the most part, changes in the real price of energy, that is, the price of energy relative to other goods, correlate with the observed shifts in the Phillips curve. Figure 37 shows the course of the price of energy as a percentage of the price of all goods except for energy and food. The increase in the real price of energy between 1973 and 1980 correlates with the upward shift in the Phillips curve relative to the initial period, and the subsequent downward shift of the real price of energy in the 1980s correlates (a bit more roughly) with the downward shift of the Phillips curve after 1983. ${ }^{14}$ The upward shift in the Phillips curve in the first decade of this century fits the same pattern.

This leaves the shifts over the periods 1970-1972 and 1994-1996 unexplained. These are not periods in which the observations can be accounted for in terms of energy-price shocks, as the shading in Figure 37 shows.

For the theory to account for the shifts in the Phillips curve during periods in which relative energy prices were flat, we must look to wage shocks rather than price shocks. The basic idea is that in these periods employment and inflation were responding to changes in the conventional wage. In the first of the two periods in question, I would argue that American workers attempted to raise the conventional wage (as a share of output) in order to defend the Golden Age rate of wage growth in the face of declining productivity growth. In the second period, their children were unable to defend themselves against the erosion of the conventional wage share.

14. I cannot explain why changes in the real price appear to play themselves out as one-time shifts rather than more gradually. It is possible that what are pictured as successive Phillips curves in fact incorporate energy-price shocks along with demand shocks, in which case the actual Phillips curves are flatter in both the upswing and the downswing in the price of energy. 
420 Review of Keynesian Economics, Vol. 5 No. 3

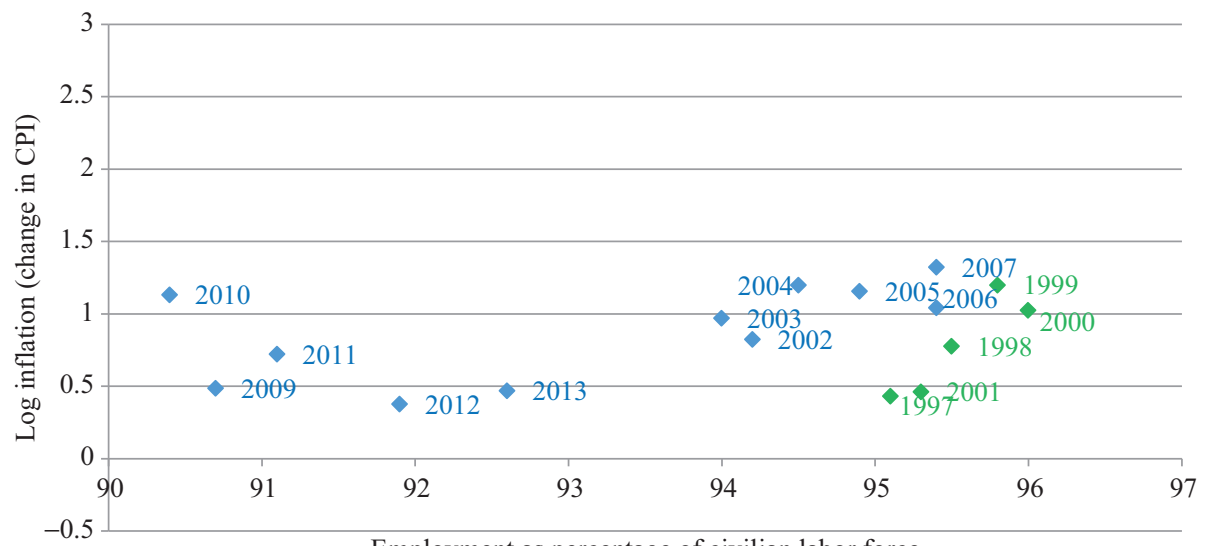

Employment as percentage of civilian labor force

Figure 36 Employment vs log (inflation +1 ), 1997-2013, excluding 2008

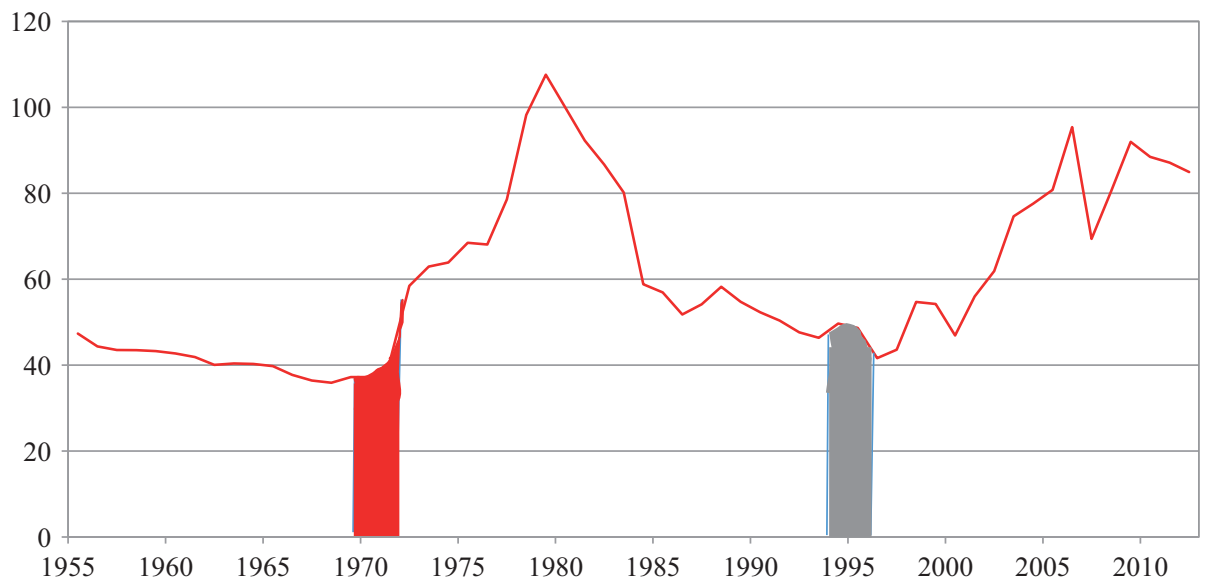

Figure 37 Energy price level as percentage of price level of all goods ex energy and food $(1982=100)$

In the late 1960s workers were riding high. Prosperity, strong unions, two terms of a Democratic Congress and Administration, an economy relatively well insulated against low-wage competition from abroad - all combined to empower workers to press wage claims vigorously. By contrast, in the 1990s, while the economy was again prosperous, none of the other ingredients of working-class vigor was present. The downward shift in the Phillips curve in the 1990s was, in this view, the result of a fall in the conventional-wage share, the culmination of trends and policies that had prevented real wages from rising over the previous 2 decades.

According to the theory I have elaborated, upward pressure on the conventional wage in the early 1970s would have been consistent with increasing inflation and falling employment in a fixprice regime, provided capital-widening investment 
dominated. And downward pressure would have produced the opposite result in the 1990s.

The following regression summarizes these results.

$$
\begin{aligned}
& \mathrm{LOG} \mathrm{INF}_{+1}=-20.7+0.221 \mathrm{EMP}+0.011 \text { ENERGY PRICE + 1.018 DUM } 1970-0.877 \text { DUM } 1994 \\
& \begin{array}{llll}
(4.74)(0.049) & (0.004) & (0.164)
\end{array} \\
& R^{2}=.58 \\
& \text { Standard Errors in Parentheses }{ }^{15} \\
& \text { Observations : } 56 \quad \mathrm{~F}(4,51)=17.9
\end{aligned}
$$

The variables are:

LOG $\mathrm{INF}_{+1}$ is the natural logarithm of the year-on-year change in the consumer price index one year ahead, CPIAUCNS in the St. Louis Fed database

EMP, Ratio of employment to labor force, 1 - UNRATE

ENERGY PRICE, Ratio of index of price of energy to consumer price index excluding energy and food $=$ PPIENG/CPILFESL indexed so that the value is 100 for 1982

DUM1970, dummy variable $=0$ for years before $1970,=1$ for 1970 and later years

DUM1994, dummy variable $=0$ for years before 1994, = 1 for 1994 and later years

The important takeaway from all this is, first, that there is indeed a trade-off between employment and price stability, not only in the short run but also in the long run. And, second, that the starting point for the trade-off depends on supply conditions. Achieving higher output and employment by stimulating aggregate demand must be paid for with higher inflation, but how much inflation is consistent with any given level of labor-force utilization depends on the supply side. The variable ENERGY PRICE captures the effect of the real price of energy, and the two dummy variables are intended to capture the effect of changes in the conventional wage.

Now we can now see why Friedman and Phelps were correct in predicting that high inflation would not see less unemployment, but, along with Lucas, could still be stunningly wrong in theorizing that this meant the demise of the Phillips Curve. As Lucas argued, the average rate of unemployment over the quarter century preceding Lucas's 1981 article did not depend very much on the level of inflation because, as the Phillips curves in Figures 33 and 34 show, the displacements due to supply-side shocks change the average rate of inflation more than the average rate of employment.

But there is no way that the analysis is as simple as Lucas pretended. The lack of correlation between the average rate of unemployment and the rate of inflation is totally consistent with the existence of a demand-induced trade-off: within each of the two periods covered in Figure 35, higher employment goes along with higher inflation, but across periods there is less difference between the average rate of unemployment (4.9 percent vs 7.3 percent) than there is between the average rate of inflation (2.1 percent vs 7.9 percent). Experience confirmed the letter of Friedman and Phelps,

15. Robust (Newey-White) standard errors cannot be calculated since the observation for 2008 is missing. I have calculated robust standard errors for a truncated sample ending in 2007 , and for this truncated sample there is little difference between the ordinary standard errors and the robust standard errors. This suggests that serial correlation is not a problem. 
but not the interpretation: the lack of a negative correlation between the average rate of inflation and the average rate of unemployment does not undermine the idea of a Phillips curve reflecting a demand-side trade-off between employment and inflation.

There is an important corollary of immediate policy relevance. If I have the logic of investment demand right, it is precisely in times like the recent past and, indeed, the present that higher wages will stimulate the economy. Not only via higher consumption demand but also via the inducement high wages provide for capital deepening. The presence of a large amount of unused capacity means that capital deepening, if not the only game in town, is where most of the investment action is taking place. Although, as Bhaduri and I argued in 1990, wage-led growth is not a panacea, it is an appropriate prescription for recession.

\section{CONCLUSIONS: A KEYNES FOR ALL SEASONS}

This essay develops a series of models suitable for analysing the economy over a period in which investment adds to the capital stock. And thus adds to the supply of goods while at the same time being a source of aggregate demand, indeed the key source of the variability of private demand so long as consumption is assumed to respond passively to income. As Harrod wrote in his review of The General Theory:

The only criticism of Mr. Keynes which I venture to offer is that his system is still static .... . In the dynamic theory, as I envisage it, ... our question will then be, what rate of growth can continue to obtain, so long as the various surrounding circumstances, including the propensity to save, remain the same? (Harrod 1937, pp. 85-86)

But the models immediately depart from Harrod and the ensuing literature in rejecting the idea of a fixed labor force. This involves two major conceptual changes. First, we have to replace that mythical notion, 'the economy,' with the portion of the economy for which the essential features of wage labor and profit maximization are present. This is not to say that sectors like the household, the family farm, and the government sectors in which one or the other distinguishing feature of capitalism is missing are not worthy of study. Rather, these non-capitalist structures require a very different framework of analysis. One size does not fit all.

Second, we have to replace the idea that the labor force available to the capitalist sector is given by population, and indeed that population is given. Over the last several centuries, capitalist economies have grown much more rapidly than the larger economic structures in which they have been embedded. To do so, they have had to draw labor from non-capitalist parts of the economy. And when domestic sources of labor have not sufficed, capitalist economies have relied on permeable national borders (whatever the official stance of governments has been towards immigration) to fill the gap. Japan is the most notable exception to this dictum, relying only marginally on immigration, and at that only during its short lived flirtation with empire in the first half of the twentieth century. South Korea and China, each for its own reasons, have followed the path charted by Japan.

The models are overdetermined because they have three independent schedules aggregate demand, goods supply, and a conventional wage - but only two state variables, real price and the labor-capital ratio. Equilibrium cannot be defined apart from the dynamic process by which the economy - strictly speaking, the capitalist sector - is assumed to adjust when it is not in equilibrium. The equilibria associated with a flexprice process and the equilibria associated with a fixprice process differ from one 
another, but fix- and flexprice equilibria share the property of being characterized by a stationary labor-capital ratio and a stationary real-price level. Equilibrium is associated not with constant prices and wages but with prices and wages that change at the same percentage rate.

Deflation and stagnation are possible in the long run. But with rare exceptions (the Great Depression of course, and, more recently, Japan since the 1990s and the current malaise of Europe and the US come to mind), the story of capitalism has been one of expanding output and ever-higher prices.

Interpreted through the lens of this model, the historical data for the US economy over the last six decades suggests three important results. First, inflation responds with a lag to the level of economic activity, which suggests that the fixprice model fits actual experience better than does the flexprice model. With fixprice adjustment the first response of the economy to disequilibrium caused by a demand shock is for output to adjust, with price adjustments following as producers struggle to get back on their goods supply curves and money wages respond to the accompanying reduction in real wages; with flexprice adjustment the sequence is the other way around: the first response is for prices to change, with output and wages both responding to the initial price change.

Second, aggregate demand shocks lead to a trade-off between the rate of inflation and the level of economic activity, à la A.W. Phillips and his eponymous curve. This generalized Phillips curve is stable in the short run.

Third, shocks to the goods-supply schedule, emanating from changes in the relative price of energy, and to a lesser extent shocks to the conventional wage, shift the Phillips curve while changing the demand-side trade-off between inflation and employment relatively little. Only in this century does the slope of the Phillips curve change markedly, while during the whole period 1956-2013 the Phillips curve shifts no fewer than five times.

In the perspective of my models, the Friedman (1970, p. 11) dictum, 'inflation is always and everywhere a monetary phenomenon' (emphasis in original) may be correct but only because we live in a monetary economy, not because causality runs from an exogenously determined money supply to the level of prices. It is not the case that '[inflation] is and can be produced only by a more rapid increase in the quantity of money than in output' (ibid., p. 11). Neither is Friedman's 1968 view that the Phillips curve is inherently unstable because of the dynamics of the inflationary process borne out by the data.

A takeaway from this essay is that inflation is the price society pays for higher levels of economic activity. In contrast to the widespread view that inflation is the enemy of a thriving real economy, the models presented here lead to the conclusion that aggregate demand matters in the long run as well as in the short run, and that higher levels of aggregate demand produce higher levels of economic activity along with higher prices.

The political problem is that the benefits of higher levels of economic activity and the benefits of more stable prices are not shared evenly. Main Street may fear inflation, but Main Street clearly benefits from high levels of economic activity. Wall Street has good reason to be at best ambivalent about high levels of economic activity, but more than ample reason to loath inflation. And Wall Street has a much easier time of getting itself heard in the halls of government, particularly in the boardrooms of central banks.

As I write this, the United States, and even more so Europe, is mired in a recovery that is moving at glacial speed, while an entire generation of Greeks, Italians, Spaniards, and Portuguese are being sacrificed on the altar of fiscal rectitude, a pillar of 
which is price stability. Keynes may have been right when he suggested, at the end of The General Theory:

The ideas of economists and political philosophers, both when they are right and when they are wrong, are more powerful than is commonly understood. Indeed, the world is ruled by little else. Practical men, who believe themselves to be quite exempt from any intellectual influences, are usually the slaves of some defunct economist. (Keynes 1936, p. 383)

He may have been right as well to stress that 'the power of vested interests is vastly exaggerated compared with the gradual encroachment of ideas' (ibid.). But the marketplace of ideas is a market far from the norm of perfect competition. It welcomes those who are backed by the purchasing power of Wall Street with more open arms than those who challenge money power. The rest of us pay the price for this particular market failure.

\section{REFERENCES}

Barro, Robert (1996), 'Inflation and growth,' Review, May-June, St. Louis: Federal Reserve Bank of St. Louis, pp. 153-169.

Bhaduri, Amit and Stephen Marglin (1990), 'Unemployment and the real wage: the economic basis for contesting political ideologies,' Cambridge Journal of Economics, 14, 375-393.

Blanchard, Olivier and Larry Katz (1999), 'Wage dynamics: reconciling theory and evidence,' American Economic Review, 89, 69-74.

Bureau of Labor Statistics (2012), Charting International Labor Comparisons, Washington, DC: United States Department of Labor, Bureau of Labor Statistics, available at: http:// www.bls.gov/fls/chartbook/2012/chartbook2012.pdf (accessed 27 November 2016).

Cai, Fang and Meiyan Wang (2011), 'Chinese wages and the turning point in the Chinese economy,' East Asia Forum, 29 January, available at: www.eastasiaforum.org (accessed 13 March 2016).

Colander, David (1995), 'The stories we tell: a reconsideration of AS/AD analysis,' Journal of Economic Perspectives, 9, 169-188.

Field, Alexander (2011), A Great Leap Forward: 1930s Depression and U.S. Economic Growth, New Haven, CT: Yale University Press.

Fischer, Stanley (1993), 'The role of macroeconomic factors in growth,' Journal of Monetary Economics, 32, 485-512.

Freeman, Richard and James Medoff (1984), What Do Unions Do?, New York: Basic Books.

Friedman, Milton (1968), 'The role of monetary policy,' American Economic Review, 58, 1-17.

Friedman, Milton (1970), 'The counter-revolution in monetary theory,' IEA Occasional Paper no 33, London: Institute of Economic Affairs.

Gordon, Robert (1984), 'Supply shocks and monetary policy revisited,' American Economic Review, 74, 38-43.

Gordon, Robert (2013), 'The Phillips curve is alive and well: inflation and the NAIRU during the slow recovery,' NBER Working Paper 19390, available at: http://www.nber.org/papers/ w19390 (accessed 26 October 2015).

Harrod, Roy (1937), 'Mr. Keynes and traditional theory,' Econometrica, 5, 74-86.

Harrod, Roy (1939), ‘An essay in dynamic theory,' Economic Journal, 49, 144-133.

Harrod, Roy (1948), Towards a Dynamic Economics: Some Recent Developments of Economic Theory and their Application to Policy, London: Macmillan.

Hicks, John (1974), The Crisis in Keynesian Economics, Oxford: Basil Blackwell.

Kalecki, Michał (1971), Selected Essays on the Dynamics of the Capitalist Economy, Cambridge, UK: Cambridge University Press.

Keynes, John Maynard (1919), The Economic Consequences of the Peace, London: Macmillan. Keynes, John Maynard (1936), The General Theory of Employment, Interest and Money, London: Macmillan. 
Khan, Moshin and Abdelhak Senhadji (2001), 'Threshold effects in the relationship between inflation and growth,' IMF Staff Papers, 48, 1-21, Washington, DC: International Monetary Fund.

Lewis, W. Arthur (1954), 'Economic development with unlimited supplies of labour,' The Manchester School, 22, 139-191.

Lucas, Robert (1981), 'Tobin and monetarism: a review article,' Journal of Economic Literature, $19,558-567$.

Marglin, Stephen and Amit Bhaduri (1990), 'Profit squeeze and Keynesian theory,' in S. Marglin and J. Schor (eds), The Golden Age of Capitalism, Oxford: Clarendon Press, pp. 153-186.

Phelps, Edmund (1968), 'Money-wage dynamics and labor-market equilibrium,' Journal of Political Economy, 76, 678-711.

Phillips, A. William (1958), 'The relation between unemployment and the rate of change of money wage rates in the United Kingdom, 1861-1957,' Economica, New Series, 25, 283-299.

Pigou, Arthur (1933), The Theory of Unemployment, London: Macmillan.

Robinson, Joan (1956), The Accumulation of Capital, London: Macmillan.

Robinson, Joan (1962), Essays on the Theory of Economic Growth, London: Macmillan.

Rowthorn, Bob (1982), 'Demand, real wages, and economic growth,' Studi Economici, 18, $3-53$.

Solow, Robert (1956), 'A contribution to the theory of growth,' Quarterly Journal of Economics, $70,565-594$.

Surowiecki, James (2011), 'State of the unions,' The New Yorker, 17 January, available at: http://www.newyorker.com/talk/financial/2011/01/17/110117ta_talk_surowiecki (accessed 10 February 2011).

World Bank (2016), World Development Indicators, Washington, DC: World Bank, available at: http://databank.worldbank.org/data/reports.aspx?source=world-development-indicators (accessed 27 November 2016). 